\title{
Recent Progress in Catalytic Synthesis of 1,2,3-Triazoles
}

\author{
Antonio De Nino*(D), Loredana Maiuolo*, Paola Costanzo*D, Vincenzo Algieri (D), Antonio Jiritano (D), \\ Fabrizio Olivito (D) and Matteo Antonio Tallarida (D)
}

Dipartimento di Chimica e Tecnologie Chimiche, Università della Calabria; Via P. Bucci, Cubo 12/C,
87036 Rende, CS, Italy; vincenzo.algieri@unical.it (V.A.); antonio.jiritano@unical.it (A.J.);
fabrizio.olivito@unical.it (F.O.); matteoa.tallarida@unical.it (M.A.T.)
* Correspondence: denino@unical.it (A.D.N.); maiuolo@unical.it (L.M.); paola.costanzo@unical.it (P.C.)

\begin{abstract}
: 1,2,3-triazoles represent a functional heterocyclic core that has been at the center of modern organic chemistry since the beginning of click chemistry. Being a versatile framework, such an aromatic ring can be observed in uncountable molecules useful in medicine and photochemistry, just to name a few. This review summarizes the progress achieved in their synthesis from 2015 to today, with particular emphasis on the development of new catalytic and eco-compatible approaches. In doing so, we subdivided the report based on their degree of functionalization and, for each subparagraph, we outlined the role of the catalyst employed.
\end{abstract}

Keywords: 1,2,3-triazoles; click chemistry; 1,3-dipolar cycloaddition; Huisgen reactions; triazole synthesis

check for updates

Citation: De Nino, A.; Maiuolo, L.; Costanzo, P.; Algieri, V.; Jiritano, A.; Olivito, F.; Tallarida, M.A. Recent Progress in Catalytic Synthesis of 1,2,3-Triazoles. Catalysts 2021, 11, 1120. https://doi.org/10.3390/ catal11091120

Academic Editor: Ioannis D. Kostas

Received: 30 July 2021

Accepted: 15 September 2021

Published: 17 September 2021

Publisher's Note: MDPI stays neutral with regard to jurisdictional claims in published maps and institutional affiliations.

Copyright: (c) 2021 by the authors. Licensee MDPI, Basel, Switzerland. This article is an open access article distributed under the terms and conditions of the Creative Commons Attribution (CC BY) license (https:// creativecommons.org/licenses/by/ $4.0 /)$.

\section{Introduction}

Triazoles are a vast family of nitrogen-based compounds alongside pyrazoles and tetrazoles, which became the main chemical characters of organic chemistry in the last years. They can exist in two isomeric forms: 1,2,3-triazoles and 1,2,4-triazoles. The two families of such aromatic compounds have been widely explored, both in terms of pure synthesis and in terms of evaluation of their usefulness in medicine [1,2], agriculture [3], etc. Such properties are related to the possibility to insert in simple and versatile ways functionalizing agents directly bonded to the heterocycle, using the so-known click chemistry approaches [4]. The main developments that involved such branch of chemistry have been based on the preparation of diverse compounds with an eye on the regioselectivity, in terms of 1,4-, 1,5- and 1,4,5-polysubstituted compounds. In this regard, Sharpless and collaborators established a new paradigm developing the first examples of clickable reactions that allowed to obtain 1,4-disubstituted species via a copper-assisted cycloaddition reaction (CuAAC) [5]. On the other hand, the use of Ru (II)-based catalyst opens the possibility to construct 1,5-disubstituted 1,2,3-triazoles in a highly regioselective way [6], furtherly expanding the knowledge about the chemistry of these compounds.

In the last years, great attention has also been devoted to the discovery of synthetic protocols paying attention the eco-sustainability. In this regard, numerous methods involved the use of new Lewis catalysts, non-conventional solvents, and ecofriendly materials [7-9]. Great attention has been devoted to the role of 1,3-dipolar cycloadditions (1,3-DPCA), a kind of reaction of paramount importance in heterocycles synthesis [10]. Such approach revealed to be particularly useful in joining in one species chemical properties often already possessed by the precursors involved (i.e., 1,3-dipoles) such as nitrones, which revealed to possess important properties as radical scavengers [11] and to be useful as dipolar partners for the preparation of new classes of bioactive compounds [12]. Furthermore, 1,3-DPCA reactions demonstrated to be particularly coherent with the use of the new technologies involved in modern green chemistry, such as microwave-assisted reactions [13,14], ultrasound-assisted reactions [15], and non-conventional solvents [7,14,16].

The goal of the review herein presented is to describe the innovations reported for the synthesis of the above-mentioned compounds with particular attention to the new 
catalytic methods proposed. The use of new different metals for the 1,2,3-triazoles synthesis, as well as, metal-free synthesis was discussed. In doing so, we focused on the papers published after 2015, subdividing the whole report on the basis of the degree of substitution of such heterocycles and outlining the role of the catalyst. This review will be for the reader a useful consultation manual in the research of the more innovative and convenient 1,2,3-triazole synthesis.

\section{Advances in Disubstituted 1,2,3-Triazole Preparation}

\subsection{Synthesis of 1,4-Disubstituted 1,2,3-Triazoles}

Many papers and reviews have been published in recent years about the synthesis of 1,4-disubstituted 1,2,3-triazoles (1,4-DTs) for their wide application as potential drugs in diverse pathologies [17]. They were found to be active as anticancer [18,19], antimicrobial [20,21], antiviral [22], anti-inflammatory [23,24]. Furthermore, their heterocycle core was found to be useful as a stable linker for the stabilization of linear peptides $[25,26]$ and solubility enhancer in prodrugs [27]. Highly regioselective synthesis of 1,4-DTs was reported by Sharpless and Meldel in 2002 by a copper-catalyzed azide-alkyne cycloaddition (CuAAC) $[5,28]$. Later, many modifications to this $\mathrm{Cu}$-based protocol were developed by using ionic liquid (IL), polymers as copper support, or alternative energy sources, such as microwave (MW) or ultrasounds (US) irradiation [29]. Very recently, two complete reviews about the $\mathrm{CuAAC}$, the main synthesis method, were published by Neto and Zeni in 2020 [30] and Saini et al. in 2021 [31]. For this reason, in the present section, we focused our attention on the recent alternative reaction procedures such as the metal-free reaction method and transition metal reaction methods different from $\mathrm{Cu}(\mathrm{I})$.

\subsubsection{Metal Synthesis of 1,4-Disubstituted 1,2,3-Triazoles Alternative to Copper}

Not many metals have been demonstrated to be able to catalyze the regioselective cycloaddition to 1,4-DTs. Among them, silver, zinc, ruthenium, and iridium have been the main investigated. In 2020, Sultana and Sarma summarized in a review most of the Agcatalyzed azide-alkyne cycloaddition (AgAAC) procedures reported in the literature [32]. Since $\mathrm{Ag}(\mathrm{I})$ has the same $\mathrm{d}^{10}$ electronic configuration of $\mathrm{Cu}(\mathrm{I})$, it was considered the best metal substituted to carry out cycloadditions with high catalytic performance. It is worth noting that, differently from copper, silver does not require the redox-active $\mathrm{Cu}(\mathrm{I})$ species as an effective catalyst for the azide-alkyne cycloaddition.

In this contest, a new interesting approach was reported in the literature by Wang et al. for the synthesis of 1,4-DTs, which involved isocyanides $\mathbf{1}$ and diazo compounds $\mathbf{2}$ and as dipolarophiles and dipoles, respectively [33]. Developing from a retrosynthetic analysis of 1,4-DTs, the authors tried to use silver salts to coordinate and activate isocyanides, as could be obtained with alkynes. Different silver salts, solvents, and temperatures were explored. Then, several substrates were explored, obtaining the final product 3 from acceptable to excellent results (Scheme 1).

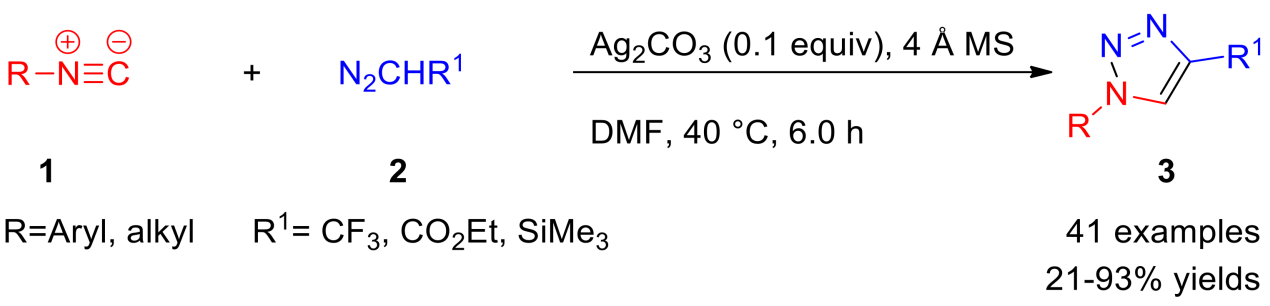

Scheme 1. Ag-catalyzed cycloaddition of various isocyanides and diazo compounds.

Finally, preliminary mechanistic studies were carried out to understand how Ag (I) could give [3 + 2] cycloaddition, although some key issues were not fully addressed. For this reason, more recently, Jia and Zhang focused their research efforts to highlight the key role of $\mathrm{Ag}(\mathrm{I})$ in the three successive steps (cycloaddition, deprotonation, and 
then protonation) involved in Wang's conditions reaction [34]. Density functional theory (DFT) calculations were employed, clarifying that silver participates in each step of the transformation and its fundamental contribution to the cycloaddition step, making the isocyanide compound more electrophilic. Furthermore, the author demonstrated that the transition state of the cycloaddition step, between the isocyanide complex (compound $\mathbf{A}$, Scheme 2) and the diazo compound $\mathbf{2}$, is the reaction rate-determining step. Its free-energy barrier is much higher if compared to the others steps, including the transition states of the two proposed side reaction pathways (Scheme 2).

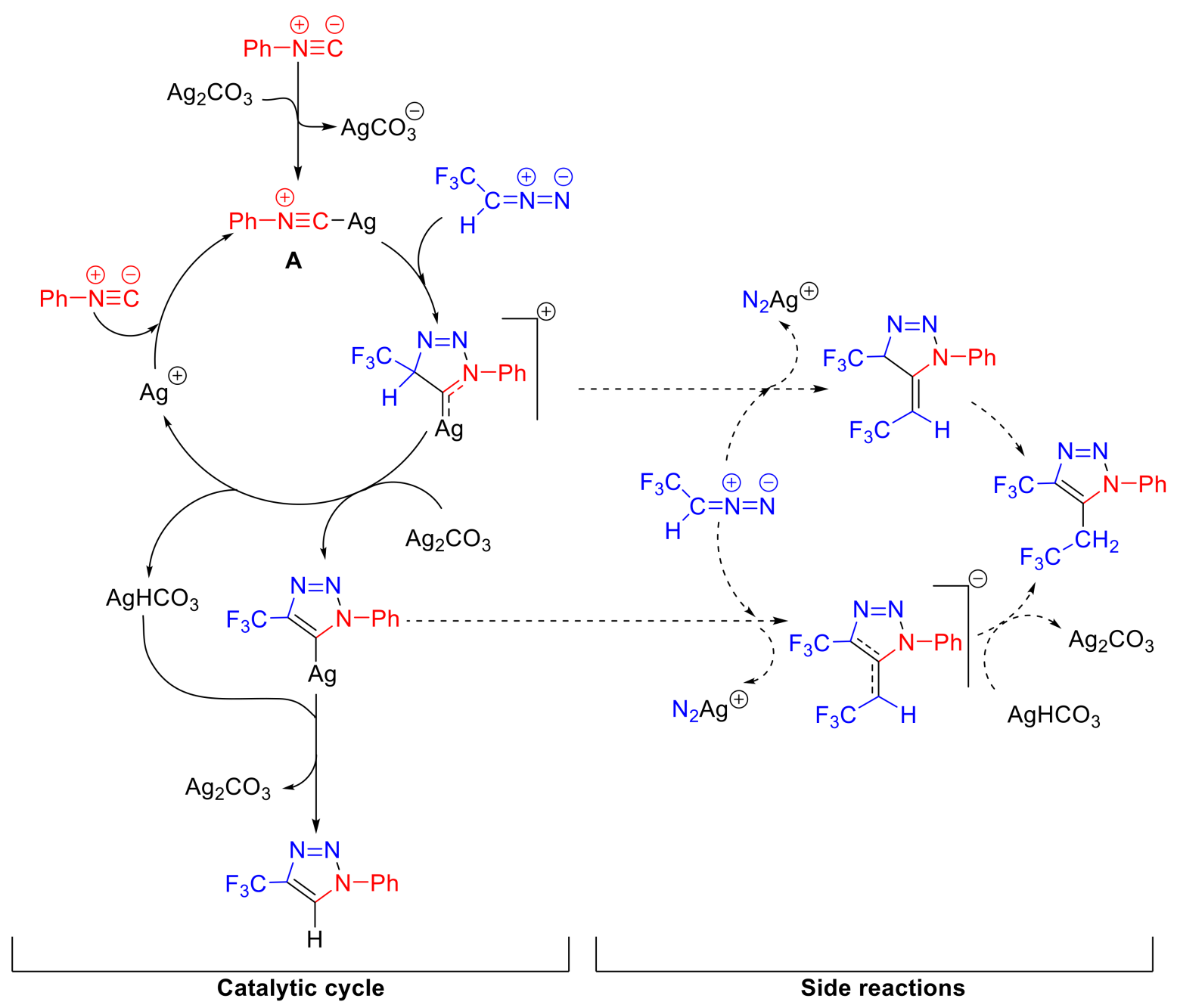

Scheme 2. Plausible mechanism for the isocyanide-diazo compounds cycloaddition.

After a first approach in 2010 about the use of zinc on charcoal as a catalyst for azide-alkyne cycloaddition [35], recently different synthetic procedures have been realized, especially on heterogeneous systems.

In 2017, Morozova et al. reported a new protocol with $\mathrm{Zn}(\mathrm{OAc})_{2}$ as an inexpensive catalyst, with the aim to change the DMF in water as a more green solvent for the environmentally friendly synthesis of 1,4-DTs [36]. The authors developed a ZnAAC applicable for alkyl or aryl azides with internal and terminal alkynes obtaining 1,4-DTs and 1,4,5trisubstituted-1,2,3-triazoles, respectively. The presence of ascorbic acid ( $20 \%$ molar) was revealed crucial for the full conversion of the starting reagents. Furthermore, microwave irradiation allowed to reduce the time of the reaction. Carrying out the reaction between aromatic and benzylic azides 4 as well as aromatic and terminal aliphatic alkynes 5 , suitable to excellent yields were obtained (Scheme 3). 


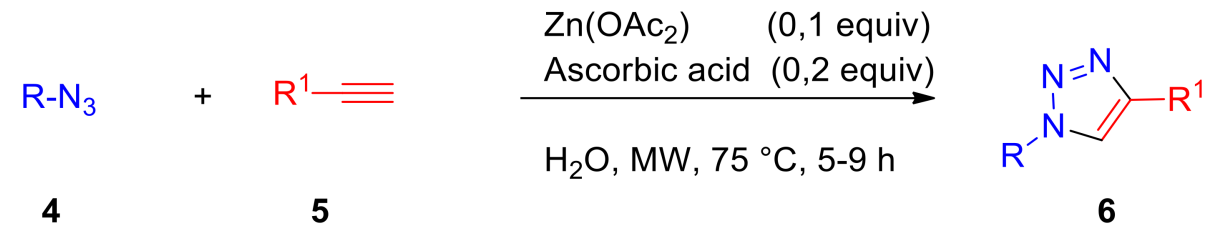

$$
\begin{aligned}
& \mathrm{R}=\mathrm{Aryl} \text {, alkyl } \\
& \mathrm{R}^{1}=\mathrm{Ph}, 4-\mathrm{O}_{2} \mathrm{~N}-\mathrm{C}_{6} \mathrm{H}_{4} \text {, pentyl, } \mathrm{HOCH}_{2}
\end{aligned}
$$

Scheme 3. ZnAAC of organic azides and terminal acetylenes for the synthesis of 1,4-DTs.

As a heterogenous catalytic system, Sharma et al., in 2016, developed a reusable silica-supported organic-inorganic hybrid zinc catalyst [37]. In fact, mesoporous materials based on silica have gained much interest in the last years as versatile support for diverse metallic heterogeneous catalysts [38]. In addition, metal nanoparticles (MNPs) combined with eco-compatible materials have been used as composites useful in environmental remediation $[39,40]$. In particular, this zinc-supported catalyst was obtained by covalent immobilization of 2-hydroxy-acetophenone on silica functionalized with aminopropyl groups and subsequent metalation with $\mathrm{ZnCl}_{2}\left(8, \mathrm{SiO}_{2} @\right.$ APTES@2HAP-Zn). This catalyst was then tested in a click chemistry reaction between diverse halides $\mathbf{7}$ and terminal alkynes 8 in the presence of sodium azide using water and tert-butanol as a solvent, obtaining excellent yields (Scheme 4). In the work, the authors also proposed a plausible mechanism involving a zinc-containing six-member cycle (compound A, Scheme 5).

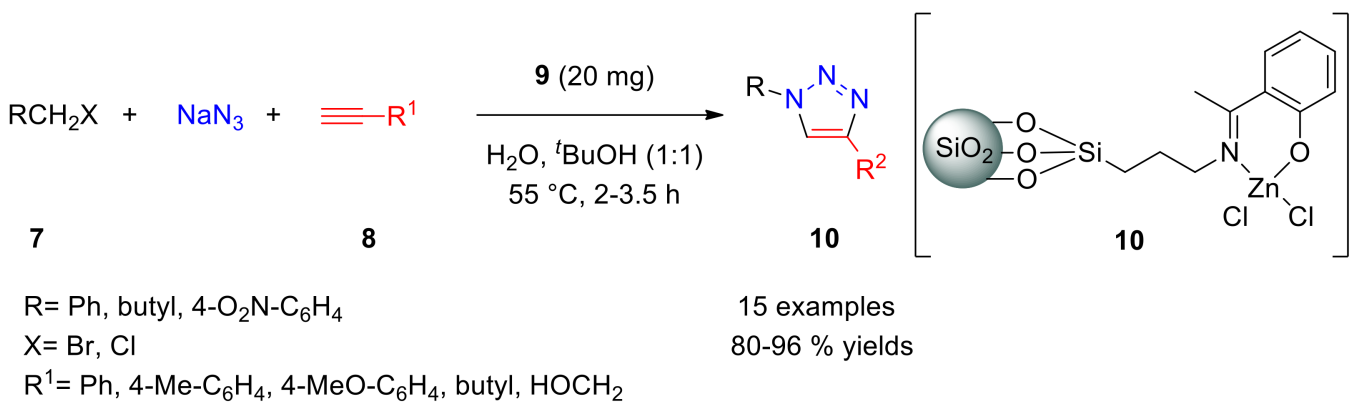

Scheme 4. One-pot synthesis of 1,4-DTs catalyzed by the $\mathrm{SiO}_{2} @ \mathrm{APTES} @ 2 \mathrm{HAP}-\mathrm{Zn}$ catalyst.

Another heterogeneous $\mathrm{Zn}$ catalyst was more recently developed by Daraie and co-workers in 2020 [41]. Briefly, poly(styrene-co-maleic anhydride) was modified with 3-aminopyridine to give poly(styrene-co-maleimide) (SMI) that was used to immobilize $\mathrm{ZnCl}_{2}$ as nanoparticles (NPs) with high surface area. This $\mathrm{Zn}(\mathrm{II})-\mathrm{SMI}$ nanocatalyst 14 was then tested to gain triazole derivatives $\mathbf{1 5}$ or $\mathbf{1 6 4}$ in suitable yields with both $\alpha$-halo ketones 10, alkyl halides 12, benzyl halide, and iodomethane (when $\mathrm{R}^{1}=\mathrm{H}$ and $\mathrm{X}=\mathrm{I}$, Scheme 6). 


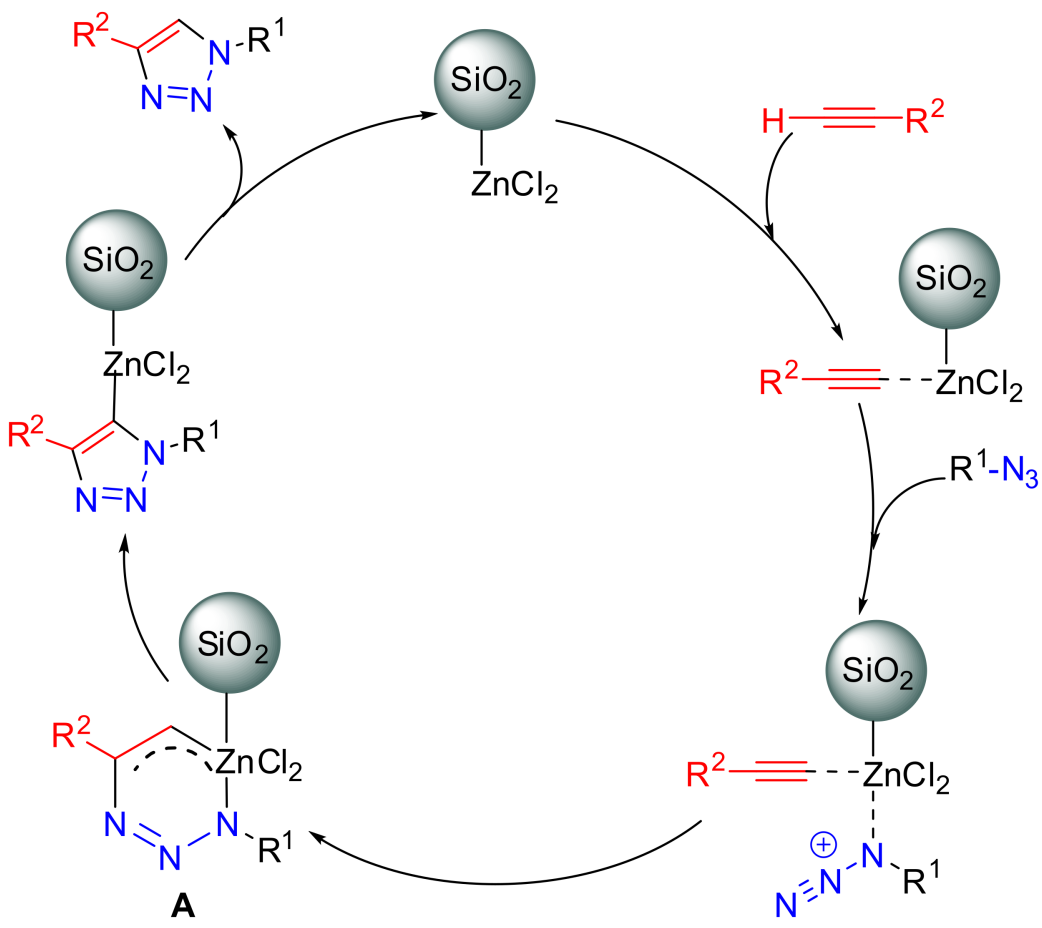

Scheme 5. Proposed mechanism for the 1,4-DTs synthesis catalyzed by $\mathrm{SiO}_{2} @ A P T E S @ 2 H A P-Z n$.

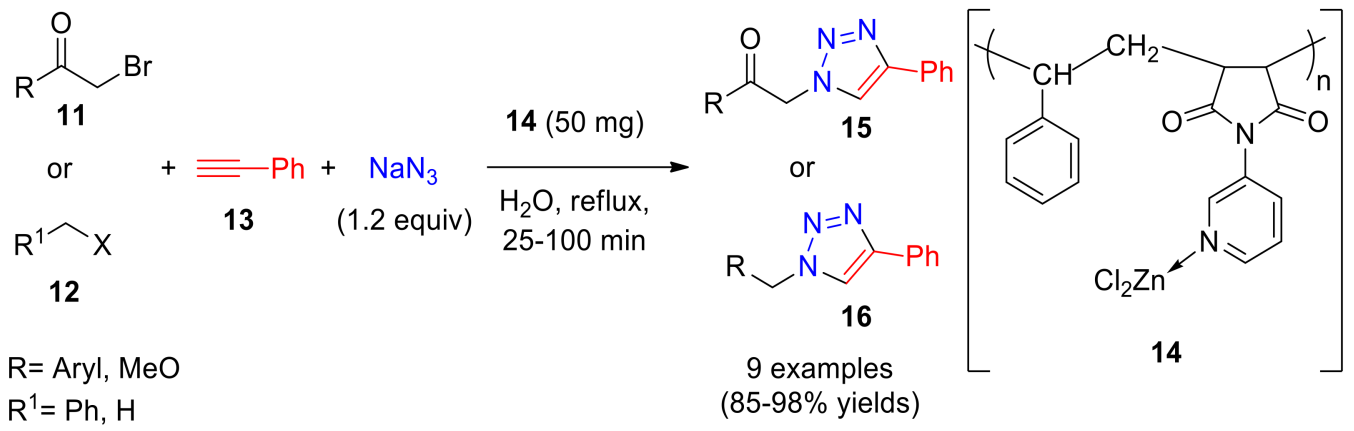

Scheme 6. Synthesis of 1,4-DTs in the presence of $\mathrm{Zn}(\mathrm{II})-\mathrm{SMI}$.

A heterogeneous catalyst based on the lanthanide cerium(III) as metal was also developed by Mondal and co-workers for the one-pot synthesis of 1,4-DTs, starting from arylamines. Cerium(III) was immobilized on polystyrene support, previously modified with an aldehyde group, then functionalized with 2-aminothiophenol. The polystyrenecerium catalyst (19, PS-Ce-amtp) was then tested for the reaction between aryl azides, obtained directly from the related anilines $\mathbf{1 7}$ and aryl alkynes $\mathbf{1 8}$ in an aqueous medium at room temperature. The corresponding 1,4-DTs 20 were obtained in excellent yields in only 3-4 h (Scheme 7) [42]. 


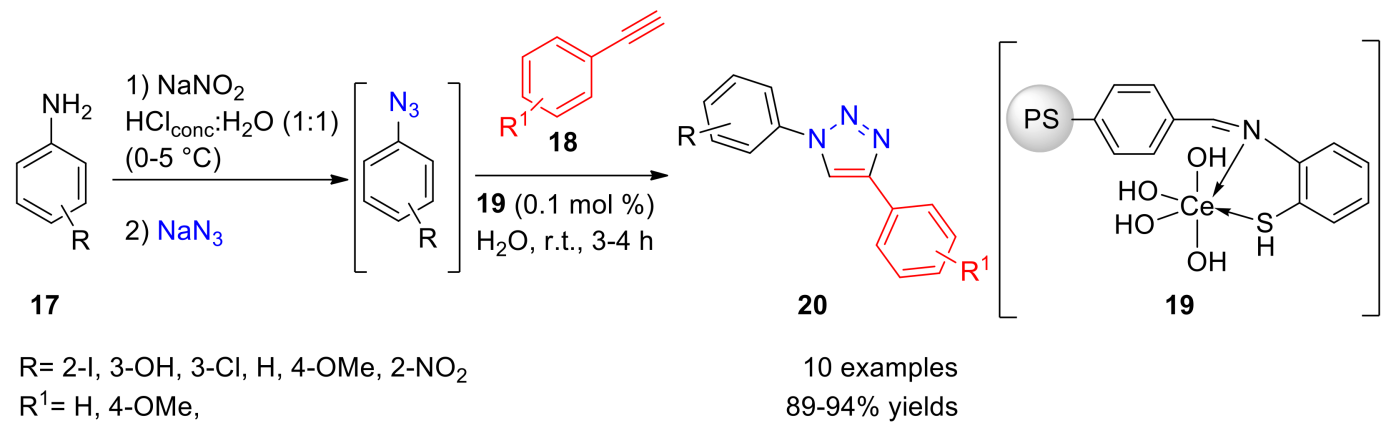

Scheme 7. Click reaction between various aryl amines and aryl alkynes catalyzed by PS-Ce-amtp 16.

About the proposed mechanism for this reaction, the key intermediate is a six-member cycle that contains cerium, as well as for zinc-catalyzed reaction (Scheme 5). Recycling tests were also performed and, after five recycling experiments, suitable yields of the product were recorded, and maintenance of high activity was confirmed.

Although ruthenium was principally employed for the synthesis of 1,5-disubstituted 1,2,3-triazoles, some examples of the synthesis of 1,4-DTs are reported [6]. An interesting heterogeneous ruthenium complex was developed by Sharma et al. in 2017 by metal ligation via click chemistry [43]. With this aim, a 1,2,3 triazole moiety was anchored over a mesoporous zeolite SBA-15. Then, $\left[\mathrm{RuCl}_{2}\left(\mathrm{PPh}_{3}\right)_{3}\right]$ was immobilized on this modified zeolite, and the resulting new heterogeneous catalyst SBA-15-Tz-Ru(II)TPP (23) was in turn tested for the one-pot synthesis of 1,4-DTs in water (Scheme 8). Thanks to this Ru complex, benzyl bromide reacted in the presence of sodium azide with different aryl alkynes and one long-chain alkyne in $12 \mathrm{~h}$ at $90^{\circ} \mathrm{C}$ to afford 1,4-DTs with suitable to excellent yields. Finally, the authors proposed a mechanism in which Ru catalyzes the cycloaddition of azide and alkyne to give 4-substituted-1H-1,2,3-triazole (compound A, Scheme 9) that subsequently give an in situ substitution reaction with the benzyl bromide to afford the $\mathrm{N}$-benzylated-products 24 (Scheme 9).

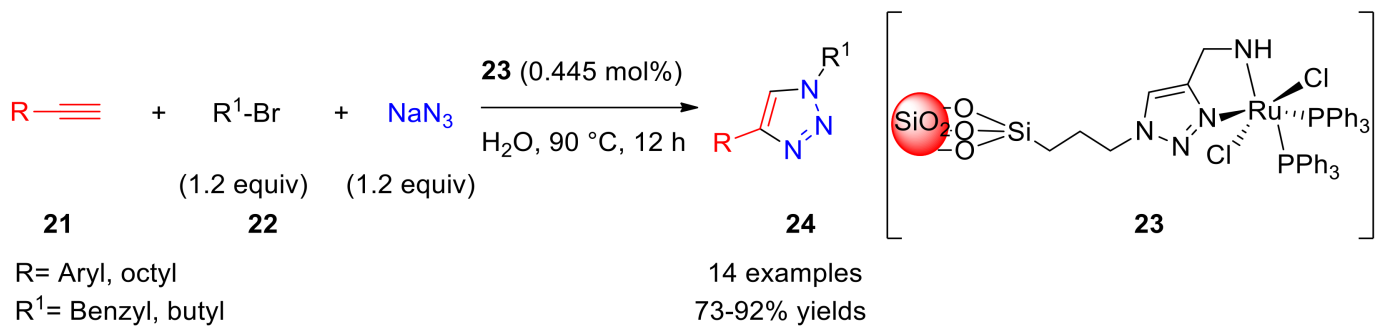

Scheme 8. Azide-alkyne cycloaddition catalyzed by the SBA-15-Tz-Ru(II)TPP (18) heterogenous catalyst. 


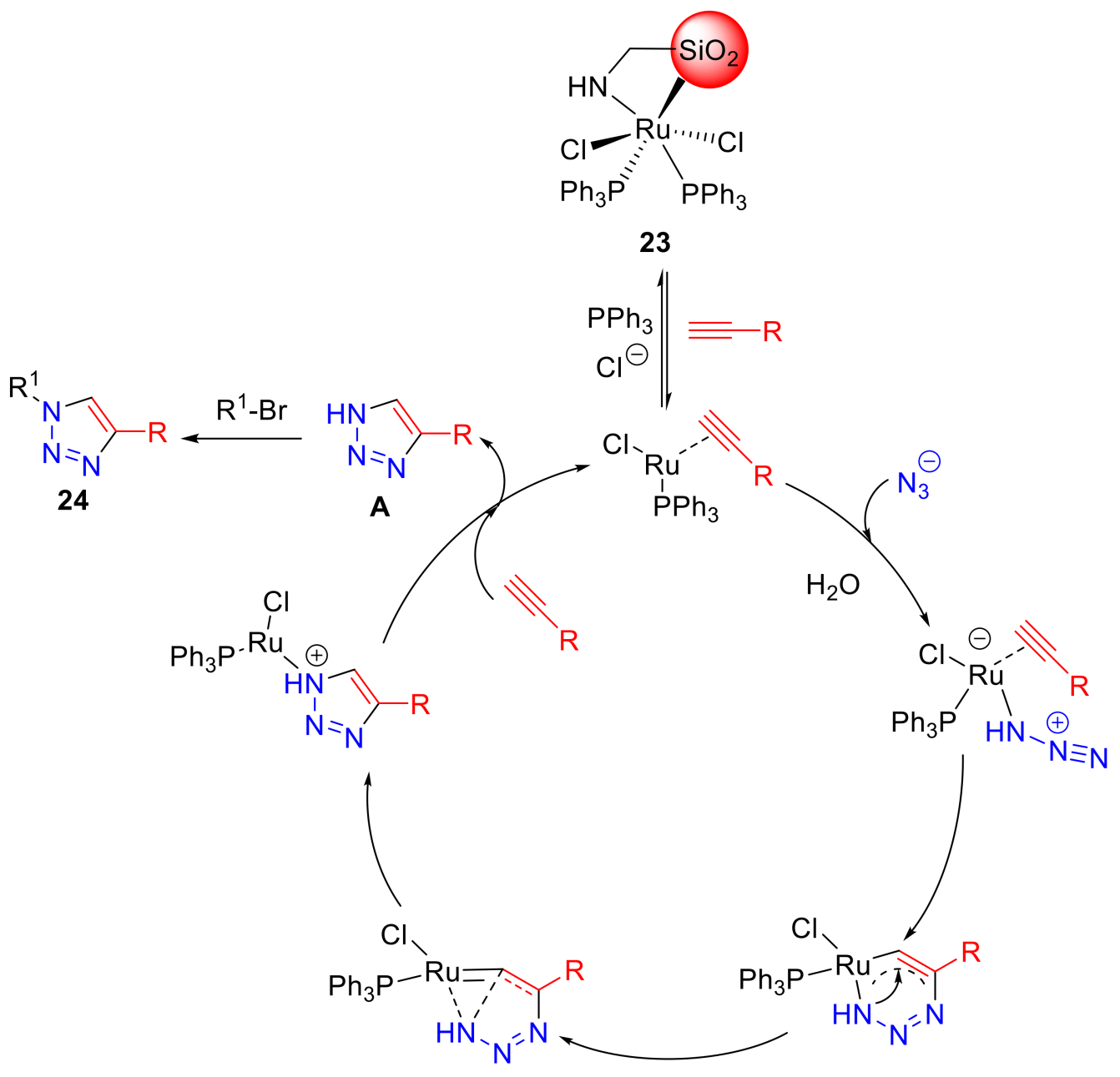

Scheme 9. Plausible mechanism for the click reaction catalyzed by SBA-15-Tz-Ru(II)TPP.

Recently, Arafa and Nayl developed a new interesting method for the regioselective synthesis of 1,4-DTs in water by using a new family of Ru complexes [44]. The main drawbacks related to the employment of ruthenium for azide-alkyne cycloaddition (AAC) reactions, such as long reaction time, limited scopes, thermal activation, were overcome in this protocol, exploiting ultrasonic irradiation as alternative energy sources. Furthermore, a sono-synthesis method was employed by the authors, also for the preparation of the catalyst, starting from diamide ligands, which were obtained by condensing $o$-phenylene diamines with picolinic acids in the presence of triphenyl phosphite as the coupling reagents. Finally, the diamide ligands reacted firstly with ruthenium (as $\left[\mathrm{Ru}(\mathrm{DMSO})_{4}\right] \mathrm{Cl}_{2}$ ) and then with 4-picoline, always under ultrasonic irradiation, to afford the Ru complex 27. Although all the prepared catalysts were capable of giving the product in excellent yields, the Ru complex 27 (Scheme 10) was selected as the most active at $0.1 \mathrm{~mol} \%$ affording the required product in quantitative yield in only $7 \mathrm{~min}$. Then, the scope of the reaction was assessed, testing different benzyl, phenyl, and cyclohexyl azides $\mathbf{2 5}$ with aromatic and heteroaromatic alkynes 26. In all cases, the yields were almost quantitative (96-99\%). Moreover, the generality and the scope of this method were also successfully extended by testing the catalyst 27 also in the one-pot synthesis of the 1,4-DTs starting from benzyl halides. Finally, new coumarin hybrids containing a triazole moiety were achieved with this method (Figure 1). Reusability, as well as Ru leaching, was evaluated, and the catalyst was efficiently used eight times. 


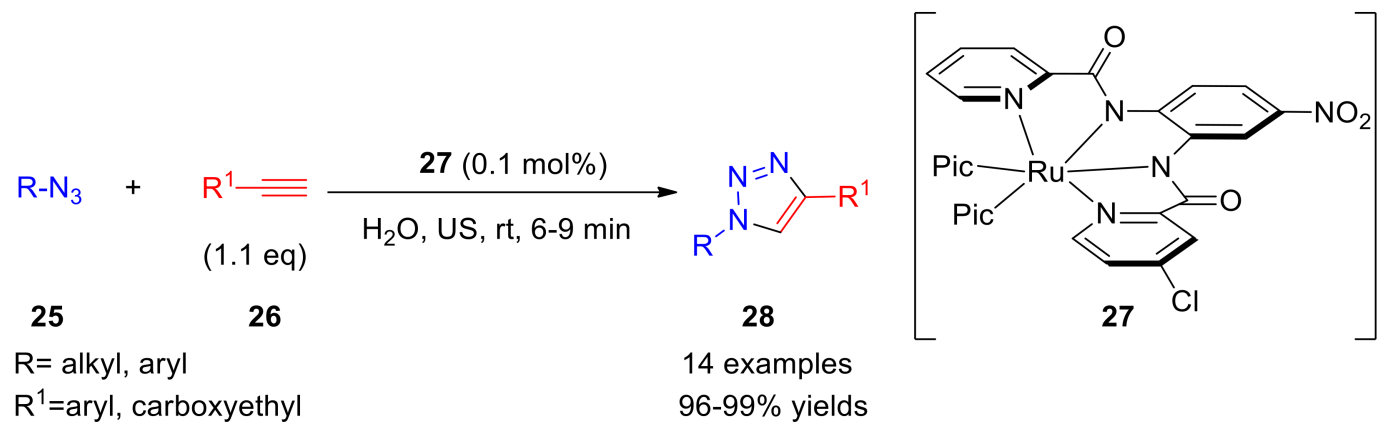

Scheme 10. Ru-complex catalysis under US irradiation of 1,3-dipolar cycloaddition toward 1,4-DTs.<smiles>[R]c1cc2cc(-c3cn(Cc4ccccc4)nn3)ccc2oc1=O</smiles>

28a $\mathrm{R}=\mathrm{COCH}_{3}$ 28b $\mathrm{R}=\mathrm{COPh}$<smiles></smiles>

28c $\mathrm{R}=\mathrm{COCH}_{3}$ 28d $\mathrm{R}=\mathrm{COPh}$

Figure 1. Coumarin hybrids tethering 1,2,3-triazole moiety.

The greenness of visible light as an alternative energy source has attracted more attention in the last years. The photoredox catalysis induced by visible light was then examined by $\mathrm{Wu}$ and co-workers in 2020 as a new pathway for the synthesis of 1,4DTs [45]. The authors demonstrated that the photocatalyzed AAC (PcAAC) is possible, by exploring diverse common photocatalysts, such as Eosin $\mathrm{Y},\left[\mathrm{Ru}(\mathrm{bpy})_{3} \mathrm{Cl}_{2}\right] \cdot 6 \mathrm{H}_{2} \mathrm{O},\left[\operatorname{Ir}(\mathrm{ppy})_{3}\right]$, $\left[(\text { piq })_{2} \operatorname{Ir}(\mathrm{acac})\right](31)$ and others, in different solvents, and under different light-emitting diodes (LEDs). The best reaction conditions were founded using [(piq $\left.)_{2} \operatorname{Ir}(\mathrm{acac})\right](31)$ as a catalyst in dichloromethane as a solvent for $6 \mathrm{~h}$ under white LED irradiation (Scheme 11).

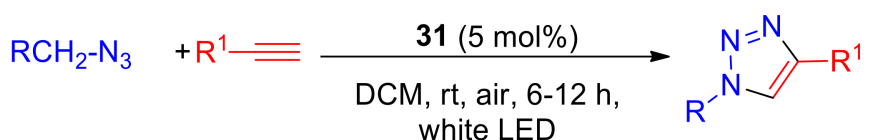

$$
\begin{aligned}
& 29 \quad 30 \\
& 30 \\
& 32
\end{aligned}
$$<smiles></smiles>

Scheme 11. PcAAC by an iridium complex 31.

No heating or inert atmosphere was required, showing suitable results in mild reaction conditions. The generality and substrate scope were investigated, obtaining moderate to excellent yields with a suitable functional group tolerance. The synthesis of a triazole active principle with anticancer activity (Figure 2) was also tested at gram-scale under sunlight irradiation, even without stirring, affording the 1,4-DT with $71 \%$ of yield. The catalyst was recycled four times, with a low reduction in the reaction yield. 
<smiles>COc1ccc(CN2C=C(CN3c4ccccc4C(=O)C4C=CC=CC43)NN2)cc1F</smiles>

Figure 2. 1,4-DT with anticancer activity obtained in gram-scale through PcAAC.

\subsubsection{Metal-Free Synthesis of 1,4-Disubstituted 1,2,3-Triazoles}

Metal-free strategies for the synthesis of 1,4-DTs present the advantage of avoiding the employ of metals, such as copper, silver, and others, that restrict their application in biological and life sciences due to their cytotoxicity and hazardous nature. In 2015, Alcaide et al. developed a regioselective protocol for the synthesis of $C$-trifluoromethanesulfonyl triazoles by using 2-(2-fluoropyridinium-1-yl)-1,1-bis[(trifluoromethyl)sulfonyl]ethane-1ide 34 as starting material in reaction with several azides, giving 1,4-DTs 35 under mild and metal-free conditions (Scheme 12) [46]. While the aliphatic azides react instantaneously with 34 , aromatic azides require more time $(3-48 \mathrm{~h})$ to be incorporated in the triazole moiety. This aspect was investigated to obtain a chemoselective reaction on a compound with the two functionalities. It is worth noting that relatively suitable yields were obtained for sugar $35 \mathbf{a}$ and $\beta$-lactam-linked triazoles $\mathbf{3 5} \mathbf{b}$ without loss of chirality (Figure 3 ).

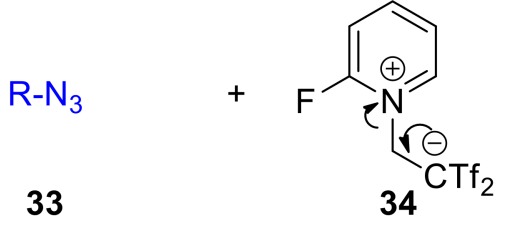

$\mathrm{R}=\mathrm{Alkyl}$, aryl

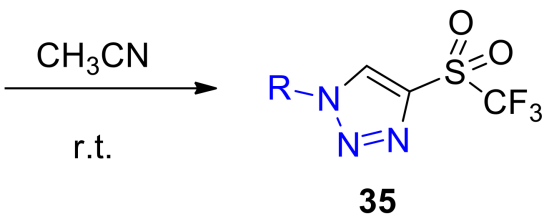

20 examples $50-99 \%$ yields

Scheme 12. Uncatalyzed synthesis of 1-alchyl- or 1-aryl-4-triflyl-1,2,3-triazoles at room temperature.<smiles>CC1(C)O[C@H]2O[C@H](C(O)CO)[C@H](n3cc([Tl])nn3)[C@H]2O1</smiles>

(+) 35a (82\%)<smiles>COc1ccc(N2C(=O)[C@@H]([C@H](O)CO)[C@H]2C2=C[In]([Tl])N2)cc1</smiles>

(-) $35 \mathrm{~b}(63 \%)$

Figure 3. 1,4-DTs obtained by Alcaide et al. maintaining the stereochemical integrity of the enantiopure reagents.

In 2016, with the aim to explore more green synthetic ways, enolizable aldehydes were used in base conditions with aryl azides in two very interesting procedures, which explored an alternative energy source and ionic liquid to afford 1,4-DTs. The first method, reported by Singh et al., exploited ultrasonic irradiation at room temperature as a driving 
force to give triazoles in the presence of 1,8-diazabicyclo[5.4.0]undec-7-ene (DBU) 39 as organic strong base catalyst combined in an ionic liquid (IL), that in this ionic form is easier to separate from the reaction mixture [47]. In the second method, directly hydrated $\mathrm{Bu}_{4} \mathrm{NOH} 40$ was tested to extend the use of IL also under conventional heating (Scheme 13). In both cases, the triazole derivatives were obtained in suitable yields and short reaction times through simple operation and easy work-up procedures.

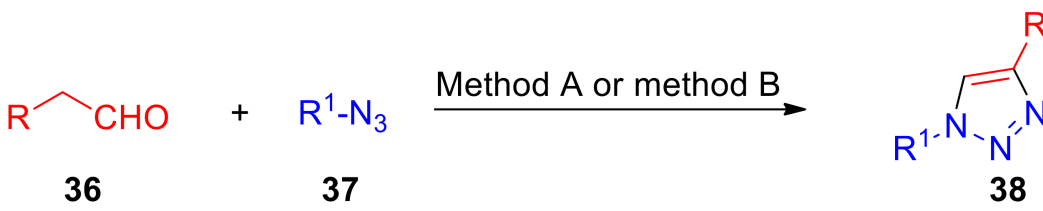

$$
\mathrm{R}=\mathrm{Ph} \text {, Et } \quad \mathrm{R}^{1}=\text { Aryl }
$$<smiles>[Y]C1CCCN2CCCCC12CC</smiles>

Method A

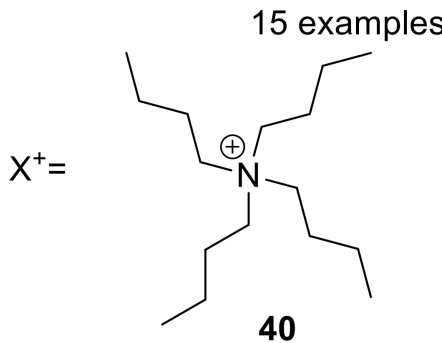

Method B

Method A: [DBU-Bu]OH (20 mol\%), US ))), r.t., 10-35 min, 85-94\% yields

Method B: Hydrated $\mathrm{Bu}_{4} \mathrm{NOH}(20 \mathrm{~mol} \%), 100{ }^{\circ} \mathrm{C}, 10-25 \mathrm{~min}, 77-85 \%$ yields

Scheme 13. Synthesis of 1,4-DTs in ionic liquids.

(E)-Methyl 3-Tosyl Acrylate $\mathbf{4 2}$ was investigated by Das et al. for the synthesis of methylcarboxylated esters of 1,4-DTs through a [3 + 2] cycloaddition reaction. In particular, compound 42 was combined with a wide range of alkyl azides 41 to afford compounds 43 in suitable yields (Scheme 14) [48].

$$
\text { R-N } \mathrm{N}_{3}
$$

41

$\mathrm{R}=$ Alkyl, benzy<smiles></smiles>

14 examples $61-77 \%$ yields

Scheme 14. Synthesis of 4-carboxylated 1,4-DTs 43

In the same reaction conditions, the authors also tested the starting reagent 42 with different diazides. Surprisingly, different unsymmetrical bis-triazoles were obtained, containing bis 1,4-DTs, or both 1,4-DTs and 1,5-DTs residues or bis 1,5-DTs, although the last one was the minor product (Scheme 15). 

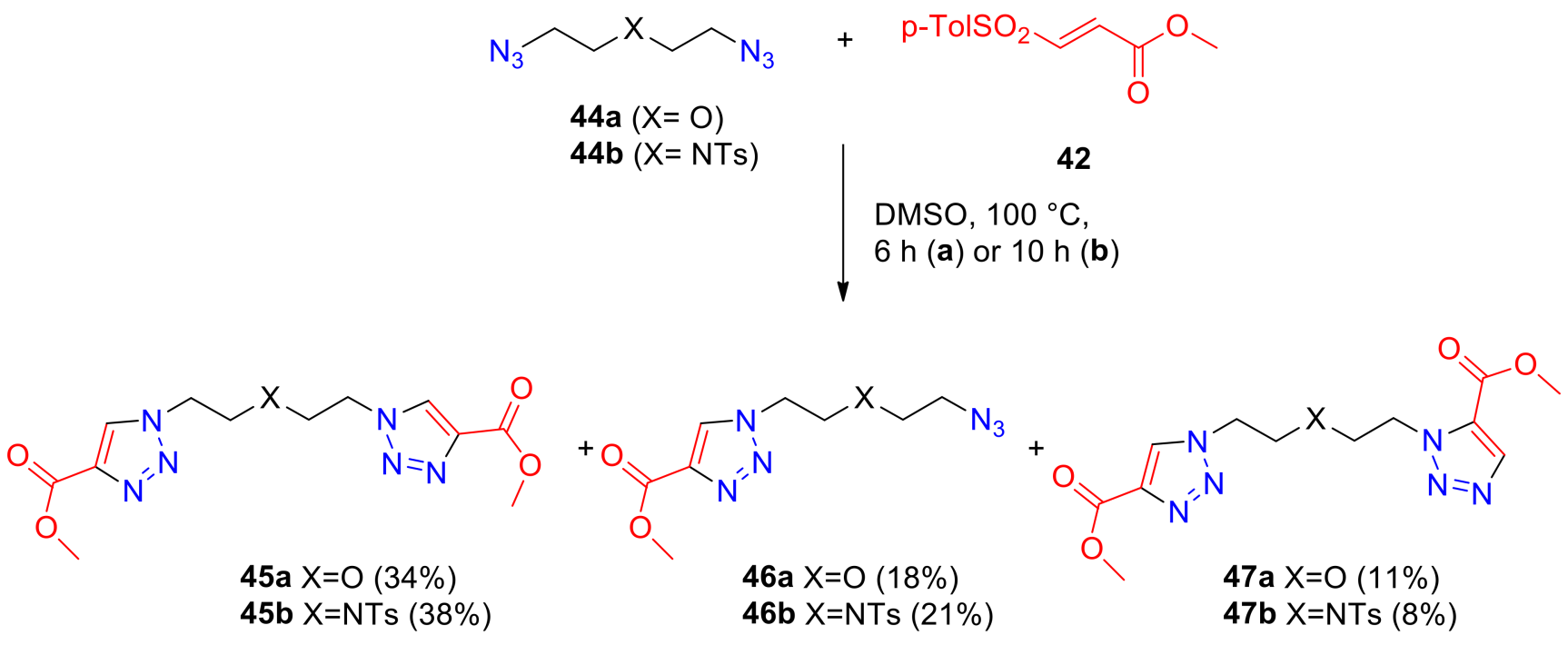<smiles>[X]CCCn1nncc1C(=O)OC</smiles>

48a $\mathrm{X}=\mathrm{O}(8 \%)$ 48b $X=N T s(9 \%)$<smiles>[X]CCn1nncc1C(=O)OC</smiles>

49b X=NTs $(6 \%)$

Scheme 15. Reaction of 42 with diazides $44 a$ or $44 b$.

Recently, Sebest et al., after have been synthesized triazolines in deep eutectic solvents (DESs), obtained 1,2,3-triazoles directly from this precursor [49]. DESs are considered very interestingly emerging green solvents, employed both for the synthesis of pharmaceutical building blocks [50] and as extraction media for natural active compounds [51]. In this work, the Sebest research group searched for the best reaction conditions to afford 1,2,3triazoles in a one-pot reaction via the formation of non-isolated triazoline intermediates. In brief, using 1,1,3,3-tetramethyl-guanidine (TMG) as a base in DES (choline chloride/urea 1:2), the authors obtained 1,5-DTs, and 1,4-DTs, regioselectively in a one-pot reaction, without the isolation step of the triazolines. In particular, 1,5-DTs were obtained working in DES for $24 \mathrm{~h}$ at r.t., while to afford 1,4-DTs, it was necessary to heat the reaction mixture. However, the limited tolerance of this approach, the 1,4-DTs 52a and 52b were obtained in a very ecofriendly process (Scheme 16) [49].

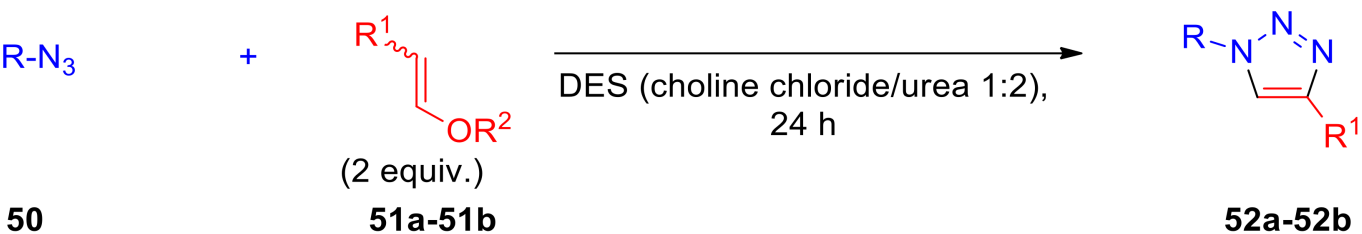

a, $\mathrm{R}=4-\mathrm{CF}_{3} \mathrm{C}_{6} \mathrm{H}_{4}, \mathrm{R}^{1}=\mathrm{Me}, \mathrm{R}^{2}=\mathrm{Et}, \mathrm{TMG}$ (1 equiv.), $80{ }^{\circ} \mathrm{C}, 82 \%$

b, $\mathrm{R}=4-\mathrm{CNC}_{6} \mathrm{H}_{4}, \mathrm{R}^{1}=\mathrm{COMe}, \mathrm{R}^{2}=\mathrm{Me}$, no base, $90{ }^{\circ} \mathrm{C}, 74 \%$

Scheme 16. One-pot synthesis of 1,2,3-triazole in DES.

Tosylazide was used as a nitrogen source by Wan et al., in a transition-metal-free cycloaddition reaction with enaminones, for the synthesis of 1,4-DTs [52]. In this work of 2016, the authors attempted to realize the direct cycloaddition reaction of the enaminones 53 (Scheme 17) in desired heterocycles 55 using $t$-BuONa as a base catalyst in $\mathrm{MeCN}$ at room temperature. For the first step, it was necessary to use a Lewis acid, such as $\mathrm{FeCl}_{3}$, to 
catalyze the transamination between 53 and the amines 54 . Then, the new enaminone $\mathbf{A}$ (Scheme 18) reacted with tosylazide to give $\mathbf{5 5}$, in the presence of a base, only present in the second step. As demonstrated by the authors, the metal catalyst is not necessary for the cycloaddition reaction, classifying the reaction as "metal-free". The authors obtained the designed 1,4-DTs, in suitable yields, in a domino reaction at room temperature with a simple procedure. The postulated reaction mechanism involves a typical Regitz diazo transfer reaction in which a diazo intermediate B (Scheme 18) is formed, and that can be rearranged to provide the cycloaddition step.<smiles>[R]C(=O)C=CN(C)C</smiles>

53
$\mathrm{R}=\mathrm{aryl}$, alkyl

$$
\begin{gathered}
\mathrm{R}^{1}-\mathrm{NH}_{2} \\
\text { (1.3 equiv.) }
\end{gathered}
$$

54

$\mathrm{R}^{1}=$ aryl, benzyl
1) $\mathrm{FeCl}_{3}$ (0.5 equiv.),

$$
\begin{aligned}
& \text { rt, MeCN } \\
& \hline \text { 2) } t \text {-BuONa, } \\
& \mathrm{TsN}_{3} \text { (1.3 equiv.) }
\end{aligned}
$$

Scheme 17. Domino reaction for the synthesis of 1,4-DTs starting from enaminones.

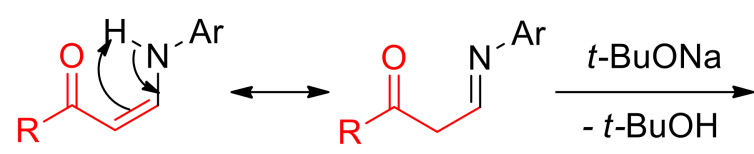

A<smiles>[R]C(=O)c1cn([Al]CC)nn1</smiles>

55

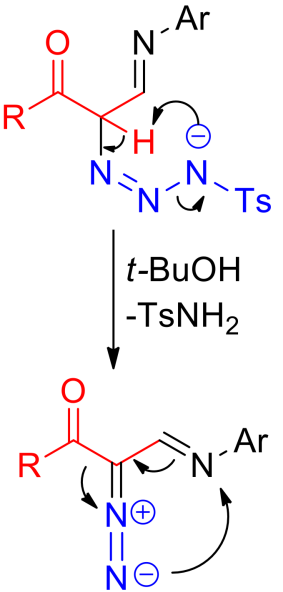

B

Scheme 18. Postulated mechanism involving a Regitz diazo transfer reaction.

In 2018, the same research group exploited alkyl propiolates for the formation of an active enamine as intermediate in a domino reaction for the switchable synthesis of 1,5and 1,4-disubstituted 1,2,3-triazoles [53]. The synthesis 1,5-DTs was also realized without the use of azides, while for 1,4-DTs, tosylazide $\left(\mathrm{TsN}_{3}\right)$ was necessary as a nitrogen source. The authors demonstrated that alkyl propiolate 56 in the presence of piperazine gives the key intermediate $\mathbf{6 0}$ (Figure 4) by an aza-Michael addition (Scheme 19). Then, $\mathbf{5 8}$ reacts with the proper aniline 57 to give $\mathrm{NH}$-enamine intermediate 58 , which in the second step affords the related 1,4-DTs $\mathbf{5 9}$ at room temperature with tosylazide. As just reported in the previous example, $\mathrm{FeCl}_{3}$ is required in the first step to catalyze the transamination between the aniline and the tertiary amine generated in situ, while $t-\mathrm{BuONa}$ is necessary for the second step as a base additive in a Regitz diazo transfer mechanism.<smiles>[R]OC=CN1CCN(C=CC([R])=O)CC1</smiles>

60

Figure 4. Tertiary enamine intermediate for the synthesis of 1,4-DTs 59. 


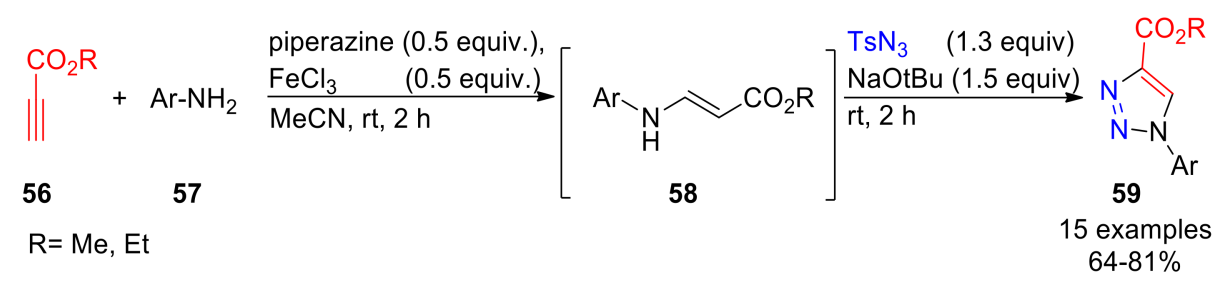

Scheme 19. Metal-free synthesis of 1,4-DTs through enamine activation.

Among the procedure that exploited both alkyl- and aryl azides in the metal-free synthesis of 1,2,3-triazoles, the methodology developed by Zhang and co-workers in 2019 was very interesting [54]. In this work, $\alpha$-bromoacrolein (62) was chosen as an excellent dienophile for the cycloaddition reaction since the nature of the leaving group of the bromide. More in detail, the authors investigated the reaction between $\alpha$-bromoacrolein 62 and diverse aryl and alkyl azides, obtaining formyl triazoles 63 in DMSO $/ \mathrm{H}_{2} \mathrm{O}$ as solvents and at room temperature (Scheme 20). This procedure that has been the important advantage to be compatible with aqueous conditions was also extended for the synthesis of formyl triazoles also substituted on the C-5 of the heterocycle.

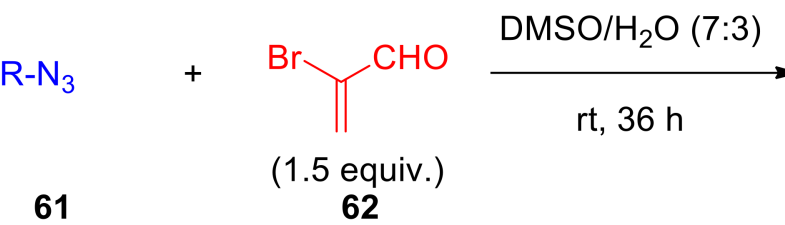

$\mathrm{R}=$ alkyl, aryl, esters, alcohol

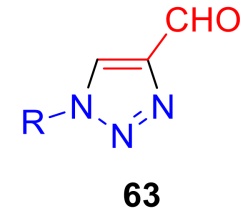

20 examples $60-99 \%$ yields

Scheme 20. $\alpha$-Bromoacrolein as a dienophile for cycloaddition with azides.

New synthetic procedures were developed in the last 10 years, eliminating not only the metal catalysts but also the azides as potential explosive substrates. Among the methods developed in the last years, it is possible to highlight two different approaches: the first one requires oxidants $\left(\mathrm{I}_{2}\right.$ or $\left.\mathrm{O}_{2}\right)$ favoring the cycloaddition of $\mathrm{N}$-tosylhydrazones and anilines; the second one avoids the use of any oxidant exploiting base conditions or the presence of suitable leaving groups. The first approach was less envisaged, except the works coming from the Wang research group $[55,56]$, but recently Mani et al. published an interesting paper in which it was described the direct transformation of aryl alkenes and aryl alkynes using $\mathrm{I}_{2}$ under $\mathrm{O}_{2}$ atmosphere [57]. The nitrogen sources consisted of $\mathrm{N}$-tosylhydrazine and aniline, which in oxidation conditions reacted with the $\alpha$-iodoacetophenone originated by the alkene/alkyne to give the 1,4-DTs (Scheme 21). Substrate scope was investigated, and suitable yields were obtained with all aromatic substrates. The possible reaction mechanism was investigated, and two plausible ways were proposed. The first one (path a, Scheme 22) carries out the product through the $\alpha$-iodoacetophenone intermediate $\mathbf{A}$. The second one (path $\mathrm{b}$, Scheme 22) needs the conversion of $\alpha$-iodoacetophenone in phenylglyoxal B through a Kornblum oxidation mechanism.

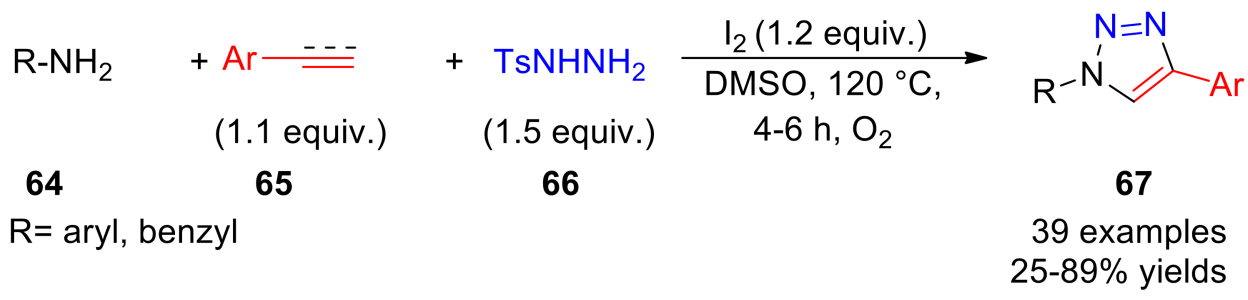

Scheme 21. $I_{2}$ catalyzed direct synthesis of 1,4-DTs from diverse aryl alkene and alkyne. 


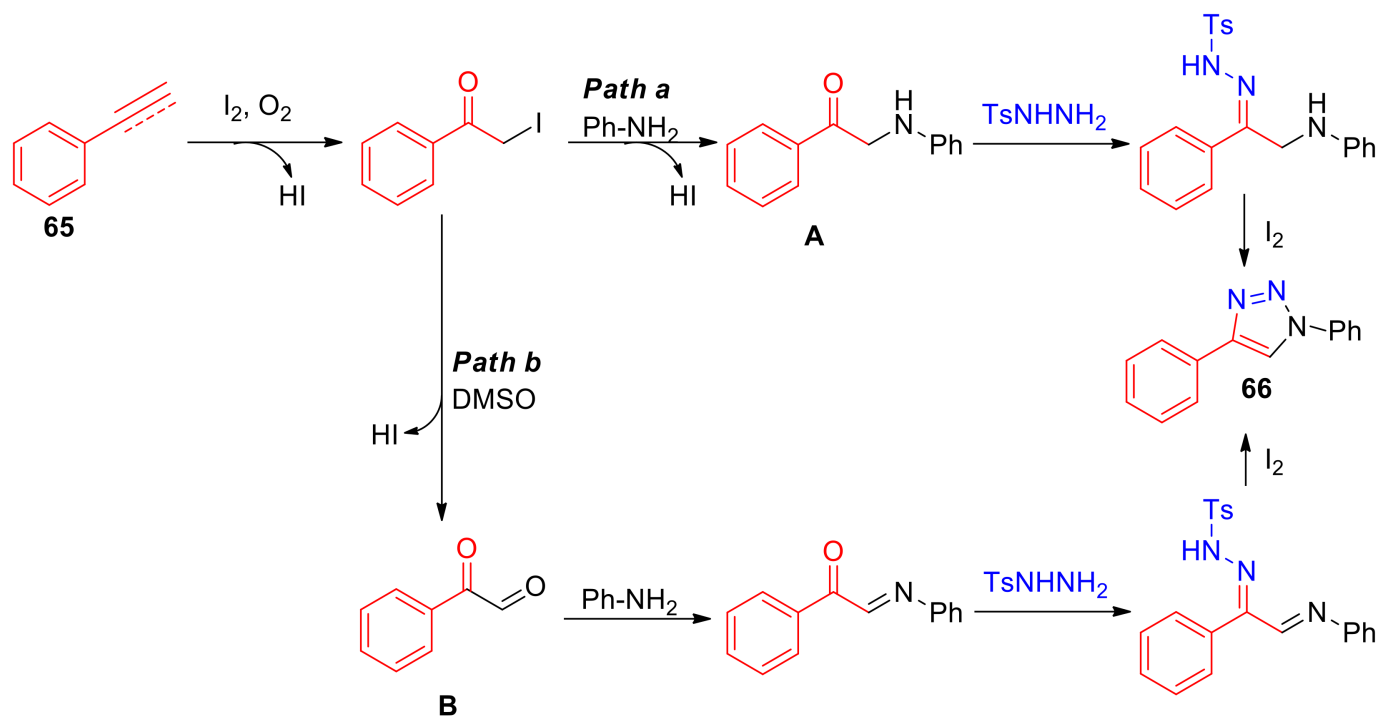

Scheme 22. Plausible mechanism for the synthesis of 1,4-DTs with $I_{2}$ as a catalyst.

Tosylhydrazones are the key intermediate of all these metal- and azide-free transformations. A review of 2017 summarized the sign of progress in the synthesis of 1,2,3-triazoles without any transition metal or azide [58], but very recently, different works were reported in the literature on the green cycloaddition of tosylhydrazones with a suitable leaving group in $\alpha$-position. Zhou et al., in 2019, used $\alpha$, $\alpha$-difluoro- $N$-tosylhydrazones 44 to carry out the synthesis of 1,2,3-triazoles through the cleavage of C-F bonds, despite this is one of the strongest single bonds [59]. In this way, it was possible to perform this reaction also on aryl substrates, unlike $\alpha, \alpha$-dichloro- $N$-tosylhydrazones, which limited the reactivity to the alkyl groups.

The use of $\mathrm{LiO}^{t} \mathrm{Bu}$ was necessary as a strong base (Scheme 23). The reaction condition and scope were investigated by the authors that observed a suitable functional tolerance for the R-group, then obtaining high yields without using azides, metals, or any oxidants.

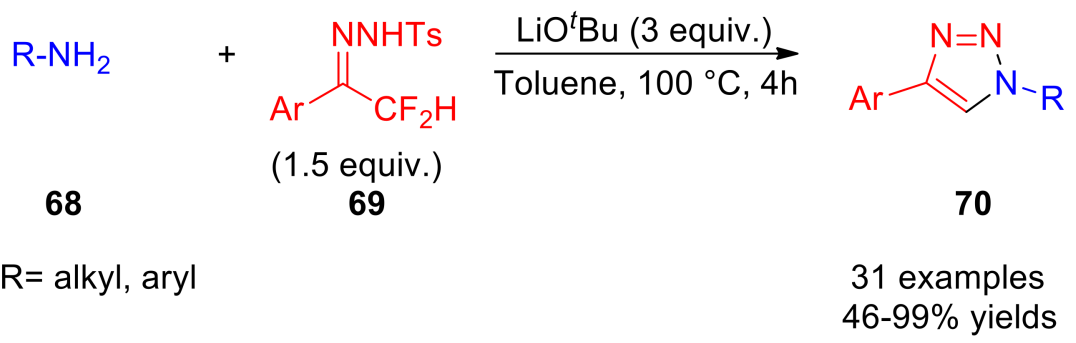

Scheme 23. $\alpha, \alpha$-difluoro-tosylhydrazone 69 as a starting substrate for the synthesis of 1,4-DTs.

$\alpha, \alpha$-Dichloro- $N$-tosylhydrazones are easily prepared by $\alpha, \alpha$-dichloroketones and tosyl hydrazine 66. Considering the low stability of $\alpha, \alpha$-dichloroketones and the undesired byproducts obtained after the base-catalyzed Favorskii rearrangement, Zhender and coworkers developed the replacement of the $\alpha$, an $\alpha$-halo functional group with the $\alpha, \alpha$ dimethoxy acetal (71) [60]. Firstly, the authors tested the two-step process with an overall yield of $53 \%$. The $N$-tosylhydrazones $\mathbf{7 2}$ obtained from $\alpha$-ketoacetals $\mathbf{7 0}$ were transformed in the related 1,4-DTs by simply heating in the presence of the desired primary amine. Then, testing the one-pot procedure, they obtained the 1,4-DTs starting from the $\alpha, \alpha-$ dimethoxyacetal, with an $87 \%$ yield. The scope of this method was explored, obtaining with suitable yields both 1,4-DTs and trisubstituted 1,2,3-triazoles (Scheme 24). 


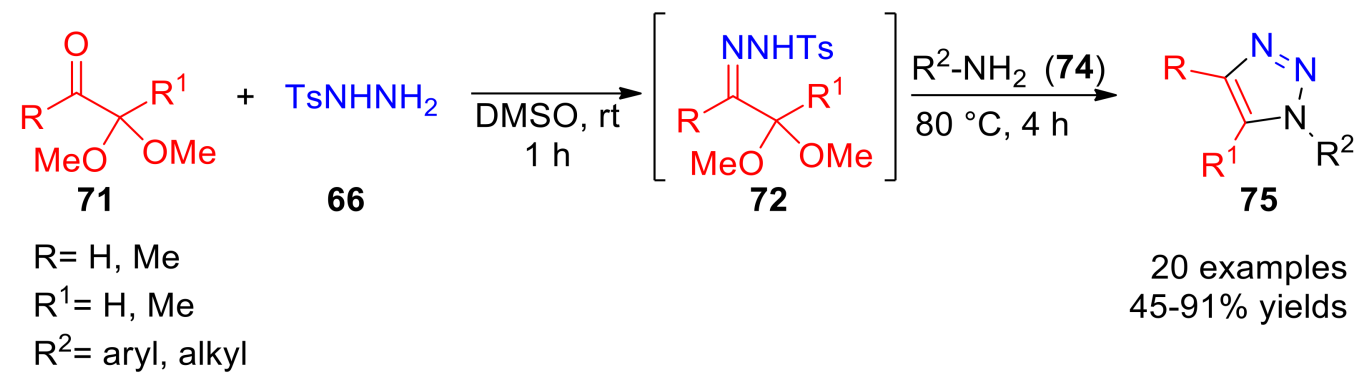

Scheme 24. Reaction scope for the synthesis of 1,4-DTs starting from $\alpha, \alpha$-dimethoxy ketones 71 and primary amines 74 .

\subsection{Synthesis of 1,5-Disubstituted 1,2,3-Triazoles}

As described above, for 1,4-disubstituted 1,2,3-triazoles, 1,5-disubstituted regioisomer of these nitrogen-based compounds too has been extensively deepened. Even in this case, the great interest toward such compounds is due to their value as peptidomimetics [61], macrocycles for drug delivery systems [62], glycomimetics [63,64], antivirals [65,66], antimicrobiotics [67], and antifungal agents [68]. In the next paragraph, we will be briefly present the evidence found in the scientific literature from 2015 for the synthesis of 1,5-disubstituted 1,2,3-triazoles, which extended highlighted the central role of such compounds as bioactive molecules.

\subsubsection{Metal-Catalyzed Synthesis of 1,5-Disubstituted 1,2,3-Triazoles}

The major advances in the metal-catalyzed synthesis of 1,5-disubstituted 1,2,3-triazoles mostly continue the trend illustrated in the reviews based on works before 2015. In fact, the main contributes consists of ruthenium (II)-catalyzed reactions for the preparation of bioactive triazolyl cores using the ruthenium-catalyzed azide-alkyne cycloaddition (RuAAC) (Scheme 25) [69]. The reaction starts with the displacement of the two ligands (L), also called spectator ligands, by the two reaction partners (77 and 78), generating an activated intermediate 79. Such an intermediate evolves through the oxidative coupling of the ligands $\mathbf{7 7}$ and $\mathbf{7 8}$ generating the intermediate $\mathbf{8 0}$ (ruthenacycle intermediate). As stated by the authors, this step controls the overall regioselectivity of the reaction. The catalytic cycle ends with reductive elimination on the intermediate $\mathbf{8 1}$ that releases the product 82 and regenerates the catalyst 76 .

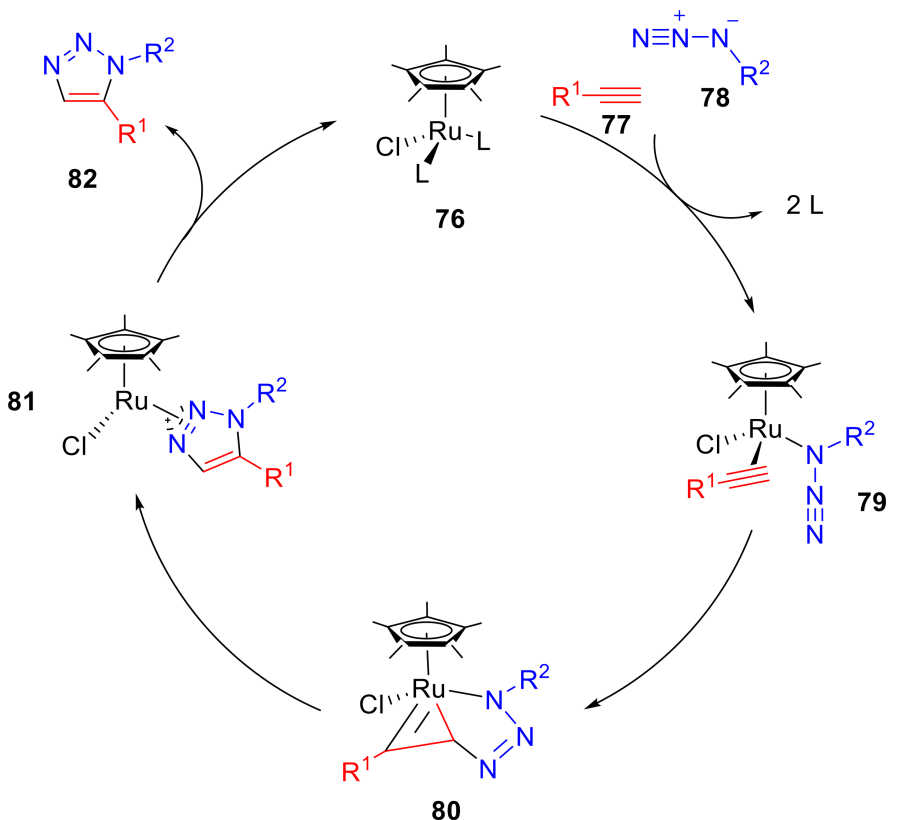

Scheme 25. Catalytic cycle of RuAAC proposed by Boren and co-workers. 
In coherence with the development of biologically active compounds, in 2015, Vernekar and collaborators [70] were able to develop new antiviral triazoles 84, particularly active against West Nile virus (WNV) and Dengue virus (DENV). The so-obtained compounds are $5^{\prime}$-silylated nucleoside scaffolds derived from $3^{\prime}$-azidothymidine (AZT) 83, synthesized via a classic RuAAC Cp* Ru(Cl)( $\left.\mathrm{PPh}_{3}\right)_{2}$ in THF as solvent (Scheme 26).<smiles>[R20]CC1(C)OC2CC(n3cc(C)c(=O)[nH]c3=O)C1C2</smiles>

83
$\mathrm{R}^{2}$-substituted alkyne

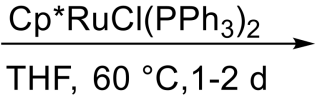

$\mathrm{THF}, 60^{\circ} \mathrm{C}, 1-2 \mathrm{~d}$

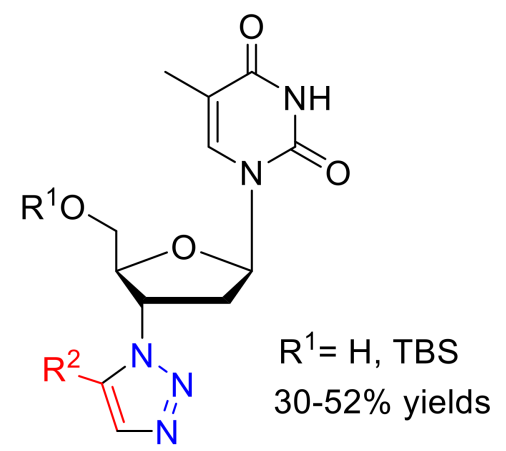

84

Scheme 26. Vernekar synthesis of 1,5-disubstituted 1,2,3-triazoles functionalized with a nucleoside scaffold.

A year later, Hornum and co-workers [71] proposed an approach for the insertion of a 1,2,3-triazolyl moiety directly on a pyrimidine ring (Scheme 27). Such a strategy can be intended as a reversed approach to the one followed by Vernekar (Scheme 26) [70]: in this case, it is the nucleoside scaffold 85 that acts as dipolarophile, whereas the role of 1,3-dipole is assumed by phenylazide 86 .<smiles>C#Cc1cn(C2CC(C)CCC2OC(C)=O)c(=O)[nH]c1=O</smiles>

85<smiles>[N-]c1ccccc1</smiles>

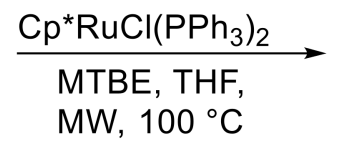

$\mathrm{MW}, 100^{\circ} \mathrm{C}$

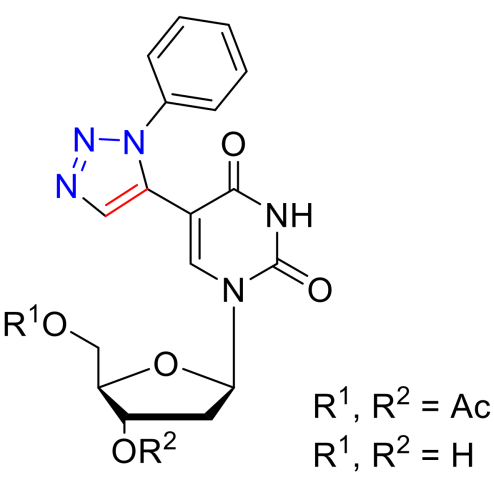

87

Scheme 27. Hornum synthesis of 1,5-disubstituted 1,2,3-triazoles bonded linked to a pyrimidine ring 51.

In 2016, Kocsis and collaborators [72] developed a synthetic protocol for the Rucatalyzed synthesis of cinchona-chalcone hybrids for the preparation of 1,5-functionalized 1,2,3-triazoles. In this case, the triazole ring has been used as a linker for a chalcone moiety directly bonded to a ferrocene $\mathbf{9 0} \mathbf{a}-\mathbf{b}$ starting from a 2-azidochalcone derivative $\mathbf{8 8} \mathbf{a}-\mathbf{b}$ and a propargyl derivative $89 \mathbf{a}-\mathbf{b}$ (Scheme 28). The obtained substrates have been evaluated against HepG-2 and HT-29 cells in vitro, displaying a significant cytostatic activity. 
<smiles></smiles>

88a-b

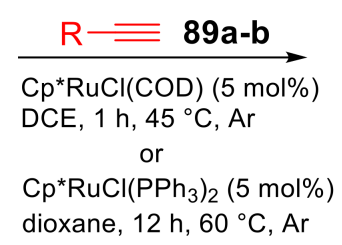<smiles>[R]c1cnnn1-c1ccccc1/C=C/C(=O)c1ccccc1F</smiles>

$90 a-b$

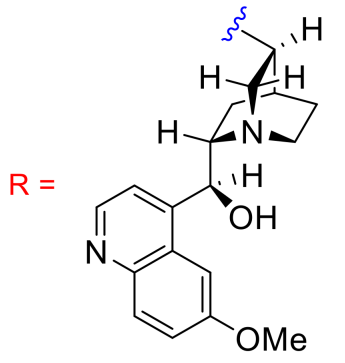

$89 a$<smiles>COc1ccc2nccc([C@@H](O)[C@H]3C[C@H]4CCN3C4)c2c1</smiles>

$89 b$

Scheme 28. 1,5-disubstituted 1,2,3-triazoles-containing ferrocene-cinchone hybrids.

Successively, a synthetic route has been proposed by Jernei et al. [73] for the preparation of similar cinchona-chalcone hybrids that were revealed to possess an interesting cytostatic activity against PANC-1 cells. Other efficient syntheses have been proposed in the last years for the preparation of numerous substrates possessing notable biological activities against specific biological targets (i.e., Chagas disease, A549, SW480, etc.) by using Ru (II) complexes as catalysts [74-79].

Interesting evidence in peptidomimetic and disulfide bond-mimetic preparation has been recently reported, enhancing the potential of 1,5-disubstituted 1,2,3-triazoles in medicinal chemistry. In these cases, triazoles are employed as innovative bioisosteres of amide or disulfide bonds, improving the conformational properties or the chemical stability of the obtained peptides. In 2018, Kracker and co-workers [80] proposed novel peptidotriazolamers combining the features of peptides and triazolamers, which are structures containing triazole rings in place of peptide bonds. In doing so, a propargyl Boc-protected amine 91 and an $\alpha$-azido Bn-protected ester 92 have been coupled using $\mathrm{Cp} * \mathrm{RuCl}(\mathrm{COD})$ 93 as catalyst (3-5 mol\%) under microwave (MW) irradiation (Scheme 29$)$. In this case, it is noteworthy that the use of a protective group using an ester is indispensable due to the incompatibility of the ruthenium-catalyzed azide-alkyne cycloaddition (RuAAC) approach with carboxylic acids.<smiles>[R]C(C#C)NC(=O)OCc1ccccc1</smiles>

91

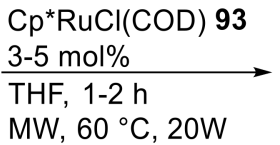

92

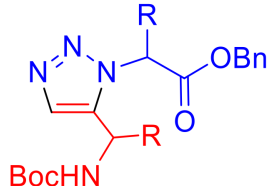

94

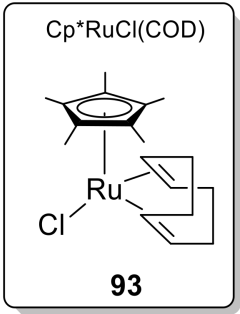

Scheme 29. RuAAC synthesis of 1,5-disubstituted 1,2,3-triazoles as peptide bond isosteres.

Following the same strategy, Stålsmeden [81] and Grob [82], and their respective collaborators, developed a series of novel peptide drugs that have also been biologically tested. In the first case, it has been realized that the RuAAC synthesis of chiral 1,5-disubstituted 1,2,3-triazoles aiming to obtain foldamers useful in pharmaceutics and biotechnology. The optimization of the reaction conditions was performed on a Boc-protected propargylamine 95 and an $\alpha$-azidomethylester 96 (Scheme 30). 
<smiles>C#CC(C)NC(=O)[O-]</smiles>

95

96

Scheme 30. Ru-catalyzed synthesis of 1,5-disubstitute 1,2,3-triazoles as bioisosteres of the amide bond.

Furthermore, Grob [82] et al. took advantage of the RuAAC synthesis of 1,2,3triazoles for realizing a series of novel minigastrin analogs successfully tested toward cholecystokinin-2 receptor (CCK2R). Scheme 31 only regards the reaction step where the triazolyl moiety is formed starting from an $\alpha$-azido Bn-protected ester $\mathbf{9 8}$ and a Fmocprotected amino-propargyl derivative $\mathbf{9 9}$.<smiles>CCCCOc1ccc(CC(N)C(=O)Oc2ccccc2)cc1</smiles>

98<smiles>C#CC(C)NC(F)F</smiles>

1) $\mathrm{Cp}{ }^{*} \mathrm{RuCl}\left(\mathrm{PPh}_{3}\right)_{2}$, DMF

2) $\mathrm{H}_{2}, \mathrm{Pd} / \mathrm{C}, \mathrm{EtOH}$<smiles>CCCCOc1ccc(CC(C(=O)O)n2nncc2C(C)NC(F)F)cc1</smiles>

100

Scheme 31. RuAAC synthesis of 1,2,3-triazolyl minigastrin analogs.

As for the use of 1,5-disubstituted 1,2,3-triazoles as disulfide bond mimetics, interesting evidence has been reported in the last three years. Tala and collaborators [83] used click chemistry to synthesize 1,2,3-triazole rings in place of a disulfide bridge inside a chimeric AGRP-melanocortin peptide 102. In doing so, they realized a RuAAC between an azide-group of a Fmoc-protected terminal amino acid and a terminal propargylic group linked to an amino acid of the same peptide chain 101 (Scheme 32).

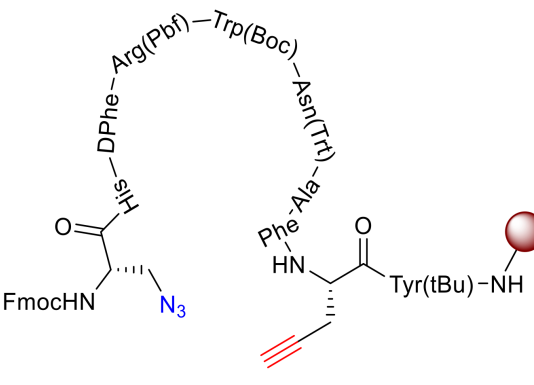

101

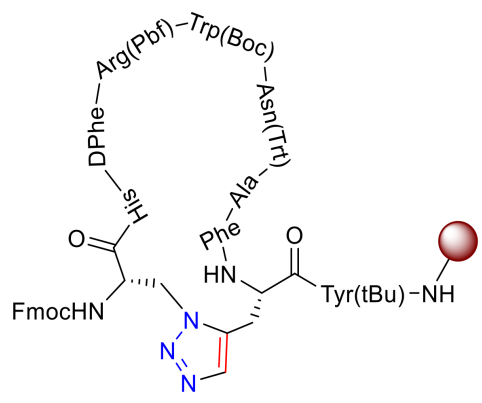

102

Scheme 32. RuAAC synthesis of 1,2,3-triazoles as disulfide bond isosteres.

Following this strategy, very recent applications of 1,2,3-triazoles as disulfide bond mimetics have been proposed [84-86]. In all the reported cases, the elected catalyst was 93 in amounts ranging from 20 to $50 \mathrm{~mol} \%$.

Among other noteworthy works, in 2015, Chen and co-workers [87] proposed a synthetic method for obtaining a 1,5-disubstituted 1,2,3-ditriazole 105 that showed important aggregation-enhanced emission characteristics forming red-emissive charge-transfer complexes. The 1,5-disubstituted product was synthesized via the so-known RuAAC approach, 
using $\mathrm{Cp}{ }^{*} \mathrm{RuCl}\left(\mathrm{PPh}_{3}\right)_{2}$ as catalyst (Scheme 33). Successively, Anand et al. [88] published a click chemistry-based approach for the regioselective synthesis of 1,5-coumarinyl 1,2,3triazoles 108 (Scheme 34).<smiles>C#Cc1ccc(-c2nc(C#N)c(C#N)nc2-c2ccc(C#C)cc2)cc1</smiles>

103

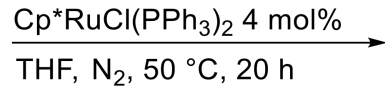

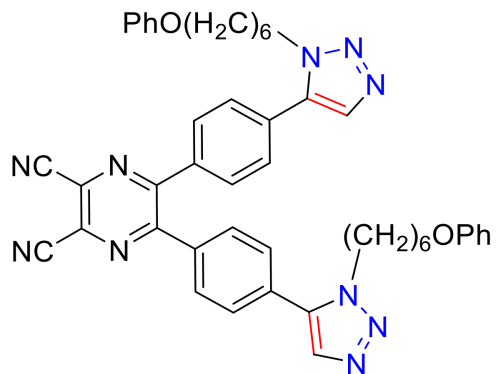

105

Scheme 33. 1,5-disubstituted 1,2,3-triazole-containing molecule with aggregation-enhanced emission characteristics developed by Chen group.<smiles></smiles>

106<smiles>C#CCN1C(=O)c2ccccc2C1=O</smiles>

107

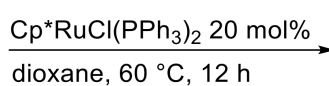
dioxane, $60^{\circ} \mathrm{C}, 12 \mathrm{~h}$<smiles>[R]C=Cc1ccccc1Cn1nncc1CN1C(=O)c2ccccc2C1=O</smiles>

$\mathrm{X}=\mathrm{O}, \mathrm{NH}$

$\mathrm{R}=6-\mathrm{Cl}, 8-\mathrm{CH}_{3}, 6-\mathrm{CH}_{3}$ 7,8-di- $\mathrm{CH}_{3}, 7-\mathrm{CH}_{3}$ 5,7-di- $\mathrm{CH}_{3}$, benzo[f]quinoline, $7-\mathrm{OCH}_{3}, 7-\mathrm{Cl}$

\section{8}

Scheme 34. 1,5-disubstituted 1,2,3-triazole employed as photosensitizer developed by Anand group.

Even though most of the syntheses are exerted using the RuAAC approach, the use of catalytic protocols that involve other metals showed important progress. In this sense, one of the most notable new catalytic development was proposed in 2017 by Mekni [89] and in 2018 by Kumar et al. [90]. In the first report, the authors propose the first attempt of intramolecular 1,3-dipolar cycloaddition of polyoxyethylene diazidoalkynes $\mathbf{1 0 9}$ catalyzed by a Cu (I) salt (Scheme 35). As a result, it has been obtained a mixture of polyoxyethylene 1,5-disubstituted fused-di(1,2,3-triazole)-1,4-oxazines 110 and 1,4-disubstituted mono(1,2,3triazole)azidoalkyne crown ether 111, with a preponderance of substrate $\mathbf{1 1 0 .}$

In a much more comprehensive work, Kumar and co-workers [90] proposed the first evidence of the capability of $\mathrm{Cu}$ (I) to catalyze the synthesis of 1,5-disubstituted 1,2,3triazoles 114 through the coupling of phenylazide derivatives 112 and substituted styryl carboxylic acids 113 with suitable yields (60-80\%) (Scheme 36). 
<smiles>C#CCOC(C)COCC(C)(CN)OCC#C</smiles>

109<smiles>CC1(CCOCC2(C)Cn3nncc3CO2)Cn2nncc2CO1</smiles>

110

$\underset{\mathrm{CuCl}(1.0 \text { eq. })}{\longrightarrow}$

Toluene

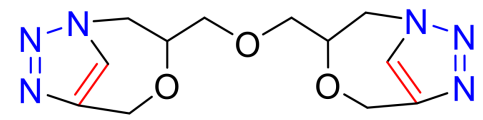

111

Scheme 35. Preparation of polyoxoethylene 1,5-disubstituted fused-di(1,2,3-triazole)-1,4-oxazines 110 via a $\mathrm{Cu}(\mathrm{I})$-catalyzed intramolecular 1,3-dipolar cycloaddition.<smiles>[R]c1ccc(N)cc1C=CC(=O)O</smiles>

112
$\mathrm{Cu}(\mathrm{OTf})_{2}(20 \mathrm{~mol} \%)$, air ascorbic acid/DMF $(1: 4, w / v)$ $115{ }^{\circ} \mathrm{C}$<smiles>[R]c1ccc(-n2nncc2-c2ccccc2)cc1</smiles>

118
23 examples $60-80 \%$ yields

Scheme 36. Synthesis of 1,5-disubstitute 1,2,3-triazoles 114 via Cu (I)-catalyzed decarboxylation method.

In this case, $\mathrm{Cu}(\mathrm{I})$ has been generated in situ using ascorbic acid dissolved in the reaction medium (DMF) at a concentration of $25 \% w / v$. It is noteworthy that the use of $\mathrm{Cu}$ (I) is highly compatible with the presence of carboxylic acids, which, on the contrary, are not used in co-presence $\mathrm{Ru}$ (II) as a catalyst. In addition, a mechanistic pathway has been proposed, showing that a reasonable interpretation of the course of the reaction includes an initial 1,3-dipolar cycloaddition followed by the decarboxylation of the intermediate 114 allowing the aromatization step with the formation of intermediate $\mathbf{1 1 7}$ that easily undergo protonolysis generating the desired product 118 (Scheme 37).

Another contribution to the novel metal-catalyzed approaches proposed in the last years comes from the use of nickel for the synthesis of 1,5-disubstituted 1,2,3-triazoles in open air and water [91]. In this case, Kim and co-workers proposed a convenient green method for the preparation of triazoles in a highly regioselective way, using $\mathrm{Cp}_{2} \mathrm{Ni}$ and Xantphos (both at $10 \mathrm{~mol} \%$ ) as catalytic systems in water at room temperature (Scheme 38 ). 


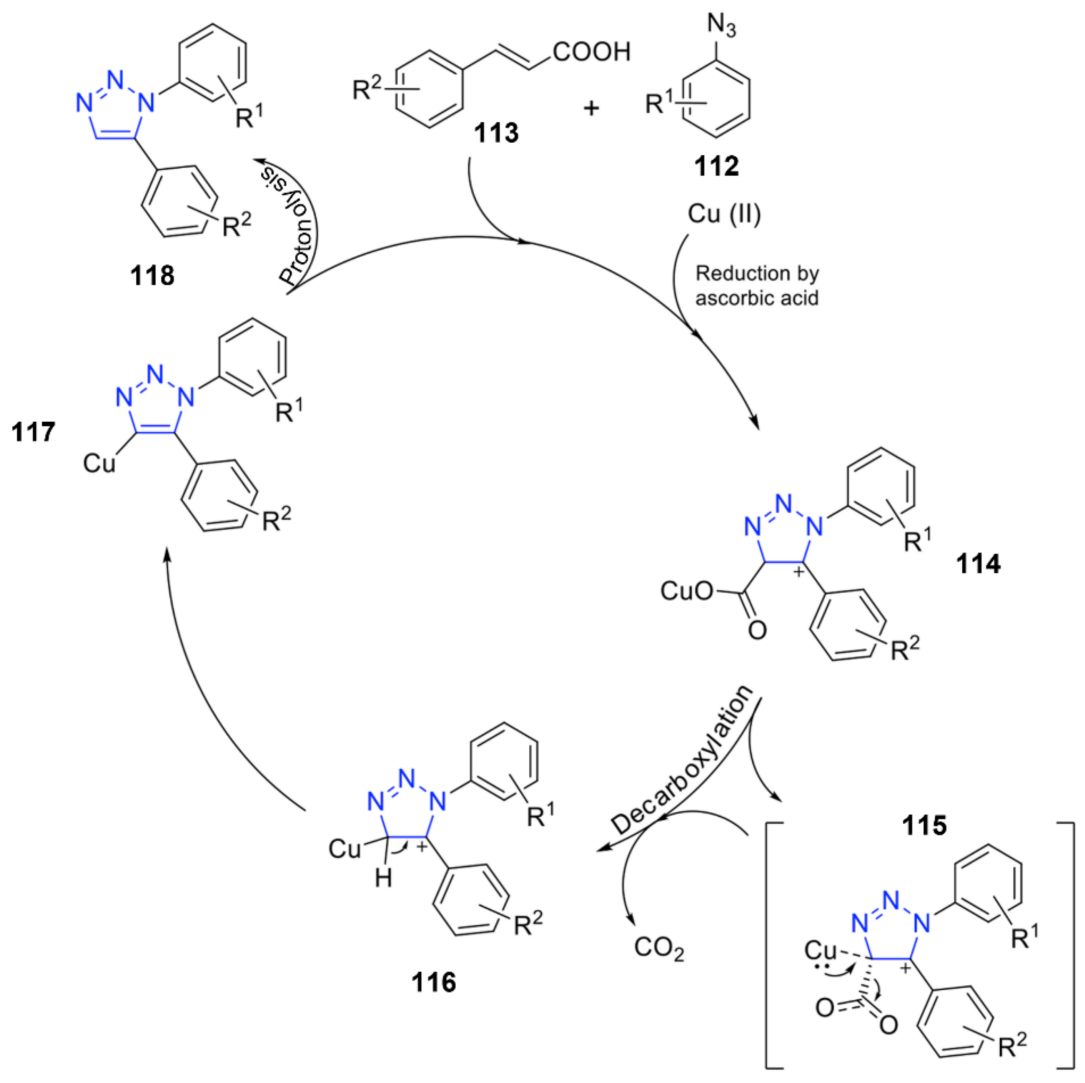

Scheme 37. Catalytic cycle for the $\mathrm{Cu}(\mathrm{I})$-catalyzed synthesis of 1,5-disubstituted 1,2,3-triazoles 118 proposed by Kumar et al.

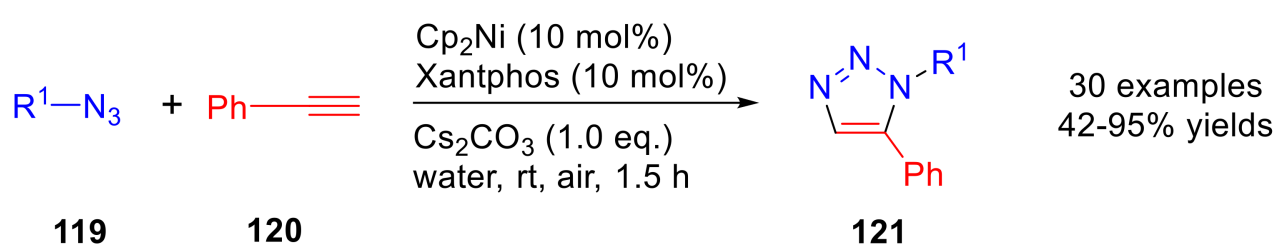

Scheme 38. NiAAC synthesis of 1,5-disubstituted 1,2,3-triazoles.

Such contribution opens new catalytic pathways, allowing to plan new syntheses of highly valuable scaffolds using a greener catalyst compatible with many substrates.

Recently, other interesting perspectives have been proposed to extend the role of metals in 1,5-disubstituted derivatives synthesis. Two examples of such developments are the papers published in 2015 and 2021, respectively, by Nanjundaswamy [92] and Mahadari [93] and co-workers. Nanjundaswamy's group indeed proposed a highly regioselective synthesis of 1,5disubstituted substrates through a heterogeneous catalyst made up by $\mathrm{AlCl}_{3}$ immobilized on $\gamma-$ $\mathrm{Al}_{2} \mathrm{O}_{3}$. Mahadari's group approach, on the other hand, lies on the role of in situ formations of chloromagnesium acetylides for the preparation of sterically bulky 1-(2-methoxy-1-naphthyl)5-substituted-1,2,3-triazoles 123 from 1-azidonaphthalene derivatives 122 (Scheme 39). Even though such an approach revealed to be particularly efficient for such substrates if compared to the classical $\mathrm{Ru}$ (II) catalysts, one can argue that the use of $\mathrm{EtMgCl}$ for the in situ formation of acetylides intermediates would not be compatible with a very large number of substrates containing, for instance, carbonyl groups. 


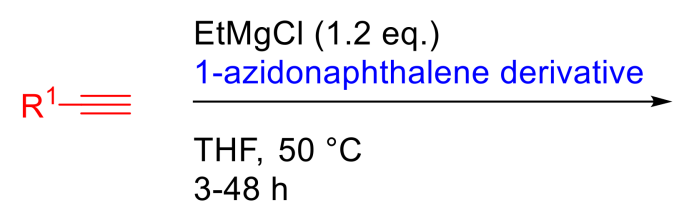

122

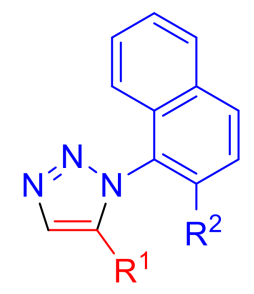

123

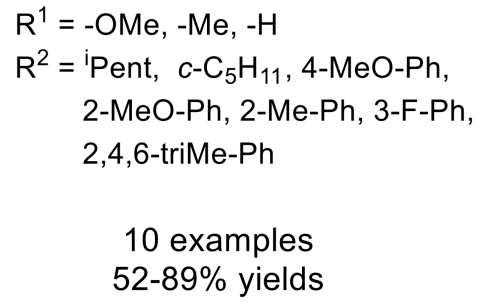

Scheme 39. 1,5-disubstituted naphtyl-1,2,3-triazoles obtained from in situ formation of chloromagnesium acetylides.

Recently, two innovative methods for the synthesis of 1,5-disubstituted 1,2,3-triazoles were proposed. In 2018, De Nino et al. achieved the unprecedented synthesis of 1,5disubstituted derivatives using $\mathrm{FeCl}_{3}$ as a catalyst in ionic liquid (IL), demonstrating the high regioselectivity of the synthesis and the high reusability performances of such a catalytic system [94] (Scheme 40). The IL employed, in this case, has been obtained from the direct condensation between pyridine and methyl trifluoromethansulfonate ([mPy]OTf) without passing through the classic anionic exchange used for the synthesis of the most common ILs [95]. Notably, several sensitive functionalities such as chloro-, methyl-, methoxy-, and nitro- were unaffected under the present reaction conditions, and the reaction also tolerated ortho-substitution on the aromatic ring. Such substrates were further revealed to possess a very interesting biological activity as $\mathrm{F}_{1} \mathrm{~F}_{\mathrm{O}}-\mathrm{ATP}$ (hydrol)ase inhibitors and in preventing permeability transition pore (mPTP) opening [96].

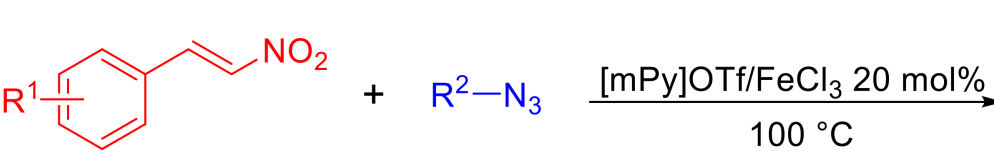

124

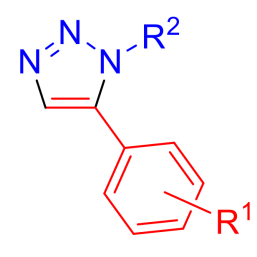

$$
\begin{gathered}
\mathrm{R}^{1}=\mathrm{H}, 2-\mathrm{Cl}, 3-\mathrm{Cl}, 4-\mathrm{Cl}, 4-\mathrm{Me}, \\
\text { 4-MeO, } 2-\mathrm{NO}_{2} \\
\mathrm{R}^{2}=\mathrm{Bn}, \mathrm{Ph} \\
\text { 14 examples } \\
81-96 \% \text { yields }
\end{gathered}
$$

Scheme 40. [mPy]OTf $/ \mathrm{FeCl}_{3} 20 \%$ as efficient and reusable catalytic systems for 1,5-disubstituted 1,2,3-triazoles synthesis.

Erbium (III), too, was revealed to be a very interesting catalyst in the regioselective synthesis of 1,5-disubstituted 1,2,3-triazoles. Maiuolo and co-workers proposed in 2019 an insight in terms of synthesis and reaction mechanism [97], analyzing the role exerted by $\mathrm{Er}(\mathrm{OTf})_{3}$, IL (methylpyridinium triflate), and water. As can be seen from Scheme 41, $\operatorname{Er}(\mathrm{III})$ may play a role in dipolarophile (nitroolephine derivatives 124) coordination, forcing it in assuming a chair conformation stabilized by the presence of water and ionic liquid's ions. Furthermore, the cations and the anions of IL may take part in the ionic self-assembly (ISA) structure, which helps in reagents stacking, favoring the cycloaddition step. Even in this case, the reusability of proposed catalytic systems has been evaluated too up to six times without loss in catalyst activity.

\subsubsection{Metal-Free Catalyzed Synthesis of 1,5-Disubstituted 1,2,3-Triazoles}

The most common synthetic methodology for the synthesis of 1,5-disubstituted 1,2,3triazoles is cyclocondensation catalyzed by metals, as described in the previous paragraph. However, in recent years, scientific research has turned its attention toward a series of reactions that do not involve the use of metals for overcoming the disposal of environmental problems. Typically, metal catalysis is avoided by the use of different approaches such as acid or bases Brønsted-catalysts, in-water reactions, and sonication systems. Below, few examples of metal-free cyclocondensations are reported. 


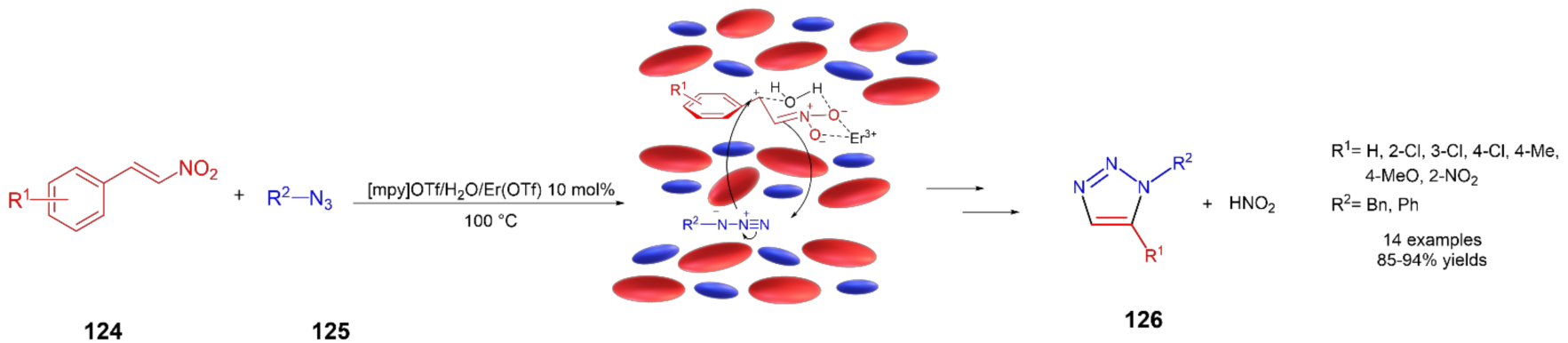

Scheme 41. Proposed role exerted by Er (III), water, and ionic liquid in 1,5-disubstituted 1,2,3-triazoles synthesis. The blue shapes represent the cation $[\mathrm{mpy}]^{+}$and the red shapes the anion [OTf] ${ }^{-}$of the IL employed.

In 2015, Kayet et al. [98] realized the synthesis of 1,5-disubstituted 1,2,3-triazolylated monofuranosides and difuranosides in a metal-free aqueous media. The reaction consists of a 1,3-dipolar cycloaddition between vinyl sulfone derivatives (128) with four different azidofuranosides (127) in agreement with Scheme 42.

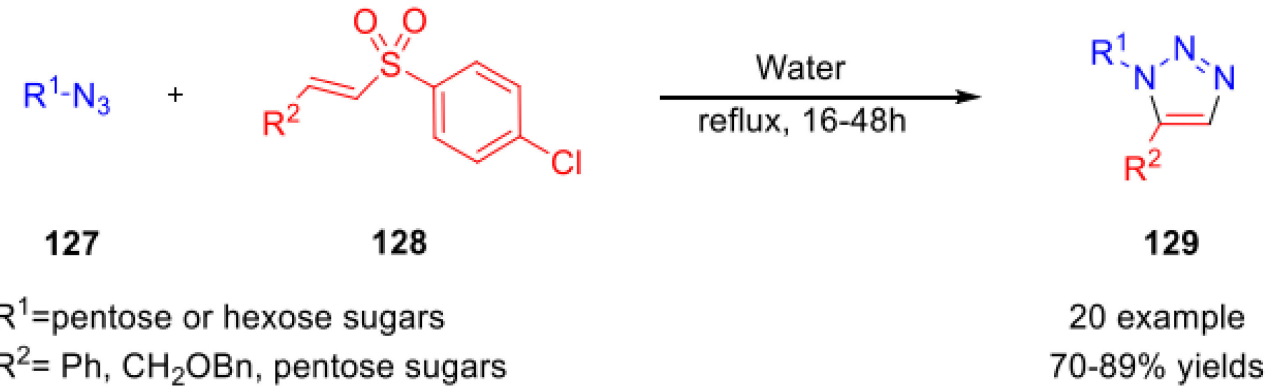

Scheme 42. Synthesis of 1,5-disubstituted 1,2,3-triazonylated monofuranosides or 1,5-disubstituted 1,2,3-triazole linked disaccharides129.

These syntheses of 1,5-disubstituted triazolylated monosaccharides, as well as 1,5disubstituted 1,2,3-triazole linked disaccharides, open up a new possibility of connecting furanosides with a stable-triazole backbone. The reaction conditions are simple, performed under reflux in aqueous media without any metal catalyst, and afford the 1,5-disubstituted 1,2,3-triazolylated monofuranosides and difuranosides in high yields (70-89\%). Successively, the same authors synthesized other 1,5-disubstituted 1,2,3-triazole linked at disaccharide to evaluate their inhibitor activity against a ribonuclease A [99]. In particular, the introduction of two carboxyl groups on the backbone of substates elicited the best result with an inhibition constant $(\mathrm{Ki})$ of $65 \pm 3 \mu \mathrm{M}$. This is the first-ever report on the use of disaccharides as RNase A inhibitors.

González-Calderón et al. [100] have synthesized novel triazole-based miconazole analogs 132 as promising antifungal agents by azide-enolate 1,3-dipolar cycloaddition reaction. The synthesis of triazole analogs that maintain the 1-(2-phenylethyl)imidazole core responsible for the biological activity of miconazole is reported in Scheme 43.

The reaction is classified as a base-assisted 1,3-dipolar cycloaddition and is performed using potassium hydroxide as a base for starting $\beta$-ketophosphonate deprotonation that generates the dipolarophile in acetonitrile. The heterocycles 132 showed suitable in vitro antifungal activity. 


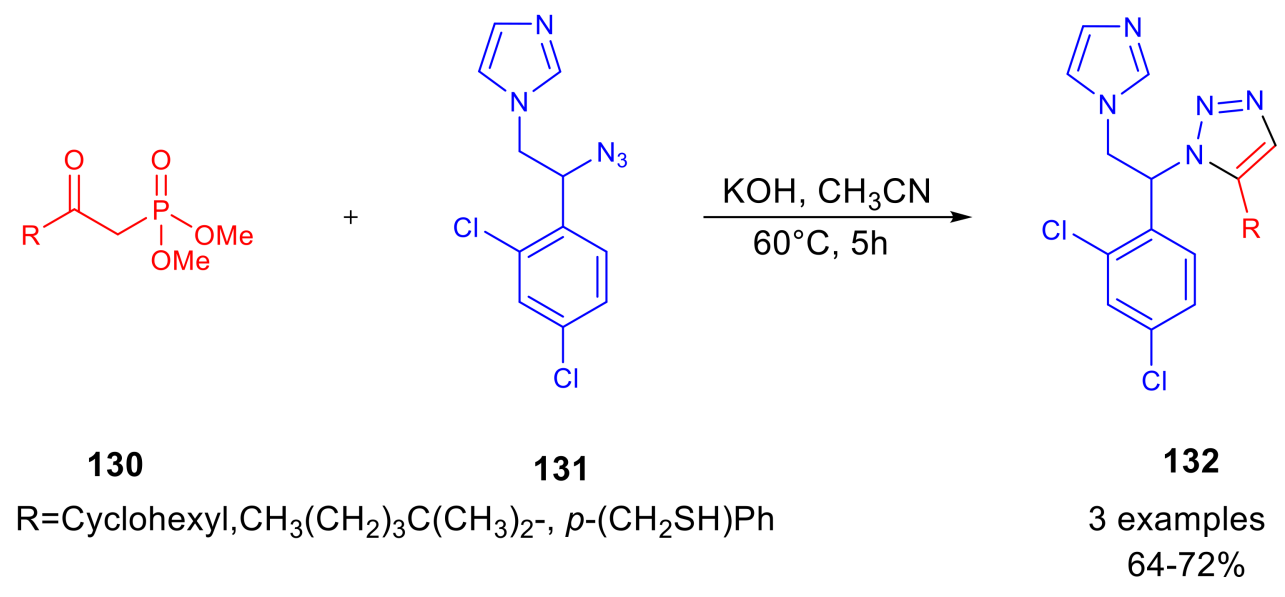

Scheme 43. Synthesis of 1,5-disubstituted 1,2,3-triazole 132 (miconazole analogs) from azide 131 by cycloaddition with $\beta$-ketophosphonates 130.

Wan and co-authors realized a metal- and azide-free regioselective-multicomponent reaction for the synthesis of 1,5-disubstituted 1,2,3-triazoles [101]. The synthesis was carried out through the cascade dual $\mathrm{C}-\mathrm{N}$ bond formation, $\mathrm{N}-\mathrm{N}$ bond formation, and an acyl migration-based $\mathrm{C}-\mathrm{C}$ bond formation via a three-component reaction of enaminones 133, tosylhydrazine $\mathbf{1 3 5}$, and primary amines $\mathbf{1 3 4}$. This methodology proceeds in the presence of only molecular iodine used as a catalyst according to Scheme 44.

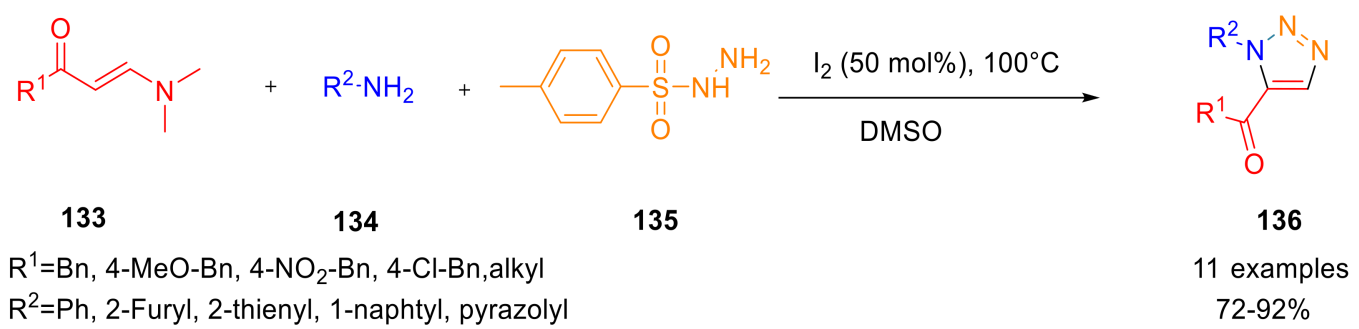

Scheme 44. Synthesis of 1,5-disubstituted 1,2,3-triazoles 136 by metal- and azide-free regioselective-multicomponent reaction.

In 2015, Bai et al. developed an aerobic oxidative cycloaddition between $\alpha$-chlorotosylh ydrazones 138 and arylamines 139 to give 1,5-disubstituted 1,2,3-triazoles 140 under azideand metal-free conditions (Scheme 45) [56]. The authors noticed that the transformation was not influenced by the position of the substituent groups.<smiles>Cc1ccc(S(=O)(=O)NN)cc1</smiles>

135<smiles>[R]C(Cl)C(=O)F</smiles><smiles>CCOCC</smiles>

137<smiles>[R]C(Cl)/C=N/NS</smiles>

138<smiles>[R]NN(C)[R6]O[R6]</smiles>

139<smiles>[R]c1cnnn1[R]</smiles>

140

$$
\begin{aligned}
& \mathrm{R}^{1}=\text { Phenyl, Hexyl } \\
& \mathrm{R}^{2}=\text { Aryl }
\end{aligned}
$$

Scheme 45. Regioselective synthesis of 1,5-disubstituted 1,2,3-triazoles 140 through an aerobic and oxidative cycloaddition. 
In 2016, Thomas and co-workers synthesized 1,5-disubstituted 1,2,3-triazoles 145 starting to primary amines 143, enolizable ketones 142 and 4-nitrophenyl azide 141 by a multicomponent reaction [102]. The reaction is regioselective and is conducted with acetic acid as an acid catalyst in concordance to Scheme 46 . All products were obtained with suitable to high yields (67-93\%).<smiles>[NH3+]c1ccc([N+](=O)[O-])cc1</smiles>

141<smiles>[R]C(C)=O</smiles>

142

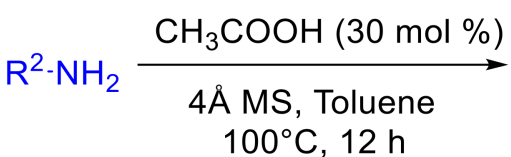

143<smiles>[R]c1cnnn1[R]</smiles>

144<smiles>Nc1ccc([N+](=O)[O-])cc1</smiles>

145

$\mathrm{R}^{1}=$ Aryl, heterocycles

23 exemples

$67-93 \%$

Scheme 46. Multicomponent reaction for the synthesis of 1,5-disubstituted 1,2,3-triazoles 89.

Kayet and Pathak [98] synthesized a series of 1,5-disubstituted 1,2,3-triazolylmethylene linked disaccharides (1,5-DTM) $\mathbf{1 4 8}$ in a biodegradable hydroxylammonium-based aqueous ionic liquid with a total absence of metals as catalysts. The molecules are obtained through a 1,3-dipolar cycloaddition reaction between a series of vinyl sulfonylmethylene-modified pyranoses or furanoses 146 and a series of sugar azides 147 under metal-free conditions. Then, the same authors, for the first time, identified a 1,5-disubstituted 1,2,3-triazolylmethylene (1,5DTM) linked disaccharide as a potential inhibitor of ribonuclease A [103] because, probably, the extra methylene bridge connecting the 1,5-DT ring and the sugar residue could increase the flexibility of 1,5-DTM linked molecules. The reactions between vinyl sulfones and azidosugars in water $/ N, N$-dimethylethanolammoniumformate (DAF) at reflux are conducted as shown in Scheme 47. The use of a mixture of an ecofriendly ionic liquid and water considerably reduced the reaction time and increased the purity of the 1,5-DTMs crude in comparison with the same reactions conducted with conventional solvents.

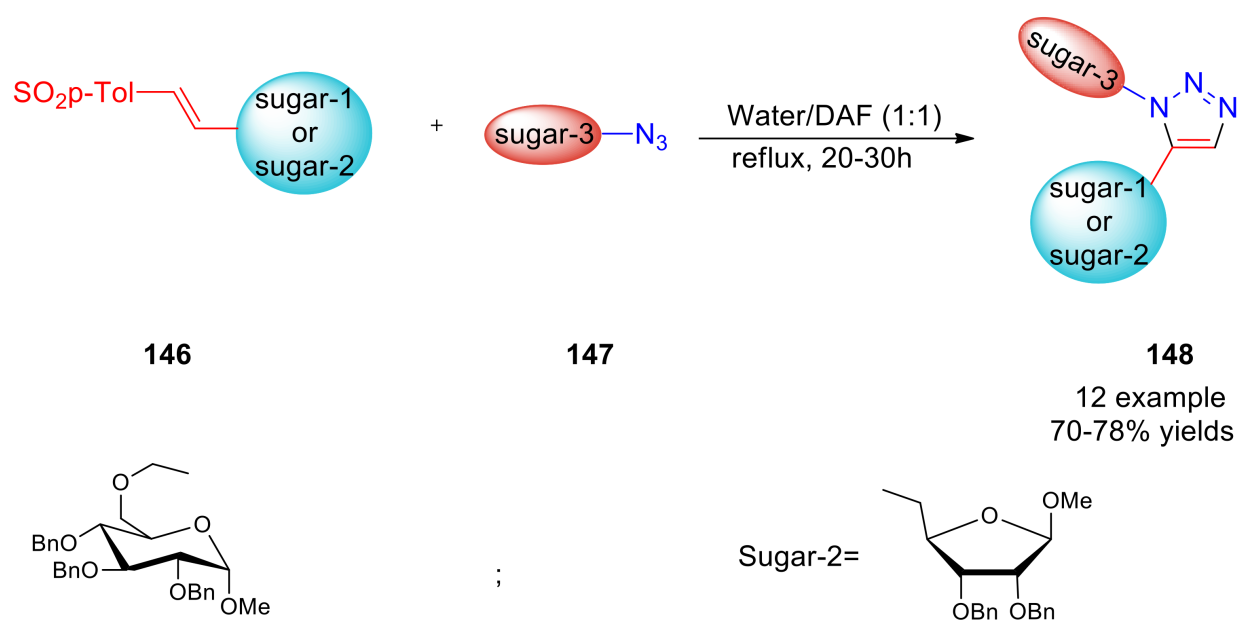

Sugar-3=
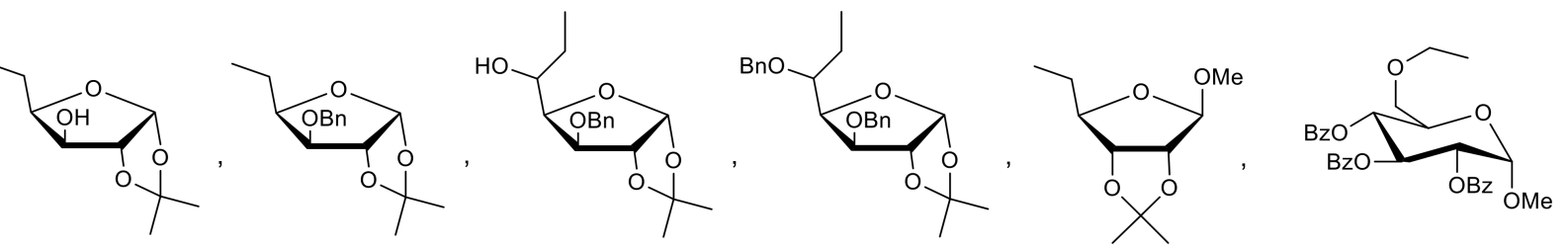

Scheme 47. Synthesis of 1,5-DTM linked disaccharides 93 by metal-free 1,3-dipolar cycloaddition in the eco-compatible system. 
In 2018, a practical and straightforward approach to synthesize, for the first time, enantiomerically pure 1,5-disubstituted 1,2,3-triazoles 151 was developed [104]. The synthesis employs enantiomerically pure amino esters 150 derived from amino acids and commercially available enolizable ketones 149 under metal-free conditions as indicated in Scheme 48 .<smiles>[N-]c1ccc([N+](=O)[O-])cc1</smiles>

141<smiles>[R6]C[C@H](N)C([R])O[R]</smiles>

149

$\mathrm{R}^{1}=$ Aryl, Naphtyl, Furanyl, Indolyl $R^{2}, R^{3}=$ aminoacid esthers

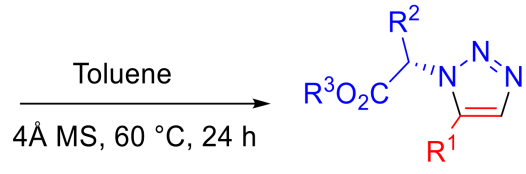

151

9 examples $50-71 \%$

Scheme 48. Synthesis of enantiomerically pure 1,5-disubstituted 1,2,3-triazoles 151.

The obtained results showed that the reaction is independent of the electron-rich or electron-deficient nature of the ketones. The products were obtained with suitable yields and, in all cases, with the retention of the chiral center. Furthermore, the reaction was shown to be widely tolerant of aromatic and heteroaromatic substituted ketones and heterocycles.

Another methodology provides the participation of alkyl propiolates 152 in [3 + 2] annulation for the synthesis of 1,5-disubstituted 1,2,3-triazoles containing ester side chain 154 [53]. The reaction consists of metal-free annulation reactions of alkyl propiolates 152 with tosyl hydrazine 135 to give 1,5-disubstituted 1,2,3-triazoles 154 in according to Scheme 49.<smiles>Cc1ccc(S(=O)(=O)NN)cc1</smiles>

135<smiles>C#CC(=O)OCC</smiles>

152<smiles>Nc1ccccc1</smiles>

153

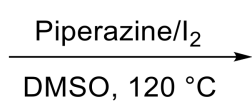<smiles>[R]OC(=O)c1cnnn1-c1ccccc1</smiles>

154

13 examples $54-71 \%$

Scheme 49. Metal-free [3 + 2] annulation reaction to synthesize 1,5-disubstituted 1,2,3-triazoles 154 .

In 2020, Zhang et al. realized a regiospecific and base-promoted synthesis of 1,5disubstituted 1,2,3-triazoles through a C-C bond cleavage process on fully substituted 1,2,3-triazoles 156 [105]. In particular, enaminones 155 react with tosyl azide 135 in basic conditions from DBU to form trisubstituted 1,2,3-triazoles 156 that, in the presence of $\mathrm{NaO}^{\mathrm{t}} \mathrm{Bu}$, produce 1,5-disubstituted 1,2,3-triazoles 157 (Scheme 50).

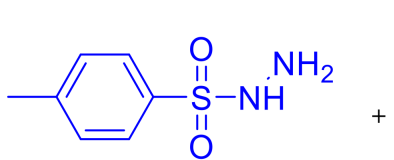

135<smiles>[R]NC([R])=CC(=O)c1cccc(C)c1</smiles>

155

$\mathrm{R}^{1}=$ Aryl, Naphtyl<smiles>[R]c1c(C(=O)c2ccccc2)nnn1[R]</smiles>

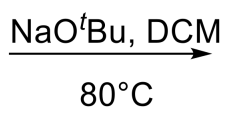<smiles>[R]c1cnnn1[Z1]</smiles>

157 17 examples $56-96 \%$

$\mathrm{R}^{2}=$ Aryl, Thiophenyl

Scheme 50. Regiospecific synthesis of 1,5-disubstituted 1,2,3-triazoles 157 through C-C bond cleavage on 1,4,5-trisubstituted 1,2,3-triazoles 156. 
More recently, Kiranmye and co-workers [106] published the synthesis of 1,5-disubstitu ted 1,2,3-triazoles 160 in aqueous medium under ultrasound-assisted catalyst-free reaction conditions. The synthetic route is straightforward, convenient, and consists of preparation of 1,5-disubstituted 1,2,3-triazoles 160 via eliminative 1,3-dipolar cycloaddition of azides 158 with nitroolefins 159 (Scheme 51). This approach exhibits high substrates versatility, short reaction time, simple work-up, high regioselectivity, and large-scale synthesis.

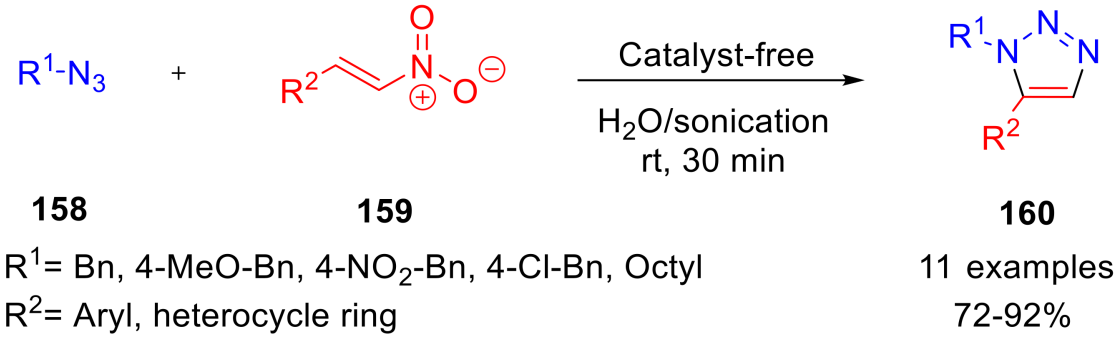

Scheme 51. Synthesis of 1,5-disubstituted 1,2,3-triazoles 160 via catalyst-free eliminative 1,3-dipolar cycloaddition.

\subsection{Synthesis of 4,5-Disubstituted 1,2,3-Triazoles}

As the reader has just been seen, many methods and catalysts have been reported in the literature for the synthesis of 1,2,3-triazoles, but only a few of them are related to the synthesis of $N$-unsubstituted 1,2,3-triazoles. The 4,5-disubstituted 1,2,3-triazoles (4,5-DTs) could be considered a direct precursor for 2-substituted 1,2,3-triazoles, which could show much interesting biological activity. Furthermore, the 1,2,3-triazole moieties disubstituted at C-4 and C-5 just demonstrated anticancer activity as analogous to combretastatin A4 , an anti-mitotic agent [107]. Since its sensitivity in solution to undergo double bond isomerization toward the trans isomer, new analogs with the 1,2,3-triazole moiety were synthesized. The key intermediate is (Z)-2,3-diarylacrylonitrile derivative (163) that, via click chemistry, afforded the 4,5-DTs. (Scheme 52). Among them, the compounds more structurally related to the combretastatin A-4 exhibited higher anticancer activity against different human cancer cell lines.

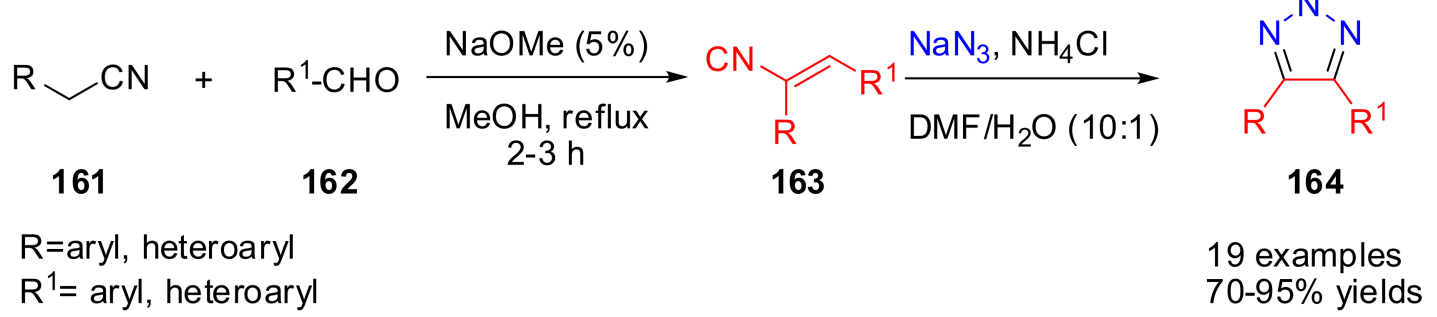

Scheme 52. Synthesis of 4,5-DTs analogs of combretastatin A-4.

In the same year, Chai and co-worker published another method catalyzed by an ammonium salt for the synthesis of 4,5-DTs. In this work, the key intermediate is a vinyl sulfone that reacts in a 1,3-dipolar cycloaddition with the more nucleophile ammonium azide obtained from sodium azide in the presence of ammonium acetate (Scheme 53). The Julia reagents, benzothiazol-2-yl sufones 165, were exploited by the authors as precursors for vinyl sulfones, in three-component reaction with aldehydes and sodium azide, in mild reaction conditions and without the inconvenient of the multistep process, such as the necessity of inert atmosphere, laborious work-up procedures, and more time required. A broad scope for this method was demonstrated, working both with ester, ketone, and amide functionalities for the Julia reagent and aryl or alkyl aldehydes 166 [108]. 


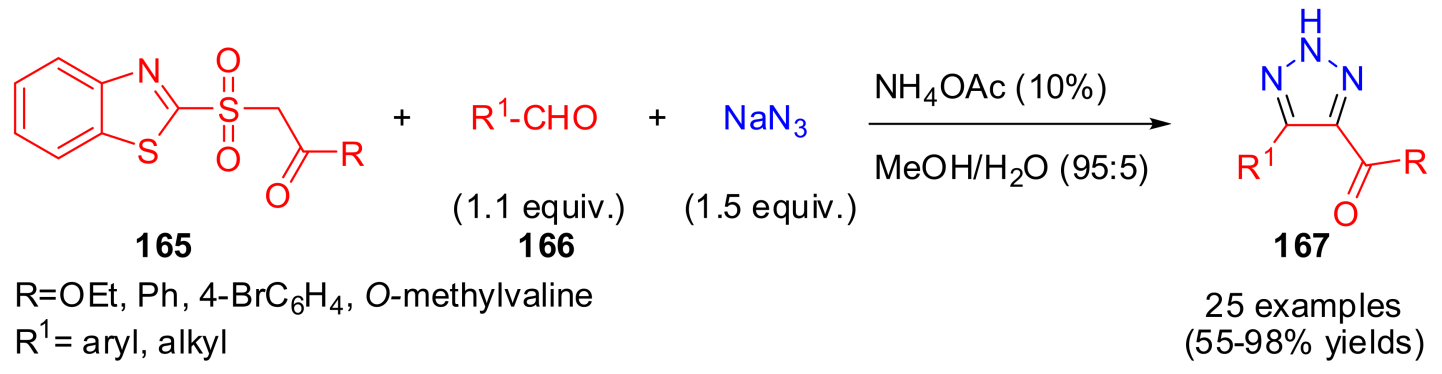

Scheme 53. Three-component reaction with Julia reagents for the synthesis of 4,5-DTs.

In 2016, enolizable cyclic ketones were also employed by Thomas et al. in a onepot reaction for the synthesis of 4,5-fused $\mathrm{NH}$-triazoles, involving ammonium acetate as a reagent and with 4-nitroaniline $\mathbf{1 4 1}$ as molecule eliminated to obtain final triazoles (Scheme 54). Simply using commercially available or naturally available (flavonoids and terpenoids) ketones, it was possible to afford both 4,5-fused, mono- and disubstituted NH-triazoles with potential biological activity. High functional group tolerance and regioselectivity were demonstrated by the authors, also in the synthesis of different mono-substituted NH-triazoles [109].

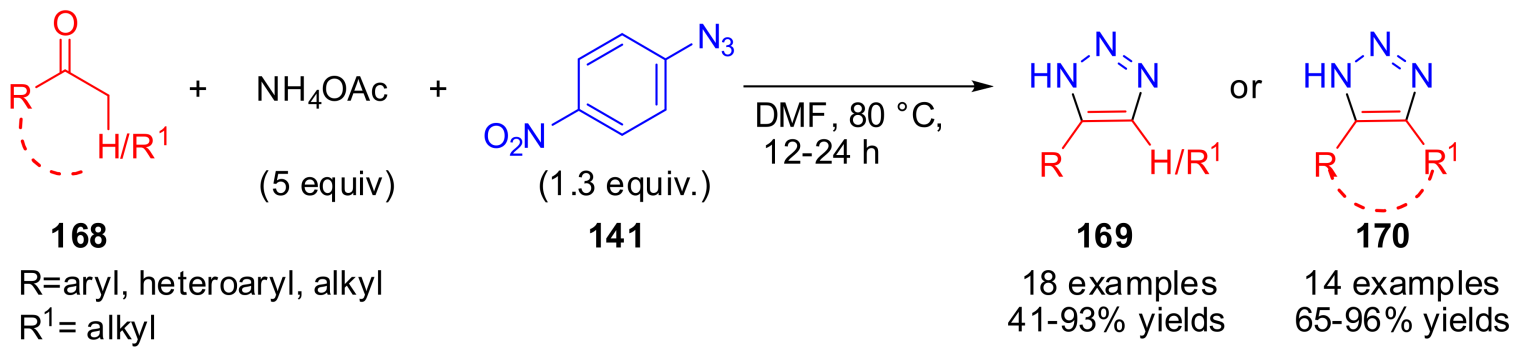

Scheme 54. Synthesis of NH-triazoles (169 and 170).

Tang and co-workers published a method for the cycloaddition of 1,3-diynes with sodium azide. The resulting 5-substituted-4-acetylene-1H-1,2,3-triazoles (171), obtained in excellent yields in a metal-free procedure (Scheme 55), possess a triple bond that could be useful in the following transition metal-mediated reactions. It is worth noting that unsymmetrical 1,3-diynes could react in these reaction conditions, but the two products, obtained with a 1:1 ratio, are chromatographically inseparable [110].
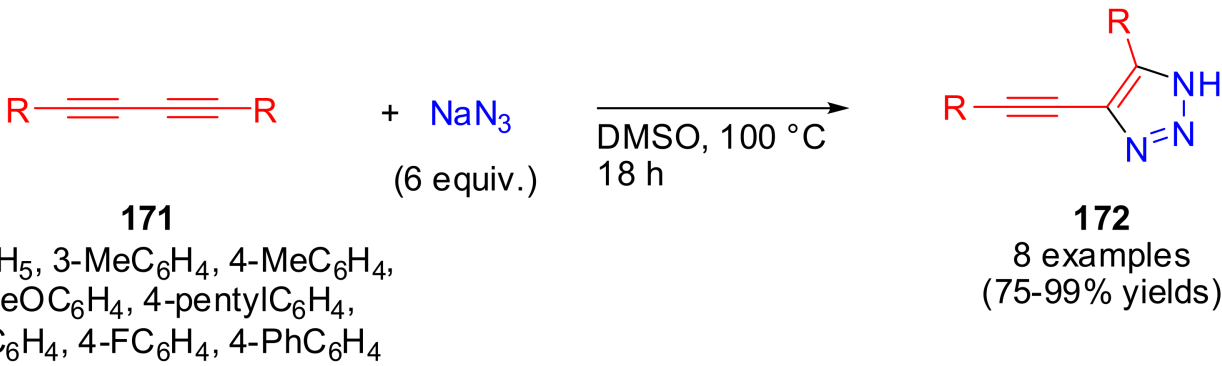

Scheme 55. Cycloaddition of various 1, 3-diynes 171 with $\mathrm{NaN}_{3}$.

To the best of our knowledge, only one example is reported in the literature on azidefree synthesis of 4,5-DTs. In this work, Panda and co-workers take advantage of the ambiphilic nature of $N$-tosylhydrazones to realize in mild basic conditions a regioselective [3 + 2] cyclization (Scheme 56). Worth noting, more reaction times and lower reaction yields were obtained with electron-rich aryl hydrazones, probably for their less electrophilic nature [111]. 
<smiles>[Y5]N/N=C/c1c#[R]ccc1</smiles>

173<smiles>[R][R1]1ccc(/C=N/N[3H])cc1</smiles>

173'

\section{$\mathrm{Cs}_{2} \mathrm{CO}_{3}$ (3 equiv.)}

DMF, $100{ }^{\circ} \mathrm{C}$,

4-10h

$\mathrm{R}=\mathrm{R}^{1}$ or $\mathrm{R}=\mathrm{EWG}, \mathrm{R}^{1}=E D G$<smiles>[R]c1cccc(-c2n[nH]nc2-c2ccccc2[R])c1</smiles>

174

\section{3 examples}

(36-90\% yields)

Scheme 56. Azide-free synthesis of 4,5-DTs with N-tosylhydrazones.

As the reader has seen so far, the use of ammonium salts as catalysts was applied with different starting reagents for the synthesis of $\mathrm{N}$-unsubstituted 1,2,3-triazoles. More recently, Swarup and co-workers explored another approach by preparing 2-methylthio 1,4-ene-diones 176 under metal-free conditions using iodine and DMSO as the source of the thio-functionality at $90^{\circ} \mathrm{C}$ (Scheme 57). With this method, symmetrical 4,5-DTs were obtained in suitable yields and avoiding the formation of the highly toxic and explosive $\mathrm{HN}_{3}$ [112].

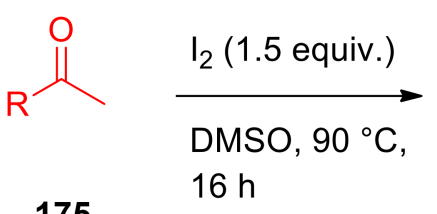<smiles>[R]C(=O)/C=C(/SC)C([R])=O</smiles>

176 (crude)<smiles></smiles>

$16 \mathrm{~h}$<smiles>[R]C(=O)c1n[nH]nc1C([R])=O</smiles>

177

15 examples (86-96\% yields)

Scheme 57. Preparation of N-unsubstituted 1,2,3-triazoles from 2-methylthio 1,4-ene-diones 176.

The presence of an electron-deficient double bond in olefinic sulfur salts was exploited by Wu G.-L. and Wu Q.-P. in 2017 to form 4,5-DTs in a [2 + 3] cycloaddition. In this work, $\alpha$-bromoacetate $\mathbf{1 7 8}$ was firstly converted in the corresponding sulfur salt $\mathbf{1 7 9}$, which then reacted with benzaldehyde in the presence of $L$-proline as organocatalyst, affording the product in high yields (95\%). Other small organic molecules, such as morpholine (91\%), piperidine $(93 \%)$, and other aminoacids, were tested in the same reaction conditions, but the best results were obtained using DMSO as a solvent at room temperature (Scheme 58). This procedure has been demonstrated high tolerance not only toward aldehyde substrates but also toward some organohalides, obtaining in all cases excellent results [113].<smiles>[X]CC([R])=O</smiles>

178

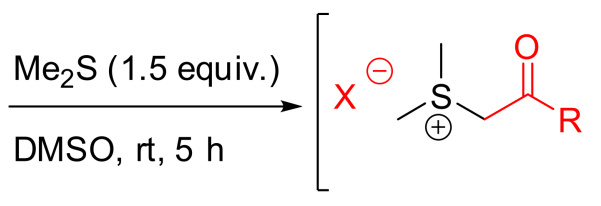

179

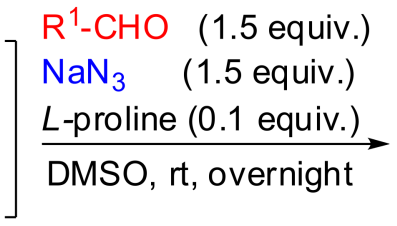<smiles>[R]C(=O)c1n[nH]nc1[R]</smiles>

31 examples (88-96\% yields)

$\mathrm{X}=\mathrm{Br}, \mathrm{I}, \mathrm{Cl}$

$\mathrm{R}^{1}=$ aryl, alkyl, heteroaryl

Scheme 58. Synthesis of 4,5-DTs through sulfur salt $\mathbf{1 7 9}$ as intermediate. 


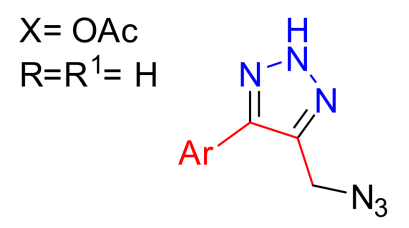

183

3 examples (39-56 \% yields)
In recent years, the cycloaddition reaction of nitroalkenes was largely explored for the synthesis of $\mathrm{NH}-1,2,3$-triazoles, using different catalytic conditions [114,115]. More recently, Reddy et al. paid their attention, in particular, to easily accessible $\alpha$-functionalized nitroolefins for the acid-assisted synthesis of 4,5-DTs [116]. The best reaction conditions were founded using $p$-toluenesulfonic acid in stoichiometric amounts with nytroallylic acetates $\mathbf{1 8 0}$ or nitroallylic alcohols $\mathbf{1 8 1}$ and nytroallylic sulfones $\mathbf{1 8 2}$ in the presence of sodium azide, to afford 4,5-DTs 183, 184, and 185, respectively (Scheme 59). A plausible mechanism was proposed by authors who considered the additive acid as an activator of the nitro group through the $\mathrm{H}$-bond, thus favoring the elimination of $\mathrm{HNO}_{2}$.

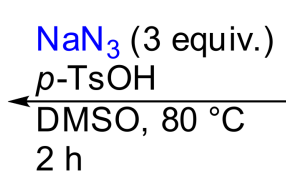<smiles>[R]C([R])(CC)C(=C[Bi])[N+](=O)[O-]</smiles>

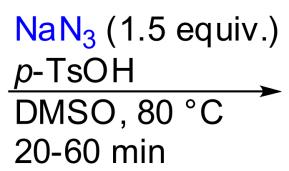

\section{0-182}

$\mid \begin{aligned} & \mathrm{NaN}_{3}(1.5 \text { equiv. }) \\ & p-\mathrm{TsOH}^{\circ} \\ & \mathrm{DMSO}, 80{ }^{\circ} \mathrm{C} \\ & 20 \mathrm{~min}\end{aligned}$<smiles>CC(C)(C)SOCc1n[nH]nc1Br</smiles>

185

6 examples

(60-76\% yields)
$\mathrm{X}=\mathrm{SO}_{2} \mathrm{Ar}$

$\mathrm{R}=\mathrm{R}^{1}=\mathrm{H}$<smiles>[R]C([R])(C)c1n[nH]nc1[Hg]</smiles>

184

18 examples (36-89\% yields)
$\mathrm{X}=\mathrm{OH}, \mathrm{NHPh}$

$\mathrm{R}=\mathrm{H}, \mathrm{CO}_{2} \mathrm{Et}$

$\mathrm{R}^{1}=\mathrm{CO}_{2} \mathrm{Et}$

Scheme 59. Acid-assisted synthesis of 4,5-DTs.

More recently, another metal-free alkyne cyclization with sodium azide was developed by Rocha et al. in 2019. In this work, the authors reported the synthesis of 4,5-DTs by simply heating in DMF at $110^{\circ} \mathrm{C}$, starting from nine different 1,3-diarylprop-2-yn-1-ones 186, previously obtained by Sonogashira cross-coupling reaction of aroyl chlorides and aryl acetylenes, with electron-neutral, -withdrawing, or -donating groups. These 1,3diarylprop-2-yn-1-ones $\mathbf{1 8 6}$ reacted with sodium azide to give as many $\mathrm{NH}-1,2,3$-triazoles under conventional heating (Scheme 60). In some cases, better results were obtained under microwave-assisted conditions, which allowed reducing the reaction times from hours to minutes, enhancing the yields at the same time [117].<smiles>[R]c1ccc(C#CC(=O)c2ccc([R])cc2)cc1</smiles>

186

$\mathrm{R}=\mathrm{H}, \mathrm{OCH}_{3}, \mathrm{NO}_{2}$

$\mathrm{R}^{1}=\mathrm{H}, \mathrm{OCH}_{3}, \mathrm{NO}_{2}$
$\mathrm{NaN}_{3}$ (2 equiv.)

DMF, $120^{\circ} \mathrm{C}$

$5-25 \mathrm{~h}$

$(\mathrm{MW}=0.5-1 \mathrm{~h})$<smiles>[R]c1ccc(C(=O)c2nn[nH]c2-c2ccc([R])cc2)cc1</smiles>

187

9 examples (40-90\% yields)

Scheme 60. Synthesis of 4,5-DTs starting from 1,3-diarylprop-2-yn-1-ones 186. 


\section{Advances in Trisubstituted 1,2,3-Triazole Preparation}

Trisubstituted 1,2,3-triazoles are a class of heterocycles with a huge number of applications in organic synthesis such as, for example, the role of ligands for catalysis, directing groups in metal-catalyzed $\mathrm{C}-\mathrm{H}$ activation, or platform molecules to build complex organic materials. They are also inserted in specific molecular structures due to their potential pharmacological activity.

\subsection{Metal-Catalyzed Synthesis of Trisubstituted 1,2,3-Triazoles}

The copper-catalyzed azide-alkyne cycloaddition is one of the most used catalytic strategies to afford trisubstituted 1,2,3 triazoles with potential applications in medicine and materials science. This reaction is usually employed for terminal alkynes due to the complex copper (I) acetylide that allows accelerating the reaction. Wei et al. [118] developed a one-pot strategy for the synthesis of differently trisubstituted triazoles by a three-component click reaction of alkynes 188, azides 189, and aryl halides 190, catalyzed by $\mathrm{Cu} / \mathrm{Pd}$. Aliphatic and aromatic alkynes were used, and different trisubstituted triazoles were obtained in suitable yield as a single regioisomer. Surprisingly, the electronwithdrawing or electron-donating group at the para position of the aromatic did not affect the reaction outcome (Scheme 61).

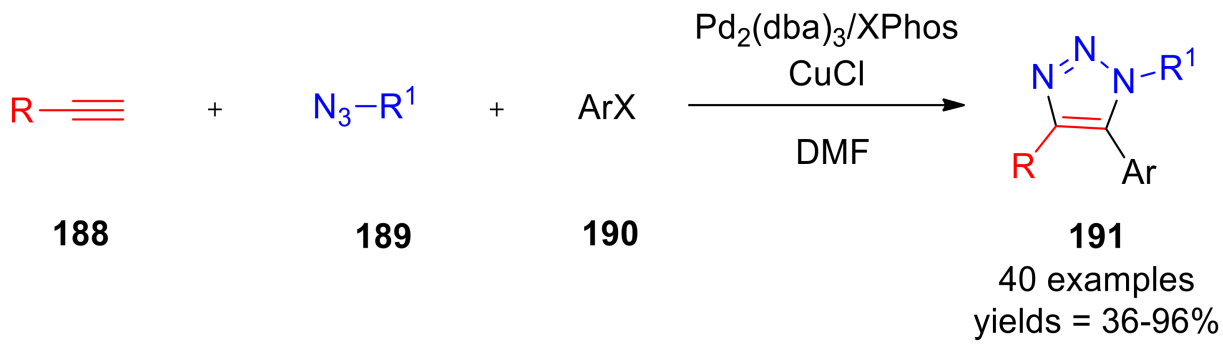

Scheme 61. Synthesis of trisubstituted triazoles 191 by a three-component click reaction.

The authors proposed a possible mechanism that starts with the cycloaddition of $\mathrm{Cu}(\mathrm{I})$ acetylide with azide to afford cuprate-triazole as a reaction intermediate. Simultaneously, the oxidative addition of aryl halide to $\operatorname{Pd}(0)$ produces the palladium intermediate. The transmetallation between the two products followed by the reductive elimination gives the trisubstituted triazole and the regenerated $\mathrm{Pd}(0)$.

Zhang et al. [119] realized a one-pot-three-component synthesis of 1,4,5-trisubstituted 5-iodo-1,2,3-triazoles 194 by using substituted azides 192, 1-copper(I)alkynes 193, and molecular iodine as illustrated in Scheme 62. All the products were obtained from acceptable to suitable yields (40-92\%).

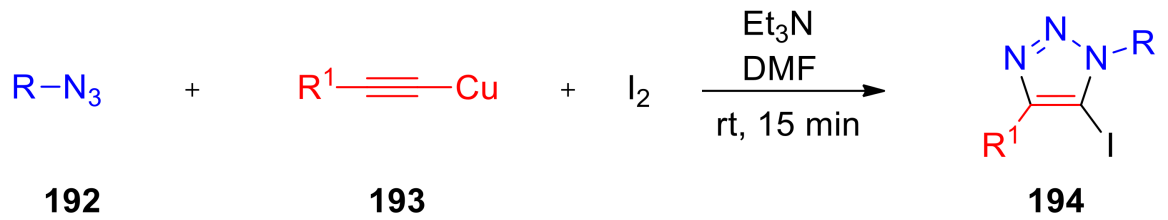

$$
\begin{aligned}
& \mathrm{R}=\mathrm{Bn}, \mathrm{Bn}-4-\mathrm{Me}, \mathrm{Bn}-4-\mathrm{F}, \mathrm{Bn}-4-\mathrm{Br}, \mathrm{Bn}-4-\mathrm{OMe}, \mathrm{Bn}-4-\mathrm{NO}_{2}, \\
& \mathrm{CH}_{2}-\mathrm{Naph}-2,1-\mathrm{CH}_{3}-\mathrm{Bn}, \text { octyl, Et-iPr, Cyhex } \\
& \mathrm{R}^{1}=4-\mathrm{Tol}, 4-\mathrm{F}-\mathrm{Ph}, 2-\mathrm{Tol}, 4-\mathrm{MeO}-\mathrm{Ph}, \mathrm{Ph}, 4-\mathrm{F}-\mathrm{Ph}, 4-\mathrm{Cl}-\mathrm{Ph}, \\
& \text { 4-Br-Ph, 4-NO} \mathrm{N}_{2}-\mathrm{Ph}, \mathrm{EtO}_{2} \mathrm{C} \text {, Cyhex, Cypr, 4-F-Ph }
\end{aligned}
$$

Scheme 62. The one-pot-three-component synthesis of 1,4,5-trisubstituted 5-iodo-1,2,3-triazoles 194.

Yamada and co-workers [120] used $\mathrm{CuBr}$ under aerobic conditions to afford an azidealkyne cycloaddition reaction of different ethynylstibanes 195 with benzylazide 196 to 
obtain trisubstituted 5-organostibano-1H-1,2,3-triazoles 197 in discrete yield (64-93\%) (Scheme 63).

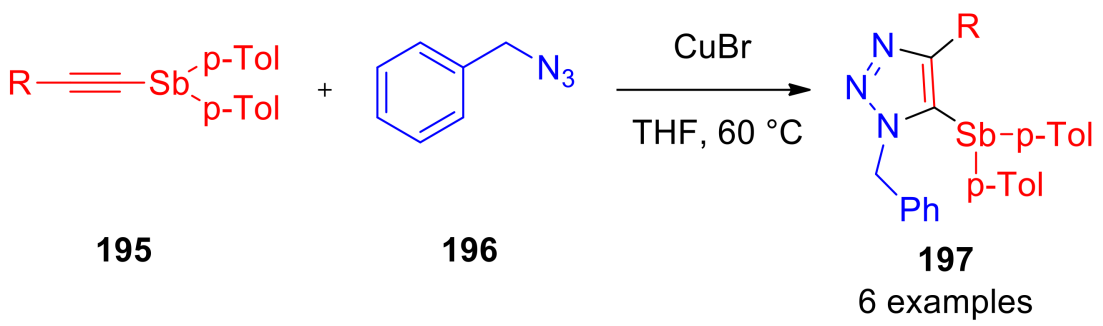

Scheme 63. Synthesis of trisubstituted 5-organostibano-1H-1,2,3-triazoles 197 using various ethynylstibanes 195.

A possible mechanism proposed by the authors involves the catalytic activity of copper, as reported in Scheme 64.<smiles>[R]C#[Sb][Pb]</smiles>

195
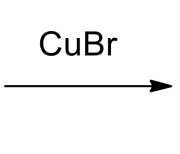<smiles>[R]C#C[Sb]([O])[Se]</smiles>

A

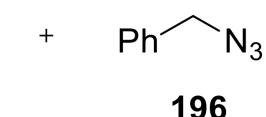

196<smiles>[R]c1nnn(Cc2ccccc2)c1[Sb]([O-])[O-]</smiles><smiles></smiles>
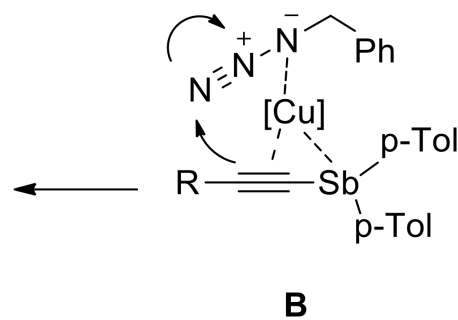

Scheme 64. Plausible synthetic mechanism of trisubstituted 5-organostibano-1H-1,2,3-triazoles 197. CuBr addition generates a $\pi$-complex A. After that, the coordination of this complex with organic azides gives another complex $\mathbf{B}$. The vinylidene transition state $\mathrm{C}$ undergoes cyclization to give the product 197.

In succession, the trisubstituted 5-organostibano-1-H-1,2,3-triazoles 197 were treated with different acyl chlorides 198, giving the corresponding trisubstituted 5-acyltriazoles 199 by deantimonation reaction (Scheme 65).

Then, in other work, the same research group [121] proposed a synthesis of newly discovered 4-substituted 1-benzyl-5-diphenyl-stibano-1,2,3-triazoles 201 through an azidealkyne cycloaddition reaction between ethynyldiphenylstibanes 200 and benzyl azide 196 catalyzed by copper. The obtained organoantimony compounds were reacted with hydrochloric acid to afford C5-unsubstituted 1,2,3-triazoles 202 in high yields (Scheme 66). The antitumoral activity and cytotoxicity were evaluated in several tumor cell lines and compared for both the products organoantimony compounds 201 and 5-unsubstituted 1,2,3 triazoles 202. The authors concluded that the presence of organometal (antimony) in the molecule was crucial for greater antitumor activity. 
<smiles>[R]c1nnn(Cc2ccccc2)c1[Se][Pb]</smiles>

197<smiles>[R]C(=O)Cl</smiles>

198<smiles>[R]C(=O)c1c([R])nnn1Cc1ccccc1</smiles>

199

12 examples yields $=0-79 \%$

$\mathrm{R}^{1}=\mathrm{n}-\mathrm{Bu}$,<smiles>Cc1ccccc1</smiles><smiles>COc1ccc(C)cc1</smiles><smiles>Cc1ccc(C(F)(F)F)cc1</smiles>

$\mathrm{R}^{2}=\mathrm{n}-\mathrm{Bu}$,<smiles>COc1ccc(C)cc1</smiles><smiles>Cc1ccc(C(F)(F)F)cc1</smiles><smiles>Cc1ccc(I)cc1</smiles><smiles>Cc1ccc([N+](=O)[O-])cc1</smiles>

Scheme 65. Synthesis of trisubstituted 5-acyltriazoles 199.

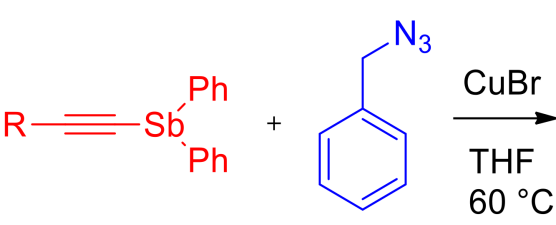

200

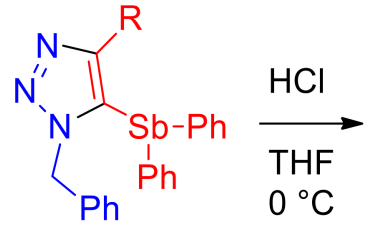

201<smiles>[R]c1cn(Cc2ccccc2)nn1</smiles>

202

yields $=75-99 \%$

Scheme 66. Synthesis of C5-unsubstituted 1,2,3-triazoles 202 through 4-substituted 1-benzyl-5diphenyl-stibano-1,2,3-triazoles 201 as intermediates.

In 2017, Amdouni and co-workers [122] developed a synthesis of 1,4,5-trisubstituted1,2,3-triazole aglycones 206 by proposing two strategies: the first follows a click/electrophilic addition, while the second a click/oxidative coupling. The two methodologies to obtain fully decorated 1,2,3-triazoles start with the trapping of the 5-cuprated-1,2,3-triazole intermediate. For the first method, the intermediate can be trapped by various electrophiles in the CUAAC/electrophilic trapping sequence. The reaction scheme is reported in Scheme 67. 


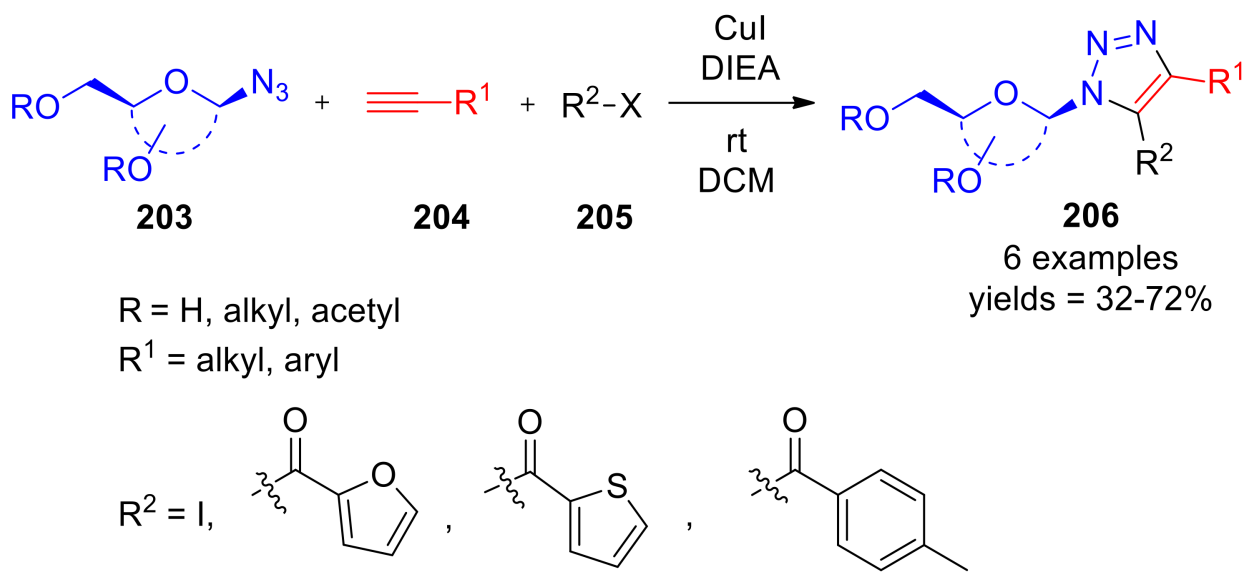

Scheme 67. Synthesis of 1,4,5-trisubstituted-1,2,3-triazole aglycones 206 by a click/electrophilic addition.

In the second method, the CuAAC/oxidative coupling reaction, copper cyanide was used as $\mathrm{Cu}$ (I) source, $\mathrm{N}, \mathrm{N}$-diisopropylethylamine as the base ligand, hydrogen peroxide as terminal oxidant as depicted in Scheme 68.

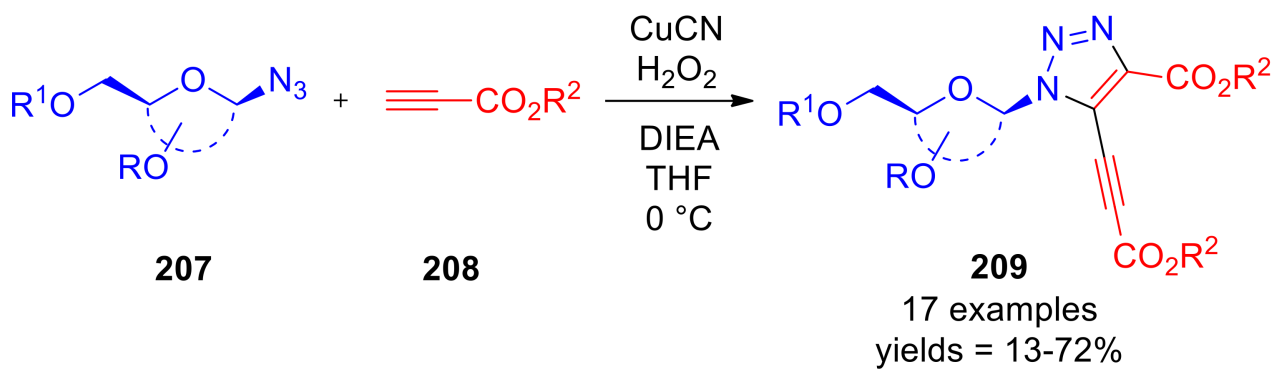

Scheme 68. Synthesis of 1,4,5-trisubstituted-1,2,3-triazole aglycones 209 by a CuAAC/oxidative coupling reaction.

Finally, the produced compounds were tested in vitro and in vivo and showed promising antileukemic effects on chronic myeloid leukemia (CML) and myelodysplastic syndromes (MDS).

In 2017, Zhou et al. [123] developed a one-pot three-components synthetic strategy to obtain enamine-functionalized 1,2,3-triazoles 213 by Cu-catalyzed reaction between terminal alkynes 210, azides 211, and 2H-azirines 212 (Scheme 69). After the reaction optimization, the authors tested alkynes differently substituted on aromatic rings. Alkynes with electron-donating groups give higher yields on the contrary of ones with electronwithdrawing groups.

In 2018, Wu and co-workers [124] proposed a copper-mediated three-component reaction for the synthesis of 5-allenyl-1,2,3-triazoles 217, starting from substituted alkynes 214, azides 215, and the carbonate derivative 216 (Scheme 70). The reaction yields were from acceptable to suitable. 


$$
=\mathrm{H}+\mathrm{R}^{1}-\mathrm{N}_{3}+\mathrm{R}_{2}^{2}
$$

Scheme 69. Synthesis of enamine-functionalized 1,2,3-triazoles 213.

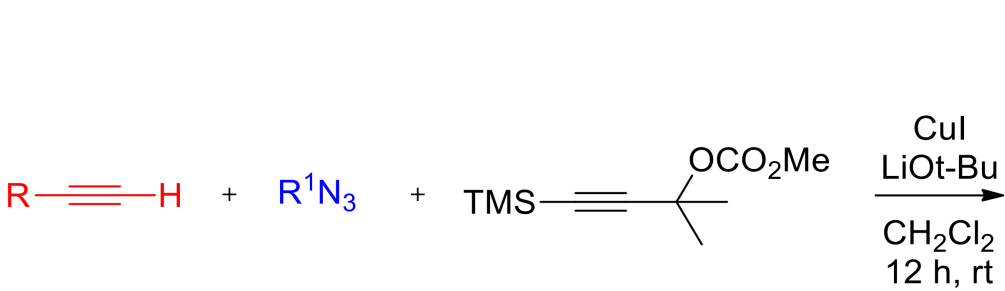

214<smiles>[R]c1nnn([R])c1C([AsH2])=C=C(C)C</smiles>

217

23 examples yields $=0-97 \%$

$\mathrm{R}=$<smiles>Cc1ccccc1</smiles><smiles>Cc1cccs1</smiles><smiles>FC(F)(F)c1ccccc1</smiles><smiles>Clc1ccccc1</smiles><smiles>C1C2CC12</smiles>

$R^{1}=-T s, \quad-o c t y l$,<smiles>c1ccccc1</smiles><smiles>Cc1ccccc1</smiles><smiles>Cc1ccc(C(C)(C)C)cc1</smiles>

Scheme 70. Synthesis of 5-allenyl-1,2,3-triazoles 217 by a copper-mediated three-component reaction.

In recent work, Chang and co-workers [125] reported the synthesis of 1,4,5-trisubtituted triazoles by a [3+2] cycloaddition reaction. In this work, the reactivity of ruthenium azide 219 , formed by 218 with sodium azide with a series of ynoate esters 220, was investigated, forming differently substituted triazolate complexes 221 that were treated with several electrophiles to form 1-alkylated-4,5-bis(ethoxycarbonyl)-1,2,3-triazoles (222) (Scheme 71). 


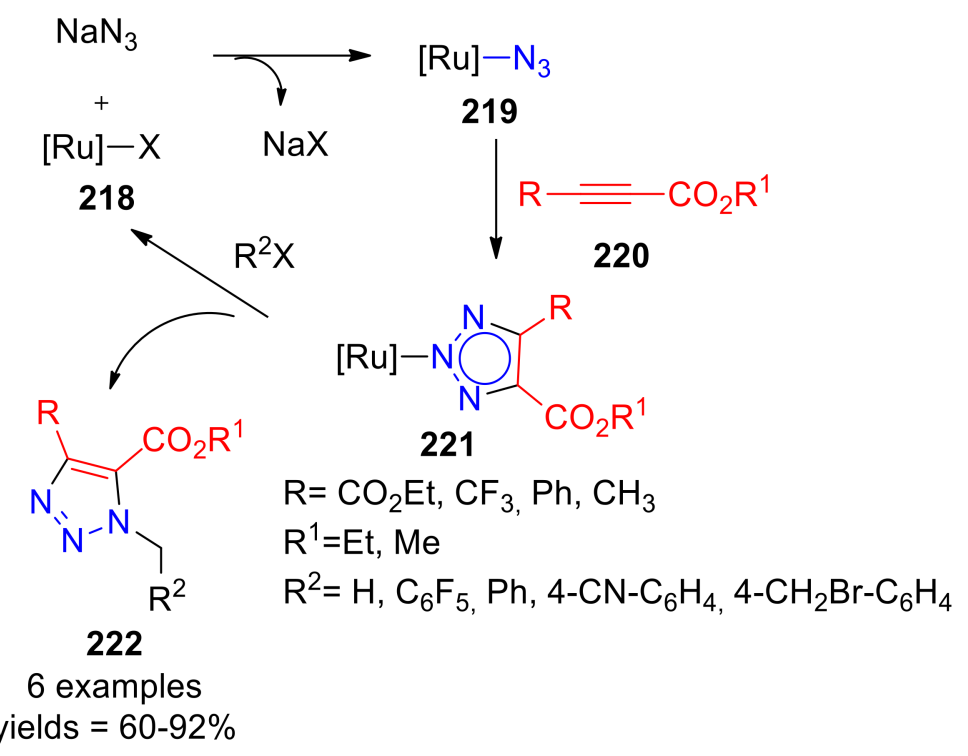

Scheme 71. Synthesis of 1,4,5-trisubstituted triazoles by a $3+2$ cycloaddition using different ynoate esters.

In 2017, Gribanov and co-workers [126] described a Suzuki-Miyaura cross-coupling of 4- or 5-halo-1,2,3-triazoles with arylboronic acids in water to obtain different 1,4,5trisubstituted-1,2,3-triazoles $\mathbf{2 2 6}$ and $\mathbf{2 2 7}$ with an expanded-ring $N$-heterocyclic carbine palladium complex as catalyst 228 (Scheme 72). The products were obtained in high yields using 4-bromo-1,2,3-triazoles with an aromatic and benzylic substituent on the nitrogen.<smiles>[X]c1nnn([R])c1[R]</smiles>

223

or<smiles>[3H][3H]</smiles><smiles>[R]c1nnn([R])c1[X]</smiles>
225

224<smiles>[R]c1nnn([R])c1[R]</smiles>

226

22 examples yields $=70-99 \%$<smiles>[R]c1nnn([R])c1[R2]</smiles>

227

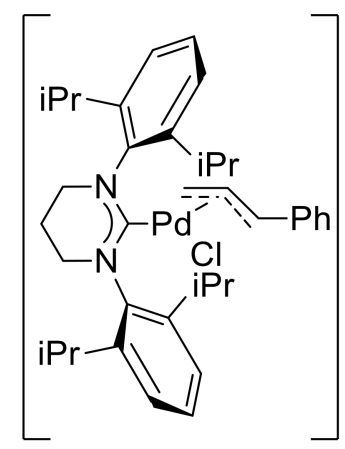

228

12 examples yields $=20-99 \%$

Scheme 72. Suzuki-Miyaura cross-coupling of 4- or 5-halo-1,2,3-triazoles with arylboronic acids.

In more recent work, Duan et al. [127] reported a palladium-catalyzed selective threecomponent tandem reaction of allenynes $\mathbf{2 2 9}$, aryl or alkenyl iodides $\mathbf{2 3 0}$, and sodium azide for the synthesis of differently substituted bicyclic 1,2,3-triazoles 231 in discrete yields (4579\%). The employed substrates include mono-substituted-,1,3-disubstituted-, trisubstituted allenynes, and different types of organic iodides. Finally, the authors proposed a plausible reaction mechanism (Scheme 73). 


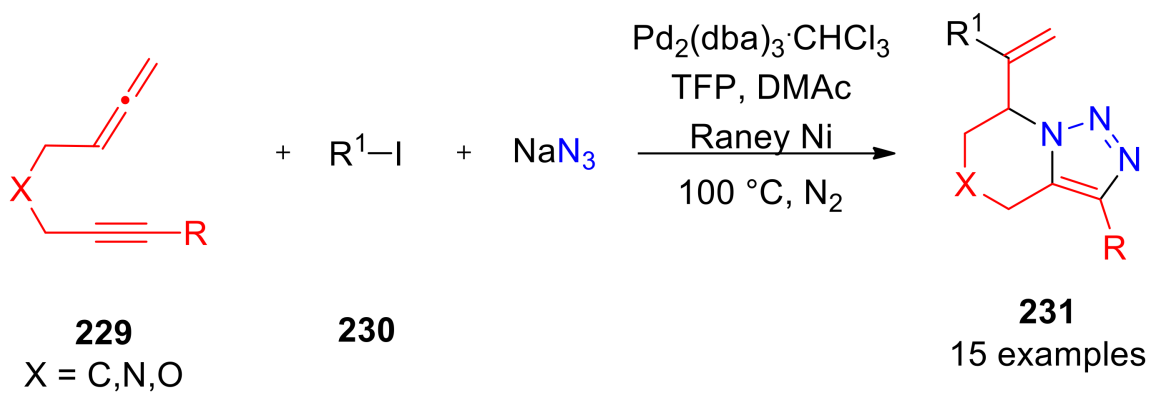

Scheme 73. Palladium-catalyzed three-component reaction using different organic iodides.

\subsection{Catalyst-Free Synthesis of Trisubstituted 1,2,3-Triazoles}

To afford more environmentally friendly synthetic procedures, many studies were recently focused on the discovery of metal-free reactions due to the negative effect of transition heavy metals on the environment and on human health.

Sulfur plays a central role in the medicinal activities of organic compounds $[128,129]$. Ramachary et al. [130] reported the regioselective synthesis of 1,5-disubstituted 4-thio1,2,3-triazoles 234, in an azide-ketone [ $3+2$ ] cycloaddition reaction. They explored the reactivity of differently substituted azides 233 with alkyl- or arylthioethanone derivatives 232 (Scheme 74). The yields are all from acceptable to suitable despite the structural change of the substrates.<smiles>[R]CC([R])=O</smiles>

232<smiles>[R]c1ccc(N)cc1</smiles>

233

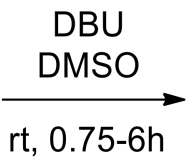<smiles>[R]c1cccc(-n2nnc([R5])c2[R])c1</smiles>

\section{4}

32 examples

yields $=40-97 \%$

Scheme 74. Synthesis of 1,5-disubstituted 4-thio-1,2,3-triazoles 234.

Gangaprasad et al. [131] described an aqueous oxidative azide-olefin cycloaddition promoted by TEMPO for the synthesis of 1,4,5-trisubstituted-1,2,3-triazoles 237, starting from a series of internal olefines $\mathbf{2 3 5}$ with several substituted azides 236 (Scheme 75).

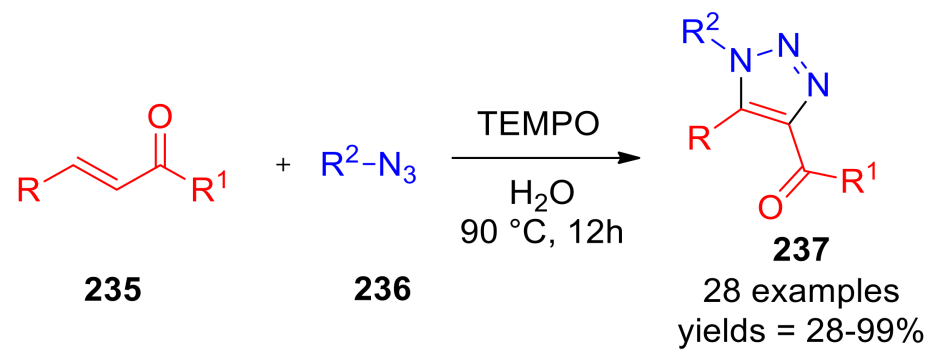

Scheme 75. Synthesis of 1,4,5-trisubstituted 1,2,3-triazoles 237.

The authors proposed a probable mechanism that starts with the production of triazoline 240, deriving from cycloaddition of olefine $\mathbf{2 3 8}$ and azide $\mathbf{2 3 9}$. Then, $\mathbf{2 4 0}$ is converted to the radical cation $\mathbf{2 4 1}$ by the action of TEMPO $\mathbf{A}$ that turns to the anionic form $\mathbf{B}$. A successive loss of hydrogen radical from 241 leads to the production of an iminium-type ion $\mathbf{2 4 2}$ that is in equilibrium with 243. Lastly, the iminium ion $\mathbf{2 4 2}$ was aromatized by losing a proton due to the base action of TEMPO anion $\mathrm{C}$ to give the final triazole 244 (Scheme 76). TEMPO A is regenerated by the action of oxygen. 


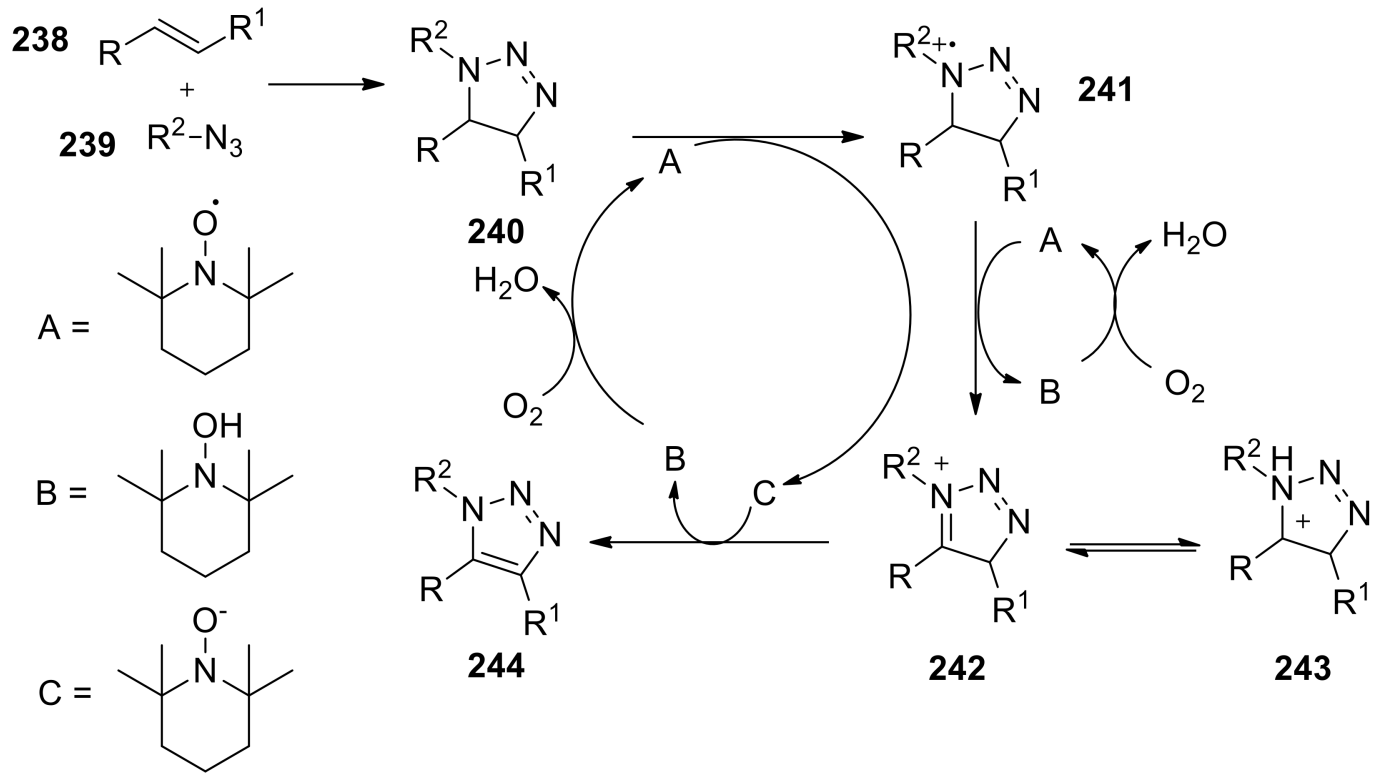

Scheme 76. Proposed mechanism for synthesis of $\mathbf{2 4 4}$ through oxidative azide-olefin cycloaddition promoted by TEMPO.

In 2018, Silveira-Dorta and collaborators [104] described a direct synthesis of enantiomerically pure 1,4,5-trisubstituted-fused triazoles 247 starting from $p$-nitrophenylazide 141 and amino esters 246 (Scheme 77). After the optimization of the reaction conditions, different starting materials were tested, observing that, in general, the nature of substituents and the steric hindrance did not affect the reaction outcome. However, when serine with free $\mathrm{OH}$ group was employed, the reaction yield was low even with prolonged time and higher temperature, a problem that was partially overcome with the protection of serine.

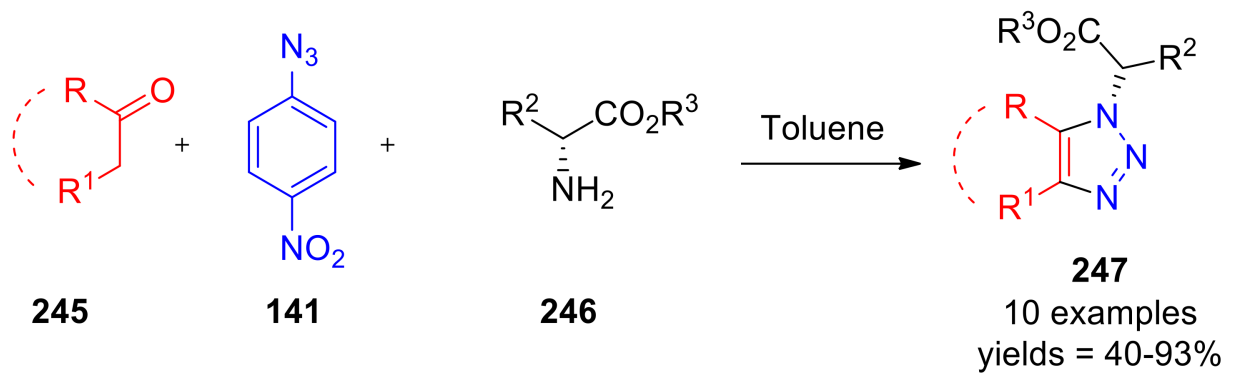

Scheme 77. Synthesis of enantiomerically pure 1,4,5-trisubstituted-fused triazoles 247.

The authors also proposed the synthesis of 1,4,5-trisubsituted 1,2,3-triazoles 250 starting from acyclic ketones 248 with encouraging yields (20-61\%), as reported in Scheme 78.

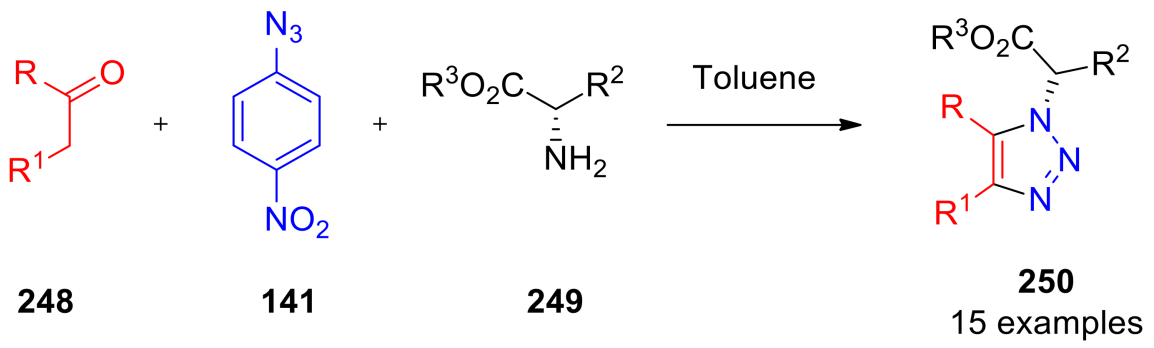

Scheme 78. Synthesis of 1,4,5-trisubsituted 1,2,3-triazoles 250 using acyclic ketones.

Another example of reactions without a catalyst to afford these products is represented by strain-promoted azide-alkyne cycloaddition (SPAAC) [132]. Yoshida and co-workers 
in 2011 [133] proposed a methodology in which 2,6-diisopropylphenyl azide showed 76 times higher reactivity than phenyl azide with dibenzo-fused cyclooctynes, and the reason was the steric inhibition of resonance. We report in the following Scheme 79 the selective SPAAC cycloaddition through the reaction of cyclooctyne 252 on the doubly sterically hindered aromatic azido group of diazide 251.<smiles>CC(C)c1cc(N)cc(C(C)C)c1N</smiles>

251<smiles>C1#Cc2ccccc2CCc2ccccc21</smiles>

252<smiles>CC(C)c1cc(-n2nnc3c2-c2ccccc2CCc2ccccc2-3)cc(C(C)C)c1N</smiles>

253

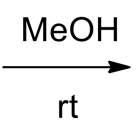<smiles>CC(C)c1cc(N)cc(C(C)(C)C)c1-n1nnc2c1-c1ccccc1CCc1ccccc1-2</smiles>

Scheme 79. SPAAC reaction using diazide 251 and cyclooctyne 252.

\subsection{Acid-Assisted Synthesis of Trisubstituted 1,2,3-Triazoles}

Among the strategies to substitute transition heavy metal catalysts for the synthesis of trisubstituted 1,2,3-Triazoles, the use of catalytic quantities of inorganic acids is one of the most used. In recent work, Guo et al. [134] reported a simple and efficient strategy for the synthesis of 1,4,5-trisubstituted 1,2,3-triazoles 258 promoted by acetic acid. The employed protocol is metal-free and makes use of 1,3-dicarbonyls 255, primary amines 256, and tosylazide 257 by a 1,3-dipolar cycloaddition reaction. After the reaction optimization, the authors starting to explore the method from several diketones and amines, obtaining triazole derivatives with yields from acceptable to suitable (24-93\%) (Scheme 80). The authors noticed that substituents with steric hindrance reduce the reaction yields.

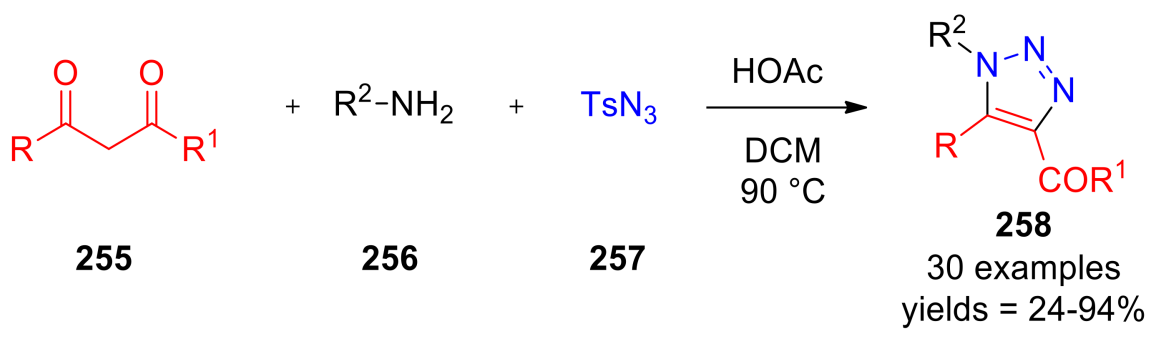

Scheme 80. Synthesis of 1,4,5-trisubstituted 1,2,3-triazoles 258.

The authors also proposed a mechanism of the reaction. In particular, they hypotized the rule of acetic acid as a promoter of ring-opening of triazoline intermediate before of formation of final triazole product.

In a recent study, Jana and collaborators [135] described a regioselective synthesis of 4-fluoro-1,5-disubstituted-1,2,3-triazoles $\mathbf{2 6 1}$ starting from $\alpha$-fluoronitroalkenes 259 as 
starting material in [3 +2$]$ cycloaddition reactions with organic azides $\mathbf{2 6 0}$, in the presence of trifluoroacetic acid as catalyst. The reaction showed suitable to excellent yields using different aryl- and alkyl azides (Scheme 81). The optimized protocol was also tested using different $\alpha$-fluoronitroalkenes. Both the substrates with electron-donating and electronwithdrawing groups showed suitable yields, but the first showed better performance.

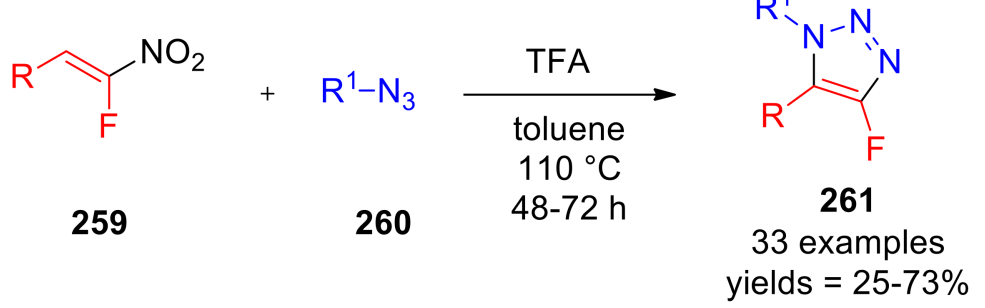

Scheme 81. Regioselective synthesis of 4-fluoro-1,5-disubstituted -1,2,3-triazoles 261 using different azides and $\alpha$-fluoronitroalkenes.

\subsection{Base-Assisted Synthesis of Trisubstituted 1,2,3-Triazoles}

Another alternative to substitute transition heavy metals is the base-assisted synthesis in which organic bases are used to afford trisubsituted 1,2,3 triazoles in suitable yield and short times. In 2015, González-Calderón et al. developed two efficient methods for the production of 1,4,5-trisubsituted 1,2,3-triazoles through a one-pot three-component azide-enolate [3 + 2] cycloaddition. In particular, in the first work [136], the authors used benzylic alcohols 262, diphenylphosphoryl azide (DPPA), several ketones 263, and DBU as a base, obtaining highly regioselective products $\mathbf{2 6 4}$ under mild conditions with yields from acceptable to suitable (62-82\%) (Scheme $82 \mathrm{~A})$. In the second approach, sodium azide and alkyl halides 265 were reacted with variously substituted ketones 266 in suitable yields (Scheme 82B) [137].

More recently, Blastik et al. [138] proposed an efficient methodology for the production of differently functionalized $N$-perfluoroalkyl-1,2,3-trizoles $\mathbf{2 7 0}$ from azidoperfluoroalkanes 268 and various $\beta$-ketoesters and 1,3-diketones 269 through an enamine-mediated azideketone [3+2] cycloaddition reaction (Scheme 83). 
A<smiles>[R]CC([R17])=O</smiles>

262

$\mathrm{R}^{1}=\mathrm{Ph}, \mathrm{CH}_{3}$

$\mathrm{R}^{2}=\mathrm{CN}$, COOEt, COPh, $\mathrm{COCH}_{3}$<smiles>[R]c1nnn(CC2=CC=C[R1]C=C2)c1[R]</smiles>

264

17 examples

yields $=62-82 \%$

B

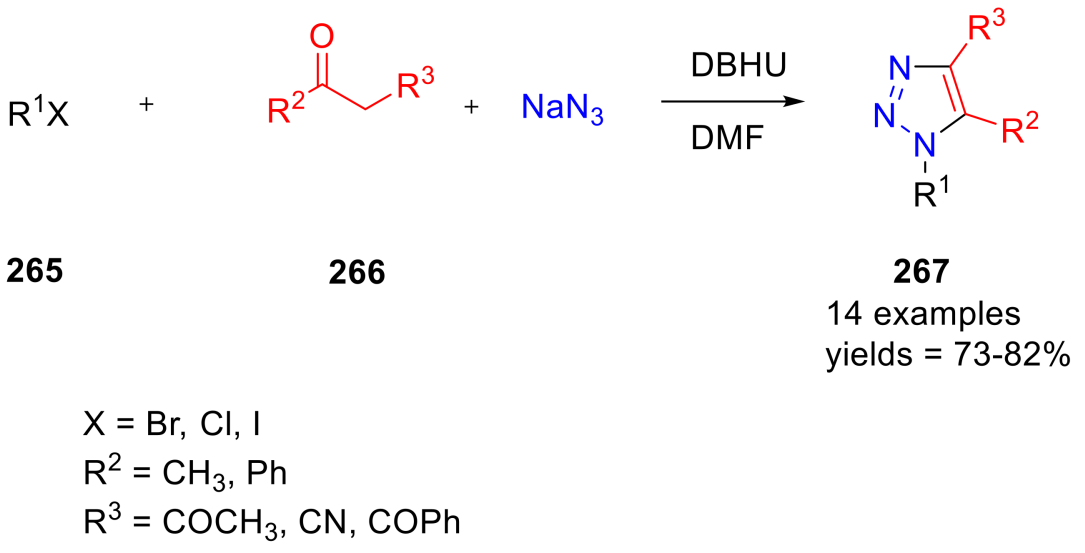

Scheme 82. Different methodologies for the synthesis of 1,4,5-trisubsituted 1,2,3-triazoles 264 $(\operatorname{method} \mathrm{A})$ and $267(\operatorname{method} \mathrm{B})$.<smiles>[R]N[C+]</smiles>

268<smiles>[R]CC([R])=O</smiles>

269

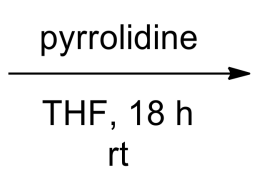

$\mathrm{rt}$<smiles>[R]c1nnn([R])c1[R]</smiles>

270

23 examples yields $=38-98 \%$

Scheme 83. Synthesis of $N$-perfluoroalkyl-1,2,3-trizoles 270 by enamine-mediated azide-ketone [3+ 2] cycloaddition.

A plausible mechanism considers an initial cycloaddition of azidoperfluoro derivative with the enamine formed in situ to obtain the triazoline intermediate. The latter undergoes a rearrangement to the zwitterionic form. The final pyrrolidine elimination leads to the triazole product 270 , regenerating the catalyst.

Such precursors have also been used in 2019 by De Nino and co-workers [139]. In particular, they synthesized 1,4,5-trisubstited 1,2,3-triazoles by the 1,3-DPCA between aryl azides 271 and the enaminones 272 (Scheme 84). 


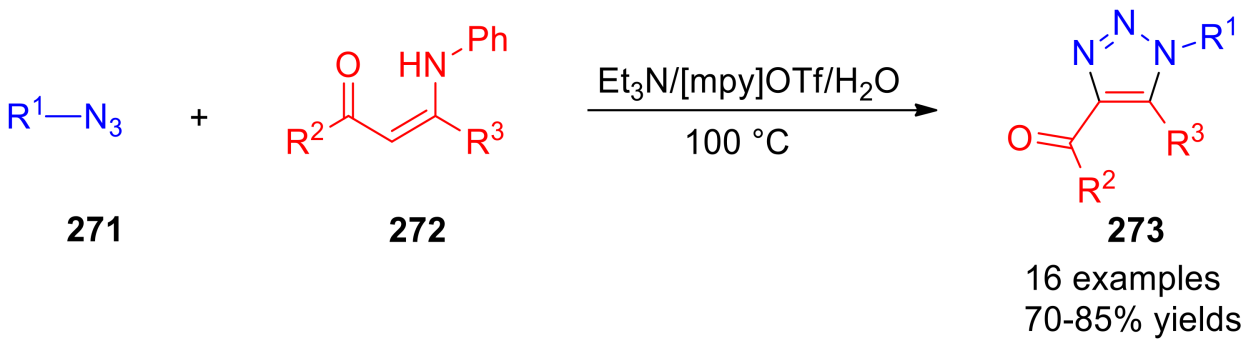

Scheme 84. Synthesis 1,4,5-tribstituted 1,2,3-triazoles 273 between base-assisted eliminative cycloaddition.

The use of an IL in the presence of water and triethylamine was revealed to be fundamental for the course of the entire reaction. The process consists of a water-promoted 1,3-DPCA followed by a base-promoted retro-aza-Michael reaction, which gave the products excellent yields. In 2020, 1,4-disubstituted-5-arylthiomethyl-1,2,3-triazoles 278 and 1,5disubstituted-4-arylthio-1,2,3-triazoles 277 were synthesized by Reddy and co-workers [140] via a metal-free organocatalytic enolate-mediated regioselective 1,3-dipolar cycloaddition between nonsymmetrical 1- alkyl- or 1-aryl-3-(arylthio)propan-2-ones $\mathbf{2 7 4}$ with a variety of aryl/vinyl/alkyl azides 275 by using DBU (279) as organocatalyst (Scheme 85 ). The proposed mechanism provides that the organocatalyst system favors the [1,3]- $\mathrm{H}$ shift of enolate that discriminates the regioselectivity of the reaction.

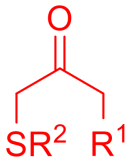

274

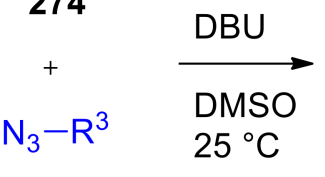

275
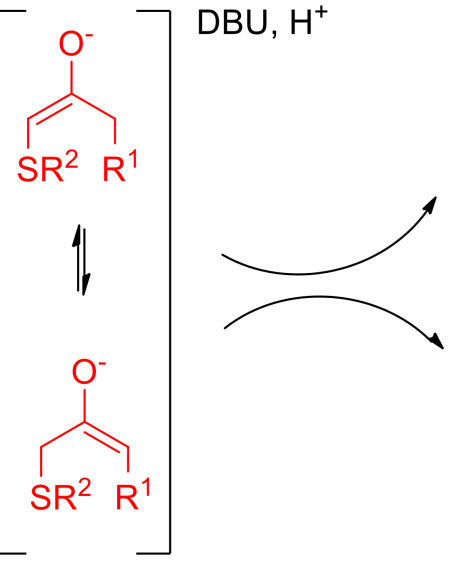<smiles>[R]Cc1c([R5])nnn1[R]</smiles>

277<smiles>[R2]Cc1c([R])nnn1[R]</smiles>

278

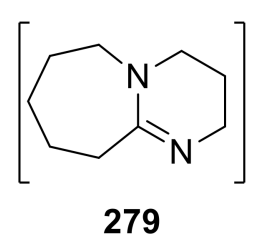

45 examples yields $=42-92 \%$

276

Scheme 85. A selective organocatalytic azide-ketone [3 + 2] cycloaddition assisted by DBU.

\section{Conclusions}

The review has been focused on the development of the chemical synthesis of 1,2,3triazoles since 2015. As it has been illustrated, the scientific production about the preparation of such compounds has been mainly oriented toward new metal catalysts alongside the implementation of new green protocols. In particular, the use of ionic liquids (ILs) and other non-conventional solvents revealed new and unprecedented chemical pathways, with particular attention not only for the use of new catalysts but also on the recyclability of the entire catalytic system. Nonetheless, the use of new metals, alternative to the classic $\mathrm{CuAAC}$ and RuAAC reactions, also allowed the realization of numerous reactions, giving rise to a fertile "green" branch of the chemical realization of unprecedented molecules.

The aims of this review are not only devoted to the synthesis of 1,2,3-trizoles itself but also fill the lack of reports on the evolution of the catalytic techniques employed in such branch of organic chemistry in last years, which reflects the importance of always greener methodologies for the synthesis of highly valued compounds. The substantial advances described in this review fill the lack of a more general and complete report on the more 
efficient, cheap, and eco-sustainable catalyzed synthesis of polysubstituted 1,2,3-triazoles in the most recent years. Of course, we are hopeful that our contribution will facilitate future synthetic chemistry research and will provide many challenges for future works, such as, for example, the development of novel and innovative metal- or metal-free catalysts to produce stereoselectively triazole derivatives as key substrates in many research fields.

Author Contributions: Conceptualization, A.D.N., L.M., and P.C.; methodology, V.A., F.O., and M.A.T.; data curation, V.A., F.O., M.A.T., A.J., and P.C.; writing-original draft preparation, A.D.N., L.M., P.C., V.A., F.O., M.A.T., and A.J.; writing-review and editing, A.D.N., L.M., and P.C.; supervision, A.D.N. and L.M. All authors have read and agreed to the published version of the manuscript.

Funding: This research received no external funding.

Institutional Review Board Statement: Not applicable.

Informed Consent Statement: Not applicable.

Data Availability Statement: Date is contained within the article.

Acknowledgments: We thank the University of Calabria and Calabria Region (PAC CALABRIA 2014-2020-Asse Prioritario 12, Azione B 10.5.12 CUP: H28D19000040006) and the Italian Ministry of University and Research (MUR) for a doctoral grant and the project SI.F.I.PA.CRO.DE (PON ARS01_00568, CONCESSIONE RNA-COR: 4646672 CUP: B29C20000360005) for financial support.

Conflicts of Interest: The authors declare no conflict of interest.

\section{References}

1. Dheer, D.; Singh, V.; Shankar, R. Medicinal Attributes of 1,2,3-Triazoles: Current Developments. Bioorg. Chem. 2017, 71, 30-54. [CrossRef] [PubMed]

2. Aggarwal, R.; Sumran, G. An Insight on Medicinal Attributes of 1,2,4-Triazoles. Eur. J. Med. Chem. 2020, 205, 112652. [CrossRef] [PubMed]

3. Toda, M.; Beer, K.D.; Kuivila, K.M.; Chiller, T.M.; Jackson, B.R. Trends in Agricultural Triazole Fungicide Use in the United States, 1992-2016 and Possible Implications for Antifungal-Resistant Fungi in Human Disease. Environ. Health Perspect. 2021, 129, 1-12. [CrossRef] [PubMed]

4. Breugst, M.; Reissig, H. The Huisgen Reaction : Milestones of the 1, 3-Dipolar Cycloaddition. Angew. Chem. Int. Ed. 2020, 115, 12293-12307. [CrossRef] [PubMed]

5. Rostovtsev, V.V.; Green, L.G.; Fokin, V.V.; Sharpless, K.B. A Stepwise Huisgen Cycloaddition Process: Copper(I)-Catalyzed Regioselective "Ligation" of Azides and Terminal Alkynes. Angew. Chem. Int. Ed. 2002, 41, 2596-2599. [CrossRef]

6. Johansson, J.R.; Beke-Somfai, T.; Said Stålsmeden, A.; Kann, N. Ruthenium-Catalyzed Azide Alkyne Cycloaddition Reaction: Scope, Mechanism, and Applications. Chem. Rev. 2016, 116, 14726-14768. [CrossRef] [PubMed]

7. Maiuolo, L.; Algieri, V.; Olivito, F.; De Nino, A. Recent Developments on 1,3-Dipolar Cycloaddition Reactions by Catalysis in Green Solvents. Catalysts 2020, 10, 65. [CrossRef]

8. Maiuolo, L.; Algieri, V.; Olivito, F.; Tallarida, M.A.; Costanzo, P.; Jiritano, A.; De Nino, A. Chronicle of Nanocelluloses (NCs) for Catalytic Applications: Key Advances. Catalysts 2021, 11, 96. [CrossRef]

9. Chetia, M.; Ali, A.A.; Bordoloi, A.; Sarma, D. Facile route for the regioselective synthesis of 1,4-disubstituted 1,2,3-triazole using copper nanoparticles supported on nanocellulose as recyclable heterogeneous catalyst. J. Chem. Sci. 2017, 129, 1211-1217. [CrossRef]

10. Huisgen, R. 1,3-Dipolar Cycloadditions. Past and Future. Angew. Chem. Int. Ed. Engl. 1963, 2, 565-598. [CrossRef]

11. Maiuolo, L.; Feriotto, G.; Algieri, V.; Nardi, M.; Russo, B.; Di Gioia, M.L.; Furia, E.; Tallarida, M.A.; Mischiati, C.; De Nino, A. Antiproliferative activity of novel isatinyl/indanyl nitrones (INs) as potential spin trapping agents of free radical intermediates. Medchemcomm 2018, 9, 299-304. [CrossRef]

12. Merino, P.; Maiuolo, L.; Delso, I.; Algieri, V.; De Nino, A.; Tejero, T. Chemical approaches to inhibitors of isoprenoid biosynthesis: Targeting farnesyl and geranylgeranyl pyrophosphate synthases. RSC Adv. 2017, 7, 10947-10967. [CrossRef]

13. Maiuolo, L.; De Nino, A.; Algieri, V.; Nardi, M. Microwave-Assisted 1,3-Dipolar Cyclo-addition: Recent Advances in Synthesis of Isoxazolidines. Mini Rev. Org. Chem. 2017, 14, 2. [CrossRef]

14. Maiuolo, L.; Merino, P.; Algieri, V.; Nardi, M.; Di Gioia, M.L.; Russo, B.; Delso, I.; Tallarida, M.A.; De Nino, A. Nitrones and nucleobase-containing spiro-isoxazolidines derived from isatin and indanone: Solvent-free microwave-assisted stereoselective synthesis and theoretical calculations. RSC Adv. 2017, 7, 48980-48988. [CrossRef]

15. Martina, K.; Tagliapietra, S.; Veselov, V.V.; Cravotto, G. Green protocols in heterocycle syntheses via 1,3-dipolar cycloadditions. Front. Chem. 2019, 7, 1-21. [CrossRef] [PubMed] 
16. Calandra, P.; Szerb, E.I.; Lombardo, D.; Algieri, V.; De Nino, A.; Maiuolo, L. A Presentation of Ionic Liquids as Lubricants: Some Critical Comments. Appl. Sci. 2021, 11, 5677. [CrossRef]

17. Kumar, S.; Sharma, B.; Mehra, V.; Kumar, V. Recent accomplishments on the synthetic/biological facets of pharmacologically active 1H-1,2,3-triazoles. Eur. J. Med. Chem. 2021, 212, 113069. [CrossRef] [PubMed]

18. Lal, K.; Yadav, P. Recent Advancements in 1,4-Disubstituted 1H-1,2,3-Triazoles as Potential Anticancer Agents. Anticancer Agents Med. Chem. 2018, 18, 21-37. [CrossRef] [PubMed]

19. Xu, Z.; Zhao, S.J.; Liu, Y. 1,2,3-Triazole-containing hybrids as potential anticancer agents: Current developments, action mechanisms and structure-activity relationships. Eur. J. Med. Chem. 2019, 183, 111700. [CrossRef] [PubMed]

20. Kaushik, C.P.; Kumar, K.; Singh, S.K.; Singh, D.; Saini, S. Synthesis and antimicrobial evaluation of 1,4-disubstituted 1,2,3-triazoles with aromatic ester functionality. Arab. J. Chem. 2016, 9, 865-871. [CrossRef]

21. Kella, C.R.; Balachandran, C.; Arun, Y.; Kaliyappan, E.; Mahalingam, S.M.; Ignacimuthu, S.; Arumugam, N.; Almansour, A.I.; Kumar, R.S.; Perumal, P.T. A novel class of 1,4-disubstituted 1,2,3-triazoles: Regioselective synthesis, antimicrobial activity and molecular docking studies. Arab. J. Chem. 2020, 13, 9047-9057. [CrossRef]

22. Jiang, X.; Wu, G.; Zalloum, W.A.; Meuser, M.E.; Dick, A.; Sun, L.; Chen, C.H.; Kang, D.; Jing, L.; Jia, R.; et al. Discovery of novel 1,4-disubstituted 1,2,3-triazole phenylalanine derivatives as HIV-1 capsid inhibitors. RSC Adv. 2019, 9, 28961-28986. [CrossRef] [PubMed]

23. Chouaib, K.; Delemasure, S.; Dutartre, P.; Jannet, H.B. Microwave-assisted synthesis, anti-inflammatory and anti-proliferative activities of new maslinic acid derivatives bearing 1,5- and 1,4-disubstituted triazoles. J. Enzyme Inhib. Med. Chem. 2016, 31, 130-147. [CrossRef]

24. Cheng, C.Y.; Haque, A.; Hsieh, M.F.; Imran Hassan, S.; Faizi, M.S.H.; Dege, N.; Khan, M.S. 1,4-Disubstituted 1H-1,2,3-Triazoles for Renal Diseases: Studies of Viability, Anti-Inflammatory, and Antioxidant Activities. Int. J. Mol. Sci. 2020, 21, 3823. [CrossRef]

25. Rečnik, L.-M.; Kandioller, W.; Mindt, T.L. 1,4-Disubstituted 1,2,3-Triazoles as Amide Bond Surrogates for the Stabilisation of Linear Peptides with Biological Activity. Molecules 2020, 25, 3576. [CrossRef]

26. Schröder, D.C.; Kracker, O.; Fröhr, T.; Góra, J.; Jewginski, M.; Nieß, A.; Antes, I.; Latajka, R.; Marion, A.; Sewald, N. 1,4Disubstituted 1H-1,2,3-Triazole Containing Peptidotriazolamers: A New Class of Peptidomimetics With Interesting Foldamer Properties. Front Chem. 2019, 7, 155. [CrossRef] [PubMed]

27. Massarotti, A.; Aprile, S.; Mercalli, V.; Del Grosso, E.; Grosa, G.; Sorba, G.; Tron, G.C. Are 1,4- and 1,5-disubstituted 1,2,3-triazoles good pharmacophoric groups? ChemMedChem 2014, 9, 2497-2508. [CrossRef] [PubMed]

28. Tornøe, C.W.; Christensen, C.; Meldal, M. Peptidotriazoles on Solid Phase: [1,2,3]-Triazoles by Regiospecific Copper(I)-Catalyzed 1,3-Dipolar Cycloadditions of Terminal Alkynes to Azides. J. Org. Chem. 2002, 67, 3057-3064. [CrossRef]

29. Nemallapudi, B.R.; Guda, D.R.; Ummadi, N.; Avula, B.; Zyryanov, G.V.; Cirandur, S.R.; Gundala, S. New Methods for Synthesis of 1,2,3-Triazoles: A Review. Polycycl. Aromat. Comp. 2020, 18, 338. [CrossRef]

30. Neto, J.S.S.; Zeni, G. A decade of advances in the reaction of nitrogen sources and alkynes for the synthesis of triazoles. Coord. Chem. Rev. 2020, 409, 213217. [CrossRef]

31. Saini, P.; Sonika, S.; Singh, G.; Kaur, G.; Singh, J.; Singh, H. Robust and Versatile Cu(I) metal frameworks as potential catalysts for azide-alkyne cycloaddition reactions: Review. Mol. Catal. 2021, 504, 111432. [CrossRef]

32. Sultana, J.; Sarma, D. Ag-catalyzed azide-alkyne cycloaddition: Copper free approaches for synthesis of 1,4-disubstituted 1,2,3-triazoles. Catal. Rev. 2020, 62, 96-117. [CrossRef]

33. Wang, S.; Yang, L.-J.; Zeng, J.-L.; Zheng, Y.; Ma, J.-A. Silvercatalyze [3+2] cycloaddition of isocyanides with diazo compounds: New regioselective access to 1,4-disubstituted-1,2,3-triazoles. Org. Chem. Front. 2015, 2, 1468-1474. [CrossRef]

34. Jia, F.; Zhang, B. Mechanistic insight into the silver-catalyzed cycloaddition synthesis of 1,4-disubstituted-1,2,3-triazoles: The key role of silver. New J. Chem. 2019, 43, 8634-8643. [CrossRef]

35. Meng, X.; Xu, X.; Gao, T.; Chen, B. Zn/C-Catalyzed Cycloaddition of Azides and Aryl Alkynes. Eur. J. Org. Chem. 2010, 16, 5409. [CrossRef]

36. Morozova, M.A.; Yusubov, M.S.; Kratochvil, B.; Eigner, V.; Bondarev, A.A.; Yoshimura, A.; Saito, A.; Zhdankin, V.V.; Trusova, M.E.; Postnikov, P.S. Regioselective Zn(OAc) 2-catalyzed Azide-Alkyne Cycloaddition in Water: The Green Click-chemistry. Org. Chem. Front. 2017, 4, 978-985. [CrossRef]

37. Sharma, R.K.; Mishra, M.; Sharma, S.; Dutta, S. Zinc(II) complex immobilized on amine functionalized silica gel: A novel, highly efficient and recyclable catalyst for multicomponent click synthesis of 1,4-disubstituted 1,2,3-triazoles. J. Coord. Chem. 2016, 69, 1152-1165. [CrossRef]

38. Oliverio, M.; Costanzo, P.; Macario, A.; De Luca, G.; Nardi, M.; Procopio, A. An erbium-based bifuctional heterogeneous catalyst: A cooperative route towards C-C bond formation. Molecules 2014, 19, 10218-10229. [CrossRef] [PubMed]

39. Mehta, D.; Mazumdar, S.; Singh, S.K. Magnetic adsorbents for the treatment of water/wastewater-A review. J. Water Process Eng. 2015, 7, 244-265. [CrossRef]

40. De Nino, A.; Tallarida, M.A.; Algieri, V.; Olivito, F.; Costanzo, P.; De Filpo, G.; Maiuolo, L. Sulfonated cellulose-based magnetic composite as useful media for water remediation from amine pollutants. Appl. Sci. 2020, 10, 8155. [CrossRef]

41. Daraie, M.; Heravi, M.M.; Sarmasti, N. Synthesis of polymer-supported $\mathrm{Zn}(\mathrm{II})$ as a novel and green nanocatalyst for promoting click reactions and using design of experiment for optimization of reaction conditions. J. Macromol. Sci. Part A 2020, 57, 488-498. [CrossRef] 
42. Mondal, P.; Ghosh, S.; Das, S.K.; Bhaumik, A.; Das, D.; Islam, S.M. Use of an efficient polystyrene-supported cerium catalyst for one-pot multicomponent synthesis of spiro-piperidine derivatives and click reactions in green solvent. Appl Organometal Chem. 2018, 32, e4227. [CrossRef]

43. Sharma, P.; Rathod, J.; Singh, A.P.; Kumar, P.; Sasson, Y. Synthesis of heterogeneous Ru(II)-1,2,3-triazole catalyst supported over SBA-15: Application to the hydrogen transfer reaction and unusual highly selective 1,4-disubstituted triazole formation via multicomponent click reaction. Catal. Sci. Technol. 2018, 8, 3246-3259. [CrossRef]

44. Arafa, W.A.A.; Nayl, A.A. Water as a solvent for Ru-catalyzed click reaction: Highly efficient recyclable catalytic system for triazolocoumarins synthesis. Appl Organometal Chem. 2019, 33, e5156. [CrossRef]

45. Wu, Z.-G.; Liao, X.-J.; Yuan, L.; Wang, L.; Zheng, Y.-X.; Zuo, J.-L.; Pan, Y. Visible-Light-Mediated Click Chemistry for Highly Regioselective Azide-Alkyne Cycloaddition by a Photoredox Electron-Transfer Strategy. Chem. Eur. J. 2020, 26, 5694-5700. [CrossRef]

46. Alcaide, B.; Almendros, P.; Lazaro-Milla, C. Metal-free [3+2] cycloaddition of azides with Tf2C=CH2 for the regioselective preparation of elusive 4-(trifluoromethylsulfonyl)-1,2,3-triazoles. Chem. Commun. 2015, 51, 6992-6995. [CrossRef]

47. Singh, H.; Khanna, G.; Nand, B.; Khurana, M.J. Metal-free synthesis of 1,2,3-triazoles by azide-aldehyde cycloaddition under ultrasonic irradiation in TSIL [DBU-Bu] HH and in hydrated IL Bu4NOH under heating. Monatsh. Chem. 2016, 147, 1215-1219. [CrossRef]

48. Das, J.; Dey, S.; Pathak, T. Metal-Free Route to Carboxylated 1,4-Disubstituted 1,2,3-Triazoles from Methoxycarbonyl-Modified Vinyl Sulfone. J. Org. Chem. 2019, 84, 15437-15447. [CrossRef]

49. Sebest, F.; Haselgrove, S.; White, A.J.P.; Diez-Gonzales, S. Metal-free 1,2,3-triazole synthesis in deep eutectic solvents. Synlett 2020, 31, 605-609. [CrossRef]

50. Di Gioia, M.L.; Cassano, R.; Costanzo, P.; Cano, N.H.; Maiuolo, L.; Nardi, M.; Nicoletta, F.P.; Oliverio, M.; Procopio, A. Green synthesis of privileged benzimidazole scaffolds using active deep eutectic solvent. Molecules 2019, 24, 2885. [CrossRef]

51. Bonacci, S.; Di Gioia, M.L.; Costanzo, P.; Maiuolo, L.; Tallarico, S.; Nardi, M. Natural deep eutectic solvent as extraction media for the main phenolic compounds from olive oil processing wastes. Antioxidants 2020, 9, 513. [CrossRef] [PubMed]

52. Wan, J.-P.; Cao, S.; Liu, Y. Base-Promoted Synthesis of N-Substituted 1,2,3-Triazoles via Enaminone-Azide Cycloaddition Involving Regitz Diazo Transfer. Org. Lett. 2016, 18, 6034-6037. [CrossRef]

53. Cao, S.; Liu, Y.; Hu, C.; Wen, C.; Wan, J.-P. Alkyl Propiolates Participated [3+2] Annulation for the Switchable Synthesis of 1,5and 1,4-Disubstituted 1,2,3-Triazoles Containing Ester Side Chain. ChemCatChem 2018, 10, 5007-5011. [CrossRef]

54. Zhang, D.; Fan, Y.; Yan, Z.; Nie, Y.; Xiong, X.; Gao, L. Reactions of $\alpha$-haloacroleins with azides: Highly regioselective synthesis of formyl triazoles. Green Chem. 2019, 21, 4211. [CrossRef]

55. Cai, Z.-J.; Lu, X.-M.; Zi, Y.; Yang, C.; Shen, L.-J.; Li, J.; Wang, S.-Y.; Ji, S.-J. I2/TBPB Mediated Oxidative Reaction of NTosylhydrazones with Anilines: Practical Construction of 1,4-Disubstituted 1,2,3-Triazoles under Metal-Free and Azide-Free Conditions. Org. Lett. 2014, 16, 5108-5111. [CrossRef]

56. Bai, H.-W.; Cai, Z.-J.; Wang, S.-Y.; Ji, S.-J. Aerobic Oxidative Cycloaddition of $\alpha$-Chlorotosylhydrazones with Arylamines: General Chemoselective Construction of 1,4-Disubstituted and 1,5-Disubstituted 1,2,3-Triazoles under Metal-Free and Azide-Free Conditions. Org. Lett. 2015, 17, 2898-2901. [CrossRef]

57. Mani, G.S.; Donthiboina, K.; Shaik, S.P.; Shankaraiah, N.; Kamal, A. Iodine-mediated C-N and N-N bond formation: A facile one-pot synthetic approach to 1,2,3-triazoles under metal-free and azide-free conditions. RSC Adv. 2019, 9, 27021-27031. [CrossRef]

58. Ahmed, M.; Razaq, H.; Faisal, M.; Siyal, A.N.; Haider, A. Metal Free and Azide Free Synthesis of 1,2,3- Triazoles Derivatives. Synth. Commun. 2017, 47, 1193-1200. [CrossRef]

59. Zhou, Q.; Fu, Z.; Yu, L.; Wang, J. Transition-Metal-Free [4+1] Cycloaddition for the Synthesis of 1,2,3-Triazole from $\alpha, \alpha$-DifluoroN-Tosylhydrazone and Amine through C-F Bond Cleavage. Asian J. Org. Chem. 2019, 8, 646-649. [CrossRef]

60. Zehnder, L.R.; Hawkins, J.M.; Sutton, S.C. One-Pot, Metal- and Azide-Free Synthesis of 1,2,3-Triazoles from $\alpha$-Ketoacetals and Amines. Synlett 2019, 30, 175-178. [CrossRef]

61. Pedersen, D.S.; Abell, A. 1,2,3-Triazoles in Peptidomimetic Chemistry. European J. Org. Chem. 2011, 11, 2399-2411. [CrossRef]

62. White, C.J.; Yudin, A.K. Contemporary Strategies for Peptide Macrocyclization. Nat. Chem. 2011, 3, 509-524. [CrossRef] [PubMed]

63. Oppilliart, S.; Mousseau, G.; Zhang, L.; Jia, G.; Thuéry, P.; Rousseau, B.; Cintrat, J.C. 1-Protected 5-Amido 1,2,3-Triazoles via Ruthenium-Catalyzed [3+2] Cycloaddition of Azides and Ynamides. Tetrahedron 2007, 63, 8094-8098. [CrossRef]

64. Crich, D.; Yang, F. Phenylthiomethyl Glycosides: Convenient Synthons for the Formation of Azidomethyl and Glycosylmethyl Glycosides and Their Derivatives. Angew. Chem. Int. Ed. 2009, 48, 8896-8899. [CrossRef]

65. Mohammed, I.; Kummetha, I.R.; Singh, G.; Sharova, N.; Lichinchi, G.; Dang, J.; Stevenson, M.; Rana, T.M. 1,2,3-Triazoles as Amide Bioisosteres: Discovery of a New Class of Potent HIV-1 Vif Antagonists. J. Med. Chem. 2016, 59, 7677-7682. [CrossRef]

66. Sirivolu, V.R.; Vernekar, S.K.V.; Ilina, T.; Myshakina, N.S.; Parniak, M.A.; Wang, Z. Clicking 3'-Azidothymidine into Novel Potent Inhibitors of Human Immunodeficiency Virus. J. Med. Chem. 2013, 56, 8765-8780. [CrossRef] [PubMed]

67. Hansen, M.R.; Jakobsen, T.H.; Bang, C.G.; Cohrt, A.E.; Hansen, C.L.; Clausen, J.W.; Le Quement, S.T.; Tolker-Nielsen, T.; Givskov, M.; Nielsen, T.E. Triazole-Containing N-Acyl Homoserine Lactones Targeting the Quorum Sensing System in Pseudomonas Aeruginosa. Bioorgan. Med. Chem. 2015, 23, 1638-1650. [CrossRef] [PubMed] 
68. Pore, V.S.; Jagtap, M.A.; Agalave, S.G.; Pandey, A.K.; Siddiqi, M.I.; Kumar, V.; Shukla, P.K. Synthesis and Antifungal Activity of 1,5-Disubstituted-1,2,3-Triazole Containing Fluconazole Analogues. Medchemcomm 2012, 3, 484-488. [CrossRef]

69. Boren, B.C.; Narayan, S.; Rasmussen, L.K.; Zhang, L.; Zhao, H.; Lin, Z.; Jia, G.; Fokin, V.V. Ruthenium-catalyzed azide-alkyne cycloaddition: Scope and mechanism. J. Am. Chem. Soc. 2008, 130, 8923-8930. [CrossRef]

70. Vernekar, S.K.V.; Qiu, L.; Zhang, J.; Kankanala, J.; Li, H.; Geraghty, R.J.; Wang, Z. 5'-silylated 3'-1,2,3-triazolyl thymidine analogues as inhibitors of West Nile Virus and Dengue virus. J. Med. Chem. 2015, 58, 4016-4028. [CrossRef]

71. Hornum, M.; Djukina, A.; Sassnau, A.K.; Nielsen, P. Synthesis of new C-5-triazolyl-functionalized thymidine analogs and their ability to engage in aromatic stacking in DNA:DNA and DNA:RNA duplexes. Org. Biomol. Chem. 2016, 14, 4436-4447. [CrossRef]

72. Kocsis, L.; Szabó, I.; Bosze, S.; Jernei, T.; Hudecz, F.; Csámpai, A. Synthesis, structure and in vitro cytostatic activity of ferroceneCinchona hybrids. Bioorgan. Med. Chem. Lett. 2016, 26, 946-949. [CrossRef] [PubMed]

73. Jernei, T.; Durò, C.; Dembo, A.; Lajkò, E.; Takacs, A.; Kohidai, L.; Schlosser, G.; Csàmpai, A. Synthesis, Structure and In Vitro Cytotoxic Activity of Novel Cinchona-Chalcone Hybrids With 1,4-Disubstituted-and 1,5-Disubstituted 1,2,3-Triazole Linkers. Molecules 2019, 24, 4077. [CrossRef]

74. De Andrade, P.; Galo, O.A.; Carvalho, M.R.; Lopes, C.D.; Carneiro, Z.A.; Sesti-Costa, R.; De Melo, E.B.; Silva, J.S.; Carvalho, I. 1,2,3-Triazole-based analogue of benznidazole displays remarkable activity against Trypanosoma cruzi. Bioorgan. Med. Chem. 2015, 23, 6815-6826. [CrossRef]

75. Toguchi, S.; Hirose, T.; Yorita, K.; Fukui, K.; Sharpless, K.B.; Omura, S.; Sunazuka, T. In situ click chemistry for the identification of a potent D-amino acid oxidase inhibitor. Chem. Pharm. Bull. 2016, 64, 695-703. [CrossRef]

76. Cao, G.; Yang, K.; Li, Y.; Huang, L.; Teng, D. Synthetic strategy and anti-tumor activities of macrocyclic scaffolds based on 4-hydroxyproline. Molecules 2016, 21, 212. [CrossRef] [PubMed]

77. Baltus, C.B.; Jorda, R.; Marot, C.; Berka, K.; Bazgier, V.; Kryštof, V.; Prié, G.; Viaud-Massuard, M.C. Synthesis, biological evaluation and molecular modeling of a novel series of 7-azaindole based tri-heterocyclic compounds as potent CDK2/Cyclin E inhibitors. Eur. J. Med. Chem. 2016, 108, 701-719. [CrossRef]

78. Bahia, S.B.B.B.; Reis, W.J.; Jardim, G.A.M.; Souto, F.T.; De Simone, C.A.; Gatto, C.C.; Menna-Barreto, R.F.S.; De Castro, S.L.; Cavalcanti, B.C.; Pessoa, C.; et al. Molecular hybridization as a powerful tool towards multitarget quinoidal systems: Synthesis, trypanocidal and antitumor activities of naphthoquinone-based 5-iodo-1,4-disubstituted-, 1,4- and 1,5-disubstituted-1,2,3-triazoles. Medchemcomm 2016, 7, 1555-1563. [CrossRef]

79. Chouaib, K.; Romdhane, A.; Delemasure, S.; Dutartre, P.; Elie, N.; Touboul, D.; Ben Jannet, H. Regiospecific synthesis by copperand ruthenium-catalyzed azide-alkyne 1,3-dipolar cycloaddition, anticancer and anti-inflammatory activities of oleanolic acid triazole derivatives. Arab. J. Chem. 2019, 12, 3732-3742. [CrossRef]

80. Kracker, O.; Góra, J.; Krzciuk-Gula, J.; Marion, A.; Neumann, B.; Stammler, H.G.; Nieß, A.; Antes, I.; Latajka, R.; Sewald, N. 1,5-Disubstituted 1,2,3-Triazole-Containing Peptidotriazolamers: Design Principles for a Class of Versatile Peptidomimetics. Chem. A Eur. J. 2018, 24, 953-961. [CrossRef] [PubMed]

81. Stålsmeden, S.A.; Paterson, A.J.; Szigyártó, I.C.; Thunberg, L.; Johansson, J.R.; Beke-Somfai, T.; Kann, N. Chiral 1,5-disubstituted 1,2,3-triazoles-versatile tools for foldamers and peptidomimetic applications. Org. Biomol. Chem. 2020, 18, 1957-1967. [CrossRef] [PubMed]

82. Grob, N.M.; Schibli, R.; Béhé, M.; Valverde, I.E.; Mindt, T.L. 1,5-Disubstituted 1,2,3-Triazoles as Amide Bond Isosteres Yield Novel Tumor-Targeting Minigastrin Analogs. ACS Med. Chem. Lett. 2021, 12, 585. [CrossRef] [PubMed]

83. Tala, S.R.; Singh, A.; Lensing, C.J.; Schnell, S.M.; Freeman, K.T.; Rocca, J.R.; Haskell-Luevano, C. 1,2,3-Triazole Rings as a Disulfide Bond Mimetic in Chimeric AGRP-Melanocortin Peptides: Design, Synthesis, and Functional Characterization. ACS Chem. Neurosci. 2018, 9, 1001-1013. [CrossRef] [PubMed]

84. Knuhtsen, A.; Whitmore, C.; McWhinnie, F.S.; McDougall, L.; Whiting, R.; Smith, B.O.; Timperley, C.M.; Green, A.C.; Kinnear, K.I.; Jamieson, A.G. $\alpha$-Conotoxin GI triazole-peptidomimetics: Potent and stable blockers of a human acetylcholine receptor. Chem. Sci. 2019, 10, 1671-1676. [CrossRef]

85. White, A.M.; de Veer, S.J.; Wu, G.; Harvey, P.J.; Yap, K.; King, G.J.; Swedberg, J.E.; Wang, C.K.; Law, R.H.P.; Durek, T.; et al. Application and Structural Analysis of Triazole-Bridged Disulfide Mimetics in Cyclic Peptides. Angew. Chem. Int. Ed. 2020, 59, 11273-11277. [CrossRef]

86. Tomassi, S.; Trotta, A.M.; Ieranò, C.; Merlino, F.; Messere, A.; Rea, G.; Santoro, F.; Brancaccio, D.; Carotenuto, A.; D’Amore, V.M.; et al. Disulfide Bond Replacement with 1,4- and 1,5-Disubstituted [1,2,3]-Triazole on C-X-C Chemokine Receptor Type 4 (CXCR4) Peptide Ligands: Small Changes that Make Big Differences. Chem. A Eur. J. 2020, 26, 10113-10125. [CrossRef]

87. Chen, M.; Li, L.; Nie, H.; Shi, Y.; Mei, J.; Wang, J.; Sun, J.Z.; Qin, A.; Tang, B.Z. N-type pyrazine and triazole-based luminogens with aggregation-enhanced emission characteristics. Chem. Commun. 2015, 51, 10710-10713. [CrossRef]

88. Anand, A.; Kulkarni, M.V. Click chemistry approach for the regioselective synthesis of iso-indoline-1,3-dione-linked 1,4 and 1,5 coumarinyl 1,2,3-triazoles and their photophysical properties. Synth. Commun. 2017, 47, 722-733. [CrossRef]

89. Mekni, N.H. Cu+-catalyzed 1,3-Dipolar Intramolecular Click Opposite Cross Cyclization Reaction of Polyoxyethylene Bis(azidoterminal alkynes): Synthesis of New 1,2,3-Triazolo-crown Ethers. J. Heterocycl. Chem. 2017, 54, 2664-2669. [CrossRef]

90. Kumar, N.; Ansari, M.Y.; Kant, R.; Kumar, A. Copper-catalyzed decarboxylative regioselective synthesis of 1,5-disubstituted 1,2,3-triazoles. Chem. Commun. 2018, 54, 2627-2630. [CrossRef] 
91. Kim, W.G.; Kang, M.E.; Lee, J.B.; Jeon, M.H.; Lee, S.; Lee, J.; Choi, B.; Cal, P.M.S.D.; Kang, S.; Kee, J.M.; et al. Nickel-Catalyzed Azide-Alkyne Cycloaddition to Access 1,5-Disubstituted 1,2,3-Triazoles in Air and Water. J. Am. Chem. Soc. 2017, 139, 12121-12124. [CrossRef]

92. Nanjundaswamy, H.M.; Abrahamse, H. Regioselective Synthesis of 1,5-Disubstituted 1,2,3-Triazoles by Reusable AlCl3 Immobilized on $\gamma$-Al2O3. Synth. Commun. 2015, 45, 967-974. [CrossRef]

93. Mahadari, M.K.; Tague, A.J.; Keller, P.A.; Pyne, S.G. Synthesis of sterically congested 1,5-disubstituted-1,2,3-Triazoles using chloromagnesium acetylides and hindered 1-naphthyl azides. Tetrahedron 2021, 81, 131916. [CrossRef]

94. De Nino, A.; Merino, P.; Algieri, V.; Nardi, M.; Di Gioia, M.L.; Russo, B.; Tallarida, M.A.; Maiuolo, L. Synthesis of 1,5-functionalized 1,2,3-triazoles using ionic liquid/iron(III) chloride as an efficient and reusable homogeneous catalyst. Catalysts 2018, 8, 364 [CrossRef]

95. De Nino, A.; Maiuolo, L.; Merino, P.; Nardi, M.; Procopio, A.; Roca-Lõpez, D.; Russo, B.; Algieri, V. Efficient organocatalyst supported on a simple ionic liquid as a recoverable system for the asymmetric diels-alder reaction in the presence of water. ChemCatChem 2015, 7, 830-835. [CrossRef]

96. Algieri, V.; Algieri, C.; Maiuolo, L.; De Nino, A.; Pagliarani, A.; Tallarida, M.A.; Trombetti, F.; Nesci, S. 1,5-Disubstituted-1,2,3triazoles as inhibitors of the mitochondrial Ca2+-activated F1FO-ATP(hydrol)ase and the permeability transition pore. Ann. N. Y. Acad. Sci. 2020, 7, 1-13. [CrossRef]

97. Maiuolo, L.; Russo, B.; Algieri, V.; Nardi, M.; Di Gioia, M.L.; Tallarida, M.A.; De Nino, A. Regioselective synthesis of 1,5disubstituted 1,2,3-triazoles by 1,3-dipolar cycloaddition: Role of $\operatorname{Er}(\mathrm{OTf})$ 3, ionic liquid and water. Tetrahedron Lett. 2019, 60, 672-674. [CrossRef]

98. Kayet, A.; Dey, S.; Pathak, T. A metal free aqueous route to 1,5-disubstituted 1,2,3-triazolylated monofuranosides and difuranosides. Tetrahedron Lett. 2015, 56, 5521-5524. [CrossRef]

99. Kayet, A.; Datta, D.; Das, A.; Dasgupta, S.; Pathak, T. 1,5-Disubstituted 1,2,3-triazole linked disaccharides: Metal-free syntheses and screening of a new class of ribonuclease A inhibitors. Bioorgan. Med. Chem. 2018, 26, 455-462. [CrossRef]

100. González-Calderón, D.; Mejía-Dionicio, M.G.; Morales-Reza, M.A.; Ramírez-Villalva, A.; Morales-Rodríguez, M.; Jau-reguiRodríguez, B.; Díaz-Torres, E.; González-Romero, C.; Fuentes-Benítes, A. Azide-enolate 1,3-dipolar cycloaddition in the synthesis of novel triazole-based miconazole analogues as promising antifungal agents. Eur. J. Med. Chem. 2016, 112, 60-65. [CrossRef]

101. Wan, J.-P.; Cao, S.; Liu, Y. A Metal- and Azide-Free Multicomponent Assembly toward Regioselective Construction of 1,5Disubstituted 1,2,3-Triazoles. J. Org. Chem. 2015, 80, 9028-9033. [CrossRef]

102. Thomas, J.; Jana, S.; John, J.; Liekens, S.; Dehaen, W. A general metal-free route towards the synthesis of 1,2,3-triazoles from readily available primary amines and ketones. Chem. Commun. 2016, 52, 2885-2888. [CrossRef] [PubMed]

103. Kayet, A.; Pathak, T. metal-free route towards 1,5-disubstituted 1,2,3-triazolylmethylene linked disaccharides: Synthesis in a biodegradable hydroxylammonium-based aqueous ionic liquid media. Tetrahedron Lett. 2018, 59, 3341-3344. [CrossRef]

104. Silveira-Dorta, G.; Jana, S.; Borkova, L.; Thomas, J.; Dehaen, W. Straightforward synthesis of enantiomerically pure 1,2,3-triazoles derived from amino esters. Org. Biomol. Chem. 2018, 16, 3168-3176. [CrossRef] [PubMed]

105. Zhang, X.; Cui, X.; Wang, W.; Zeng, T.; Wang, Y.; Tan, Y.; Liu, D.; Wang, X.; Li, Y. Base-Promoted Regiospecific Synthesis of Fully Substituted 1,2,3-Triazoles and 1,5-Disubstituted 1,2,3-Triazoles. Asian J. Org. Chem. 2020, 9, 2176-2183. [CrossRef]

106. Kiranmye, T.; Vadivelu, M.; Sampath, S.; Muthu, K.; Karthikeyan, K. Ultrasound-assisted catalyst free synthesis of 1,4-/1,5disubstituted-1,2,3-triazoles in aqueous medium. Sustain. Chem. Pharm. 2021, 19, 100358. [CrossRef]

107. Madadi, N.R.; Penthala, N.R.; Howk, K.; Ketkar, A.; Eoff, R.L.; Borrelli, M.J.; Crooks, P.A. Synthesis and biological evaluation of novel 4,5-disubstituted 2H-1,2,3-triazoles as cis-constrained analogues of combretastatin A-4. Eur. J. Med. Chem. 2015, 103, 123. [CrossRef]

108. Chai, H.; Guo, R.; Yin, W.; Cheng, L.; Liu, R.; Chu, C. One-Pot, Three-Component Reaction Using Modified Julia Reagents: A Facile Synthesis of 4,5-Disubstituted 1,2,3-(NH)-Triazoles in a Wet Organic Solvent. ACS Comb. Sci. 2015, 17, 147-151. [CrossRef]

109. Thomas, J.; Hana, S.; Liekens, S.; Dehaen, W. A single-step acid catalyzed reaction for rapid assembly of NH-1,2,3-triazoles. Chem. Commun. 2016, 52, 9236-9239. [CrossRef]

110. Tang, J.-L.; Ming, L.; Zhao, X.-M. Highly Efficient Cycloaddition Reaction of 1,3-Diynes with Sodium Azide: A New Way to 5-Substituted-4-acetylene-1H-1,2,3-triazoles. J. Heterocycl. Chem. 2016, 53, 1367-1370. [CrossRef]

111. Panda, S.; Maity, P.; Manna, D. Transition Metal, Azide, and Oxidant-Free Homo- and Heterocoupling of Ambiphilic Tosylhydrazones to the Regioselective Triazoles and Pyrazoles. Org. Lett. 2017, 19, 1534-1537. [CrossRef]

112. Swarup, H.A.; Mantelingu, K.; Rangappa, K.S. Effective and Transition-Metal-Free Construction of Disubstituted, Trisubstituted 1,2,3-NH-Triazoles and Triazolo Pyridazine via Intermolecular 1,3-Dipolar Cycloaddition Reaction. ChemistrySelect 2018, 3, 703-708. [CrossRef]

113. Wu, G.-L.; Wu, Q.-P. Metal-Free Multicomponent Reaction for Synthesis of 4,5-Disubstituted 1,2,3-(NH)-Triazoles. Adv. Synth Catal. 2018, 360, 1949-1953. [CrossRef]

114. Hui, R.; Zhao, M.; Chen, M.; Ren, Z.; Gua, Z. One-Pot Synthesis of 4-Aryl-NH-1,2,3-Triazoles through Three Component Reaction of Aldehydes, Nitroalkanes and NaN3. Chin. J. Chem. 2017, 35, 1808-1812. [CrossRef]

115. Wu, L.; Wang, X.; Chen, Y.; Huang, Q.; Lin, Q.; Wu, M. 4-Aryl-NH-1,2,3-Triazoles via Multicomponent Reaction of Aldehydes, Nitroalkanes, and Sodium Azide. Synlett 2016, 27, 437-441. [CrossRef] 
116. Reddy, R.J.; Waheed, M.; Karthik, T.; Shankar, A. An efficient synthesis of 4,5-disubstituted-2H-1,2,3-triazoles from nitroallylic derivatives via a cycloaddition-denitration process. New J. Chem. 2018, 42, 980-987. [CrossRef]

117. Rocha, D.H.A.; Pinto, D.C.G.A.; Silva, A.M.S. Synthesis of 4,5-disubstituted-1H-1,2,3-triazoles. Monatsh. Chem. 2019, 150, 1479-1486. [CrossRef]

118. Wei, F.; Li, H.; Song, C.; Ma, Y.; Zhou, L.; Tung, C.H.; Xu, Z. Cu/Pd-Catalyzed, Three-Component Click Reaction of Azide, Alkyne, and Aryl Halide: One-Pot Strategy toward Trisubstituted Triazoles. Org. Lett. 2015, 17, 2860-2863. [CrossRef] [PubMed]

119. Zhang, J.; Chen, W.; Wang, B.; Zhao, Z.; Wang, X.; Hu, Y. One-pot three-component synthesis of 1,4,5-trisubstituted 5-iodo-1,2,3triazoles from 1-copper(I) alkyne, azide and molecular iodine. RSC Adv. 2015, 5, 14561-14566. [CrossRef]

120. Yamada, M.; Matsumura, M.; Murata, Y.; Kawahata, M.; Saito, K.; Kakusawa, N.; Yamaguchi, K.; Yasuike, S. Synthesis of 5-organostibano-1H-1,2,3-triazoles by Cu-catalyzed azide-alkyne cycloaddition and their application in the acyl-induced deantimonation for the preparation of fully substituted 5-acyl-1,2,3-triazoles. Tetrahedron 2017, 73, 2614-2622. [CrossRef]

121. Yamada, M.; Takahashi, T.; Hasegawa, M.; Matsumura, M.; Ono, K.; Fujimoto, R.; Kitamura, Y.; Murata, Y.; Kakusawa, N.; Tanaka, M.; et al. Synthesis, antitumor activity, and cytotoxicity of 4-substituted 1-benzyl-5-diphenylstibano-1H-1,2,3-triazoles. Bioorg. Med. Chem. Lett. 2018, 28, 152-154. [CrossRef] [PubMed]

122. Amdouni, H.; Robert, G.; Driowya, M.; Furstoss, N.; Métier, C.; Dubois, A.; Dufies, M.; Zerhouni, M.; Orange, F.; Lacas-Gervais, S.; et al. In Vitro and in Vivo Evaluation of Fully Substituted (5-(3-Ethoxy-3-oxopropynyl)-4-(ethoxycarbonyl)-1,2,3-triazolylglycosides as Original Nucleoside Analogues to Circumvent Resistance in Myeloid Malignancies. J. Med. Chem. 2017, 60, 1523-1533. [CrossRef]

123. Zhou, W.; Zhang, M.; Li, H.; Chen, W. One-Pot Three-Component Synthesis of Enamine-Functionalized 1,2,3-Triazoles via Cu-Catalytic Azide-Alkyne Click (CuAAC) and Cu Catalyzed Vinyl Nitrene Transfer Sequence. Org. Lett. 2017, 19, 10-13. [CrossRef] [PubMed]

124. Wu, F.; Zhou, W.; Chen, K.; Chen, W.; Liu, M.; Wu, H. Copper Mediated Three-Component Reactions of Alkynes, Azides, and Propargylic Carbonates: Synthesis of 5-Allenyl-1,2,3-Triazoles. Adv. Synth. Catal. 2018, 360, 2435-2439. [CrossRef]

125. Chang, C.W.; Lee, G.H. Synthesis of 1,4,5-trisubstituted triazoles by [3+2] cycloaddition of a ruthenium azido complex with ynoate esters. J. Organomet. Chem. 2019, 896, 146-153. [CrossRef]

126. Gribanov, P.S.; Chesnokov, G.A.; Topchiy, M.A.; Asachenko, A.F.; Nechaev, M.S. A general method of Suzuki-Miyaura crosscoupling of 4- and 5-halo-1,2,3-triazoles in water. Org. Biomol. Chem. 2017, 15, 9575-9578. [CrossRef]

127. Duan, X.; Huang, X.; Fu, C.; Ma, S. Palladium-Catalyzed Selective Three-Component Tandem Reaction to Bicyclic 1,2,3-Triazole Derivatives. Adv. Synth. Catal. 2020, 362, 627-647. [CrossRef]

128. Olivito, F.; Costanzo, P.; Di Gioia, M.L.; Nardi, M.; Oliverio, M.; Procopio, A. E_cientsynthesis of organic thioacetates in water. Org. Biomol. Chem. 2018, 16, 7753-7759. [CrossRef]

129. Olivito, F.; Amodio, N.; Di Gioia, M.L.; Nardi, M.; Oliverio, M.; Juli, G.; Tassone, P.; Procopio, A. Synthesis and preliminary evaluation of the anti-cancer activity on A549 lung cancer cells of a series of unsaturated disulfides. MedChemComm 2019, 10, 116-119. [CrossRef]

130. Ramachary, D.B.; Krishna, P.M.; Gujral, J.; Reddy, G.S. An Organocatalytic Regiospecific Synthesis of 1,5-Disubstituted 4-Thio1,2,3-triazoles and 1,5-Disubstituted 1,2,3-Triazoles. Chem. Eur. J. 2015, 21, 16775-16780. [CrossRef]

131. Gangaprasad, D.; Raj, J.P.; Kiranmye, T.; Karthikeyan, K.; Elangovan, J. Another Example of Organo-Click Reactions: TEMPOPromoted Oxidative Azide-Olefin Cycloaddition for the Synthesis of 1,2,3-Triazoles in Water. Eur. J. Org. Chem. 2016, 18, 5642-5646. [CrossRef]

132. Dommerholt, J.; Rutjes, F.P.J.T.; van Delft, F.L. Strain-Promoted 1,3-Dipolar Cycloaddition of Cycloalkynes and Organic Azides. Top. Curr. Chem. 2016, 16, 374-393.

133. Yoshida, S.; Shiraishi, A.; Kanno, K.; Matsushita, T.; Johmoto, K.; Uekusa, H.; Hosoya, T. Enhanced clickability of doubly-stericallyhindered aryl azides. Sci. Rep. 2011, 1, 82-85. [CrossRef]

134. Guo, N.; Liu, X.; Xu, H.; Zhou, X.; Zhao, H. A simple route towards the synthesis of 1,4,5-trisubstituted 1,2,3-triazoles from primary amines and 1,3-dicarbonyl compounds under metal-free conditions. Org. Biomol. Chem. 2019, 17, 6148-6152. [CrossRef]

135. Jana, S.; Adhikari, S.; Cox, M.R.; Roy, S. Regioselective synthesis of 4-fluoro-1,5-disubstituted-1,2,3-triazoles from synthetic surrogates of a-fluoroalkynes. Chem. Commun. 2020, 56, 1871-1874. [CrossRef] [PubMed]

136. González-Calderón, D.; Santillán-Iniesta, I.; González-González, C.A.; Fuentes-Benítes, A.; González-Romero, C. A novel and facile synthesis of 1,4,5-trisubstituted 1,2,3-triazoles from benzylic alcohols through a one-pot, three-component system. Tetrahedron Lett. 2015, 56, 514-516. [CrossRef]

137. González-Calderón, D.; Aguirre-De Paz, J.G.; González-González, C.A.; Fuentes-Benítes, A.; González-Romero, C. A straightforward and versatile approach to the synthesis of 1,4,5-trisubstituted 1,2,3-triazoles from alkyl halides via a one-pot, threecomponent reaction. Tetrahedron Lett. 2015, 56, 1713-1715. [CrossRef]

138. Blastik, Z.E.; Klepetářová, B.; Beier, P. Enamine-Mediated Azide-Ketone [3 + 2] Cycloaddition of Azidoperfluoroalkanes. ChemistrySelect 2018, 3, 7045-7048. [CrossRef]

139. De Nino, A.; Algieri, V.; Tallarida, M.A.; Constanzo, P.; Pedrón, M.; Tejero, T.; Merino, P.; Maiuolo, L. Regioselective Synthesis of 1,4,5-Trisubstituted-1,2,3-Triazoles from Aryl Azides and Enaminones. Eur. J. Org. Chem. 2019, 2019, 5725-5731. [CrossRef]

140. Reddy, G.S.; Reddy, L.M.; Kumar, A.S.; Ramachary, D.B. Organocatalytic Selective [3+2] Cycloadditions: Synthesis of Functionalized 5-Arylthiomethyl-1,2,3-triazoles and 4 Arylthio-1,2,3-triazoles. J. Org. Chem. 2020, 85, 15488-15501. [CrossRef] 